\title{
Cold Testing of a Russian Pulsating Mixer Pump at the Oak Ridge National Laboratory, Oak Ridge, Tennessee
}

January 2002

Prepared by

B. E Lewis

J. D. Randolph 


\title{
DOCUMENT AVAILABILITY
}

Reports produced after January 1, 1996, are generally available free via the U.S. Department of Energy (DOE) Information Bridge.

Web site http://www.osti.gov/bridge

Reports produced before January 1, 1996, may be purchased by members of the public from the following source.

\author{
National Technical Information Service \\ 5285 Port Royal Road \\ Springfield, VA 22161 \\ Telephone 703-605-6000 (1-800-553-6847) \\ TDD 703-487-4639 \\ Fax 703-605-6900 \\ E-mail info@ntis.fedworld.gov \\ Web site http://www.ntis.gov/support/ordernowabout.htm
}

Reports are available to DOE employees, DOE contractors, Energy Technology Data Exchange (ETDE) representatives, and International Nuclear Information System (INIS) representatives from the following source.

Office of Scientific and Technical Information

P.O. Box 62

Oak Ridge, TN 37831

Telephone 865-576-8401

Fax 865-576-5728

E-mail reports@adonis.osti.gov

Web site http://www.osti.gov/contact.html

\begin{abstract}
This report was prepared as an account of work sponsored by an agency of the United States Government. Neither the United States government nor any agency thereof, nor any of their employees, makes any warranty, express or implied, or assumes any legal liability or responsibility for the accuracy, completeness, or usefulness of any information, apparatus, product, or process disclosed, or represents that its use would not infringe privately owned rights. Reference herein to any specific commercial product, process, or service by trade name, trademark, manufacturer, or otherwise, does not necessarily constitute or imply its endorsement, recommendation, or favoring by the United States Government or any agency thereof. The views and opinions of authors expressed herein do not necessarily state or reflect those of the United States Government or any agency thereof.
\end{abstract}




\title{
COLD TESTING OF A RUSSIAN PULSATING MIXER PUMP AT THE OAK RIDGE NATIONAL LABORATORY, OAK RIDGE, TENNESSEE
}

\author{
B. E Lewis \\ J. D. Randolph \\ Oak Ridge National Laboratory \\ Oak Ridge, Tennessee 37981
}

January 2002

\author{
Prepared by \\ OAK RIDGE NATIONAL LABORATORY \\ P.O. Box 2008 \\ Oak Ridge, Tennessee 37831-6285 \\ managed by \\ UT-Battelle, LLC \\ for the \\ U.S. DEPARTMENT OF ENERGY \\ under contract DE-AC05-00OR22725
}




\section{CONTENTS}

Page

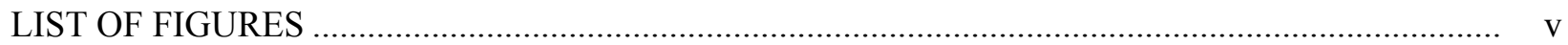

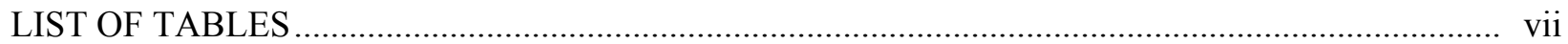

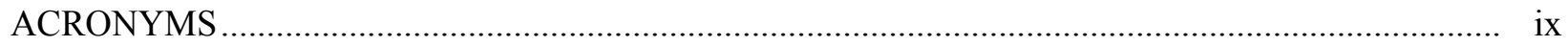

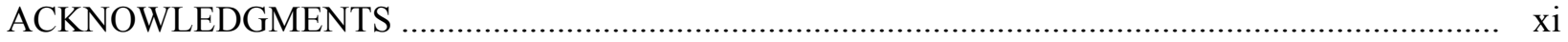

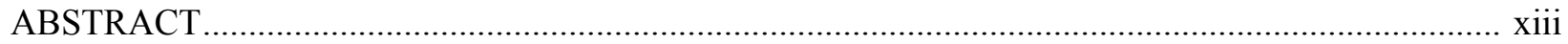

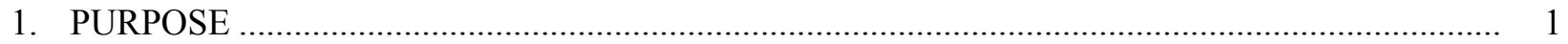

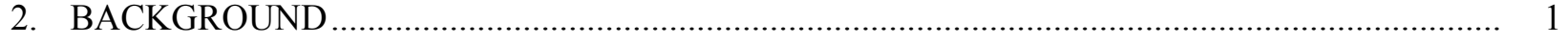

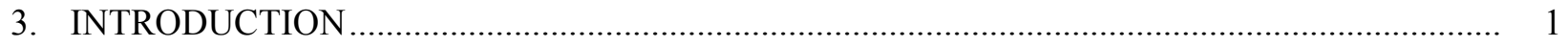

4. EQUIPMENT DESCRIPTION AND OPERATIONAL OVERVIEW ...................................... 3

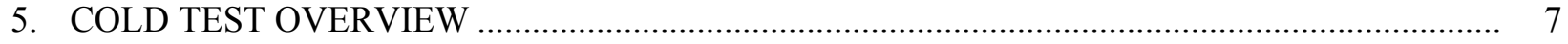

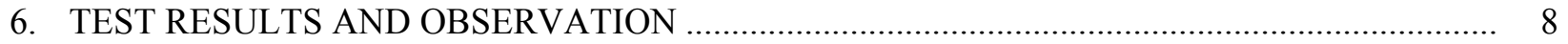

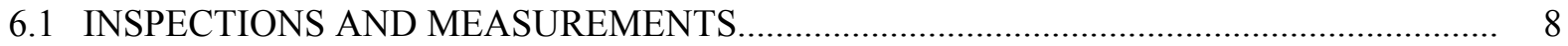

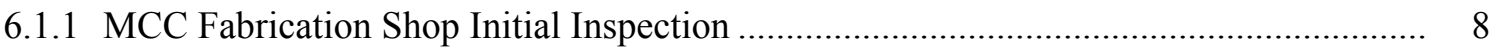

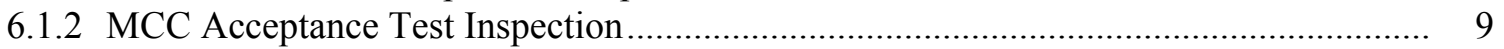

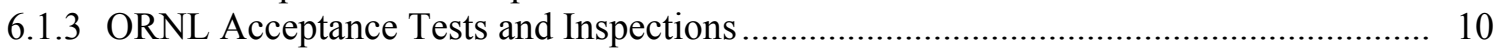

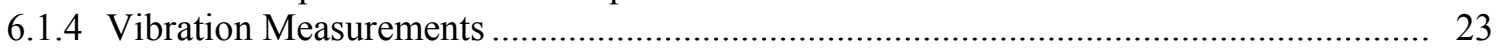

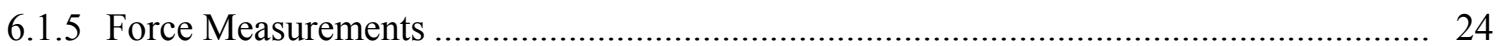

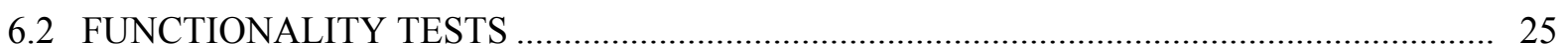

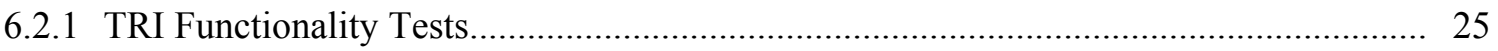

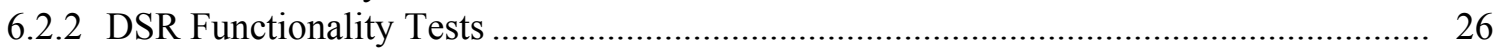

6.2.3 Valves, Actuators, Sensors, and CS Functionality Tests ........................................ 27

6.2.4 Hoisting and Rigging and Support Fixture Functionality Tests.................................... 29

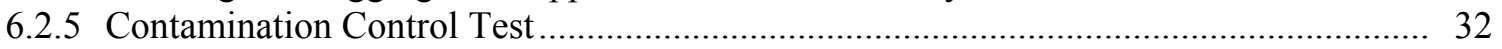

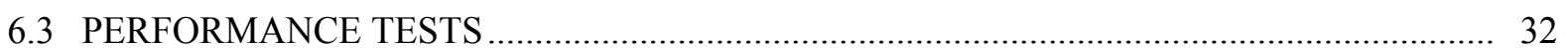

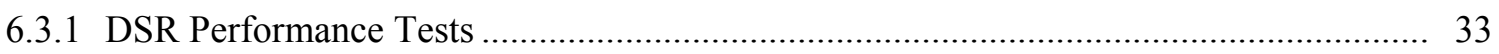

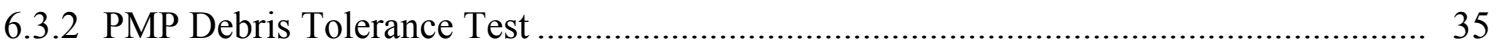

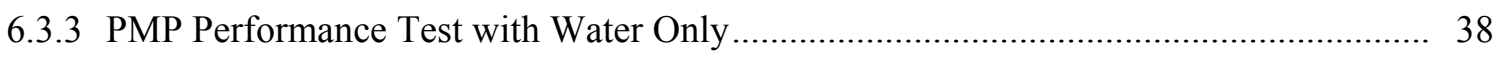

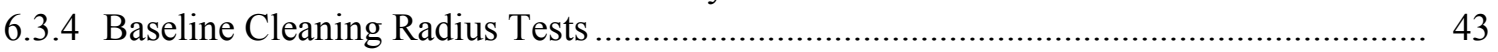

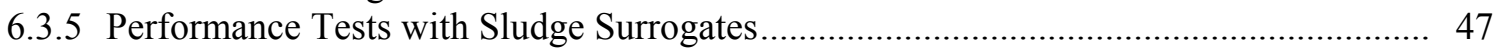

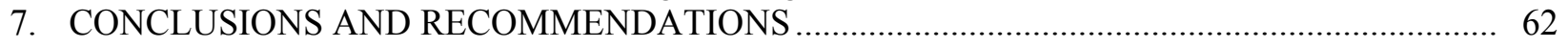

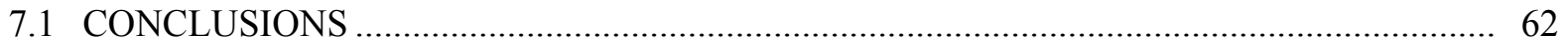

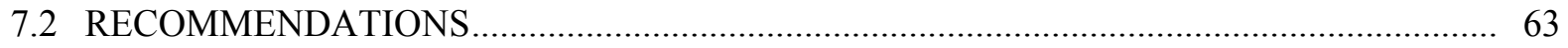

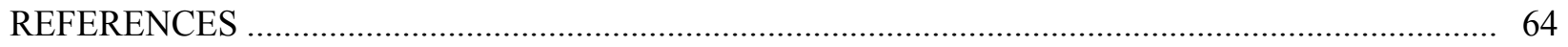

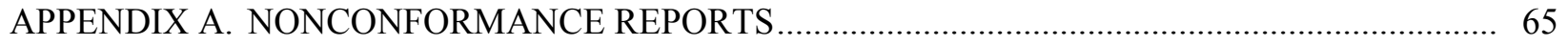

APPENDIX B. SUMMARY OF PROPOSED TECHNICAL APPROACH FOR ACCEPTANCE OF RUSSIAN MANUFACTURED PULSATING MIXER PUMP ..........................6 68

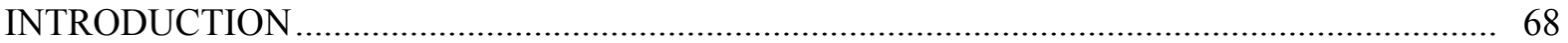

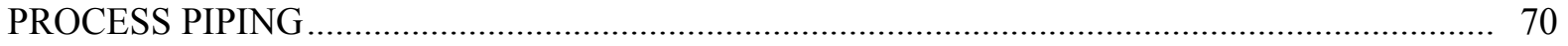

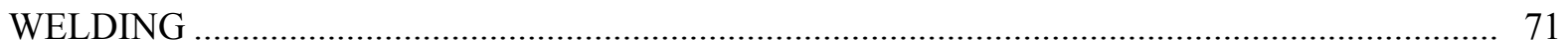

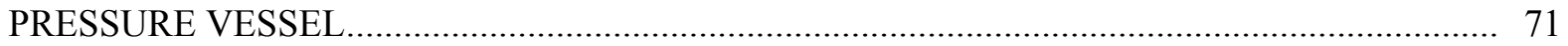

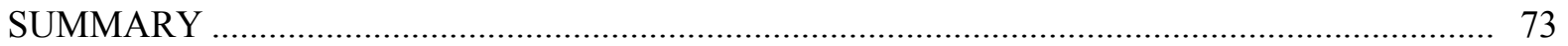




\section{LIST OF FIGURES}

Figure $\quad$ Page

1. Russian pulsating mixer pump for use in the Gunite and Associated Tanks remediation........... 4

2. Sketch of Russian pulsating mixer pump in GAAT TH-4 .............................................. 5

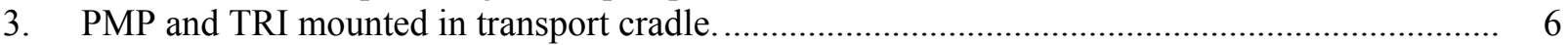

4. PMP unit 1 strapped in shipping container with outside walls of container removed................. 10

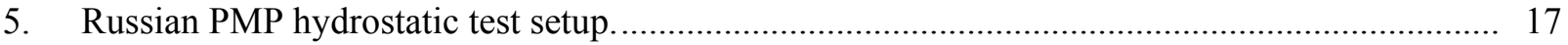

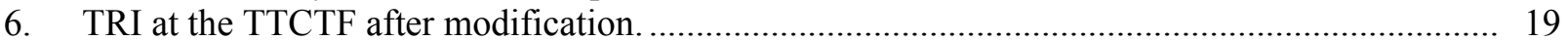

7. View of the top of the PMP and drive table inside the TRI. ............................................. 20

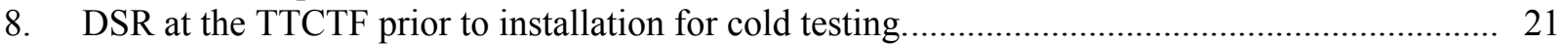

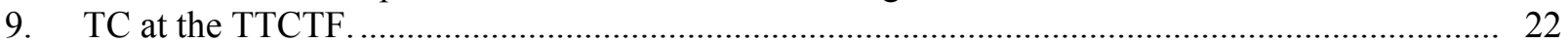

10. Check valve assembly before installation in the bottom of the PMP PV ................................ 24

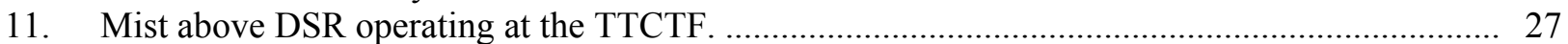

12. Sequence of views of two-crane lift of PMP from TTCTF.................................................... 30

13. Mock tank in TTCTF before addition of plastic liner. .......................................................... 33

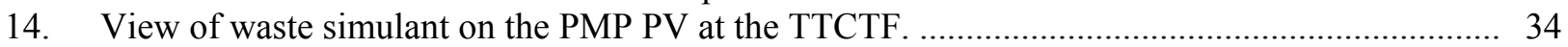

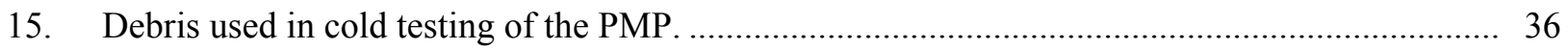

16. Air release at end of discharge cycle................................................................................ 37

17. View of the bottom of PMP showing the orientation of the screened inlet port relative to the discharge nozzles................................................................................................... 38

18. Typical pressure time curve for the fill/discharge cycle using a 90 psig air supply................... 40

19. Cross section of mock tank showing the measurement points for the sand displacement patterns

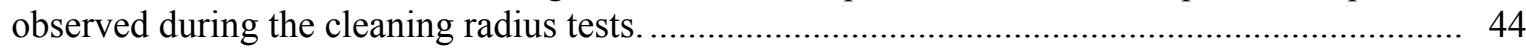

20. Minimum cleaning radius growth for $16 \mathrm{~mm}$ diameter nozzles............................................ 45

21. Composite photo of sand displacement pattern after dynamic cleaning radius tests with 16-mm-diam nozzles.

22. Minimum cleaning radius growth for 10 -mm-diam nozzles. .................................................. 46

23. Typical sand mound test observations before and after testing. ........................................... 48

24. Screen views from the as-received and new control systems................................................ 49

25. Composite overview of mock tank floor after the gravel displacement test.............................. 51

26. Clay-sand mounds in mock tank before mixing. ............................................................... 52

27. Overview of mock tank after the dual mound clay-sand displacement test. .............................. 53

28. View of clay-sand mound before mixing and filling of mock-tank. ......................................... 54

29. View of mock-tank after mixing a single in-line clay-sand mound. ......................................... 54

30. End of long-pole sampling tool, showing sample collection vials......................................... 57

31. Raw sample data from mixing test on August 15, 2000 where curve 1 is for the sample position nearest the floor of the mock tank, and curve 4 is for the sample position farthest from the floor (numbers in parentheses indicate height from floor of mock tank)........................................ 58

32. Solids mixing profile during simulant retrieval where curve 1 is for the sample position nearest the floor of the mock tank, and curve 4 is for the sample position farthest from the floor (numbers in parentheses indicate height from floor of mock tank) ........................................ 60

33. Variation of fill time with run time for the PMP pump down test........................................... 60

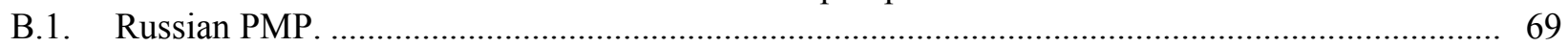




\section{LIST OF TABLES}

Table

Page

1. PMP 1 construction material composition comparison .................................................. 12

2. $\quad$ PMP 2 construction material composition comparison ....................................................... 12

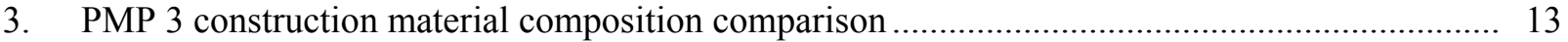

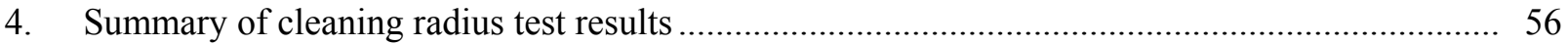

B.1. Alignment of ASME and Russian welding requirements................................................... 72 


\section{ACRONYMS}

$\mathrm{AD}$ ANSI

ARES

ASME

ASTM

AWS

B\&PV

CFR

CS

DOE

DSR

EM

FETC

FY

GAAT

$H \& R$

ISO

LLC

LMES

MCC

NCR

NDA

NETL

ORNL

PMP

PNNL

PT

PV

QA

QE\&I

RPSD

RT air distributor

American National Standards Institutes American Russian Environmental Services American Society of Mechanical Engineers American Society for Testing and Materials American Welding Society

boiler and pressure vessel

Code of the Federal Register

control system

U.S. Department of Energy

decontamination spray ring

Environmental Management

Federal Energy Technology Center

fiscal year

Gunite and Associated Tanks

hoisting and rigging

International Standards Organization

limited liability corporation

Lockheed Martin Energy Systems

Mining and Chemical Combine

nonconformance report

nondestructive assay

National Energy Technology Laboratory

Oak Ridge National Laboratory

pulsating mixer pump

Pacific Northwest National Laboratory

dye penetration

pressure vessel

quality assurance

Quality Engineering and Inspection

Robotics and Process Systems Division

radiographic examination 
QE\&I Quality Engineering and Inspection

TC transport cradle

TRI tank riser interface

TTCTF Tanks Technology Cold Test Facility

UNC Unified National Coarse

WSS work smart standards 


\section{ACKNOWLEDGMENTS}

The design, fabrication, and cold testing of the Russian pulsating mixer pump (PMP) were successfully accomplished through the dedicated efforts, cooperation, and ingenuity of a diverse team of professionals. Technical and managerial personnel in both government and private industry worked together to produce and cold test the system, which includes the first application of a Russian technology in a United States environmental restoration project. Each team member exhibited a high degree of professionalism and cooperation to make this project a success and to overcome the inherent difficulties of a multinational collaboration. The authors acknowledge the following individuals for their efforts in making this project a success:

Oak Ridge National Laboratory, UT-Battelle

Richard Bowman

Roger Bradley

Andy Christopher

David Dunning

Douglas (Chico) Edwards

Jim Ellis

Curtis Fitzgerald

Mike Fraker

Larry Hammon

Ric Hobson

Steve Killough

Bill Palmer

Randy Parrish

Steve Rose

Steve Tallent

Harold Toy

Dirk Van Hoesen

Oak Ridge National Laboratory, Bechtel-Jacobs

Company, LLC

Tom Koepp
Y-12 National Security Complex, BWXT/Bechtel

Enterprise

Jeff Gardner

Richard Hammond

Tetra Tech, Inc.

Marshall Johnson

Mining and Chemical Combine, Zheleznogorsk, Russia

Boris Barakov

Konstanin Kudinov

Vasily Zhidkov

American Russian Environmental Services, Dunedin, FL

Tanya Albert

Tom Albert

U.S. Department of Energy

Jacquie Noble-Dial, Oak Ridge Operation

William Haslebacher, National Environmental

Technology Laboratory

Battelle Memorial Institute

Brian Hatchell 


\begin{abstract}
Russian pulsating mixer pump (PMP) technology was identified in FY 1996 during technical exchanges between the U.S. Department of Energy (DOE) Tanks Focus Area Retrieval and Closure program, the DOE Environmental Management International Programs, and delegates from Russia as a technology that could be implemented in tank waste retrieval operations in the United States. The PMP is basically a jet mixer powered by a pressure/vacuum supply system. A prototype PMP was provided by the Russian Mining and Chemical Combine and evaluated as a potential retrieval tool in FY 1997 at Pacific Northwest National Laboratory (PNNL). Based on this evaluation, Oak Ridge National Laboratory (ORNL) and DOE staff determined that a modified PMP would meet project needs for bulk mobilization of sludge from one or more of the Gunite and Associated Tanks (GAAT) at ORNL. In FY 1998, PMP technology was selected for deployment in one of the GAAT to mobilize settled solids. Deployment of the PMP was expected to reduce operation and maintenance costs required to utilize more expensive retrieval systems. The following series of cold tests and inspections were conducted on one of the three PMP units provided to verify the acceptability and readiness of the mixing system for operation in the GAATs at ORNL:
\end{abstract}

1. Inspections and measurements designed to evaluate the integrity of the equipment

- Fabrication shop inspections

- Equipment inspections

- Vibration/oscillation measurements

- Hydrostatic pressure tests

2. Functionality of the system components

- Tank riser interface functionality

- Decontamination spray ring (DSR) functionality

- Valves, actuator, sensors, and control system functionality

- Support fixture tests

- Contamination control assessment

3. Mixing and operational performance of the PMP system

- DSR performance

- PMP debris tolerance

- PMP performance with water only

- PMP cleaning radius determination

- PMP performance with sludge surrogates

The results from these tests indicate that the PMP should be successful in mixing materials with characteristics similar to sand, kaolin clay, and gravel at moderate operating pressure in a 20 -ft-diam tank similar to the GAAT TH-4. Minimum cleaning radii in the range of $\sim 5.5$ to $\sim 8 \mathrm{ft}$ were observed. After various control system modifications and improvements, the PMP was successfully operated for several hours in the presence of both floating and submerged debris and various waste surrogates. After completion of cold testing, the system was successfully deployed in Gunite tank TH-4 in FY 2001. 


\section{PURPOSE}

The cold tests described in this document include the tests and inspections needed to verify the acceptability and readiness of the Russian pulsating mixer pump (PMP) system for operation in the Gunite and Associated Tanks (GAAT) at Oak Ridge National Laboratory (ORNL). The PMP system comprises the PMP, tank riser interface (TRI), decontamination spray ring (DSR), transport cradle (TC), and control system (CS). Tests and inspections were conducted to assess the integrity of the system components, demonstrate the operational performance of the system, perform a preliminary checkout of operating procedures, and train the operators.

\section{BACKGROUND}

Russian PMP technology was identified in FY 1996 during technical exchanges between the U.S. Department of Energy (DOE) Tanks Focus Area Retrieval and Closure Program, the DOE Environmental Management International Programs, and delegates from Russia as a technology that could be implemented in tank waste retrieval operations in the United States. The PMP is basically a jet mixer powered by a pressure/vacuum supply system. A prototype PMP was provided by the Russian Mining and Chemical Combine and evaluated as a potential retrieval tool in FY 1997 at Pacific Northwest National Laboratory (PNNL). Based on this evaluation, ORNL and DOE staff determined that a modified PMP would meet project needs for bulk mobilization of sludge from one or more of the Gunite tanks at ORNL. In FY 1998, PMP technology was selected for deployment in one of the tanks to mobilize settled solids. Because of the simplicity of the PMP design, it was expected to reduce operation and maintenance costs anticipated for the use of more expensive robotic retrieval systems. After completion of cold testing, the system was successfully deployed in Gunite tank TH-4 in FY 2001. A detailed description of the observations from the hot deployment will be covered in a follow-on report. Summary information on the hot deployment can be found in PNNL-SA-34056. ${ }^{l}$

\section{INTRODUCTION}

The Oak Ridge PMPs are functionally similar to the prototype mixer pump tested by PNNL; however, the Oak Ridge PMP has been designed to accommodate the unique constraints and requirements for operations in the GAAT. The GAAT PMP system consists primarily of four major subsystems: (1) the PMP assembly, (2) the tank riser interface (TRI), (3) the DSR, and (4) the TC. The Mining and Chemical Combine (MCC) at Zheleznogorsk, Russia, fabricated the PMP under a contract with the Russian commercial firm, RadioChem Services Company. A total of three PMPs and one CS were fabricated. A single TRI was fabricated by Battelle, Inc., to couple the PMP with the GAAT. Battelle also fabricated the DSR and TC. Both Battelle and RadioChem Services were under subcontract to American Russian Environmental Services, Inc. (ARES), which served as the integrating contractor responsible for fabrication and delivery of the PMP system to ORNL and was funded by the National Energy Technology Laboratory (NETL) (formerly Federal Energy Technology Center [FETC]). The CS components were procured from U.S. vendors by ARES and shipped to Zheleznogorsk, Russia, for assembly and development of the CS algorithms. Installation, checkout, and deployment of the system were funded through the Tank Focus Area Retrieval and Closure Task at ORNL. 
Because the PMP was fabricated in Russia and not under the jurisdiction of U.S. fabrication standards, identification of and compliance with appropriate U.S. fabrication standards was a significant issue. The Work Smart Standards (WSS) for engineering design applicable to industrial, radiological, and nonreactor nuclear facilities is the governing document that identified the required codes and standards for the GAAT project. Since detail design and fabrication of the PMPs occurred in a Russian facility that did not work to U.S. standards, compliance with the letter of the existing WSS was not feasible. As an alternative, the equipment was fabricated to the appropriate existing Russian standards, and steps were taken to ensure that the technical intent of the U.S. standards was met. The equipment is an adaptation of an existing Russian design in use for radiochemical waste applications in Russia, which are similar to those of the GAAT remediation project. The PMP was designed and fabricated by the Russian Federation Ministry for Atomic Energy Mining and Chemical Combine in Zheleznogorsk, which has extensive experience providing equipment for radiochemical service, using the appropriate Russian codes and standards. Pressure tests and inspections of the equipment were conducted in Russia and in the United States to ensure the integrity of the system prior to deployment. Functional tests of the equipment were also conducted in the United States to verify the operation of the system. Necessary and appropriate safety precautions were also taken to ensure personnel safety during testing.

The effectiveness of the mixer is dependent on the size of the tank to be mixed and the characteristics of the waste. The Gunite tanks at ORNL were chosen for the deployment of this technology because of the need for a mixing and mobilization system capable of (1) breaking up and suspending materials that are difficult to mix and pump without adding liquids to the tank, (2) reducing the work load on the robotic retrieval systems then in use, and (3) operating in a tank with limited space and significant quantities of waste. The system was designed with the flexibility to permit deployment in either the 50-ft-diam or 20$\mathrm{ft}$-diam Gunite tanks at ORNL and can be used in conjunction with U.S. technology, such as Flygt mixers, to provide an efficient mixing system for the larger diameter tanks. 


\section{EQUIPMENT DESCRIPTION AND OPERATIONAL OVERVIEW}

A schematic of the PMP assembly along with a listing of the major components is shown in Fig. 1. The system consists primarily of an in-tank pumping chamber coupled with a pressurized air source. In addition to the PMP assembly shown in Fig. 1, a TRI and DSR are used to couple the PMP with the GAAT. A sketch of the installation of the TRI and PMP at GAAT TH-4 is shown in Fig. 2. The TRI supports the PMP and permits height adjustments and alignment with the tank riser. Because of a difference in the separation between the TRI and simulated tank riser at the TTCTF, the bellows was not used during cold testing. The DSR provides water wash down of the contaminated equipment as it is removed from the tank. The DSR is mounted to the tank riser and is connected to the TRI by a flexible bellows to allow adjustment of the elevation of the PMP. A transport was provided to facilitate movement of PMP from tank to tank. A sketch of the PMP in the TC is shown in Fig. 3.

During operation of the PMP, materials from the waste tank are pulled inside the pumping chamber through an inlet check valve when a vacuum is applied to the pumping chamber. The inlet port is separated from the discharge line and is at a higher elevation relative to the bottom of the tank. The discharge outlet is typically positioned in the sludge layer, closer to the bottom of the tank, while the inlet remains in the supernatant. This orientation allows supernatant to be drawn into the pumping chamber and discharged into the sludge layer and improves mixing performance. After the pumping chamber is full, the vacuum is turned off and air pressure is applied to close the check valve and force the material out of the pumping chamber through four nozzles on the bottom of the discharge line from the pumping chamber. These operations are repeated using the waste fluid material in the tank to break up and mix the solids in the bottom of the tank. Conventional pumping systems are then used to transfer the waste out of the tank. During mixing operations, the PMP can be rotated through a 90-degree arc in alternating clockwise and counterclockwise directions to sweep the entire bottom of the tank.

Compressed air is used to create a vacuum using the in-tank eductor. Control valves are operated in conjunction with an electromechanical axial valve in the air distributor (AD) of the PMP to direct either the compressed air flow or vacuum to the pump chamber. Tank waste is drawn into the pumping chamber through a coarse screen and check valve assembly on the bottom of the inlet to the chamber when vacuum is applied. In the event of a plug in the inlet screen, wash water can be admitted to clean the inlet screen. A level sensor inside the chamber is used to control the durations of the pressure and vacuum cycles. A spherical magnetic float attached to a sealed pipe inside the pumping chamber is used as a level indicator. A sensor inside the pipe detects the high- and low-level positions of the float. The high-level signal is used to pressurize the pumping chamber and the low-level signal is used to admit vacuum to the chamber. The pressure vacuum cycle can also be controlled either locally by using mechanical timers or remotely by using timers built into the computer-based CS.

PMP units 2 and 3 are slightly different from unit 1 . Unit 1 was delivered to ORNL from Russian in the summer of 1999 and units 2 and 3 in the spring of 2000. The design of PMP units 2 and 3 was modified to include a small hole in the bottom of the AD section to limit the vacuum applied and permit drainage of condensate. Units 2 and 3 also had an improved check valve restraining system. A modification kit for unit 1 was shipped with units 2 and 3 along with instructions on how to modify unit 1 . The check valve modification was made during the functional tests of unit 1 , but the drain hole modification was not made. Battelle, Inc., shipped the TRI and DSR in the spring of 1999 and the transport cradle in the winter of 1999. 


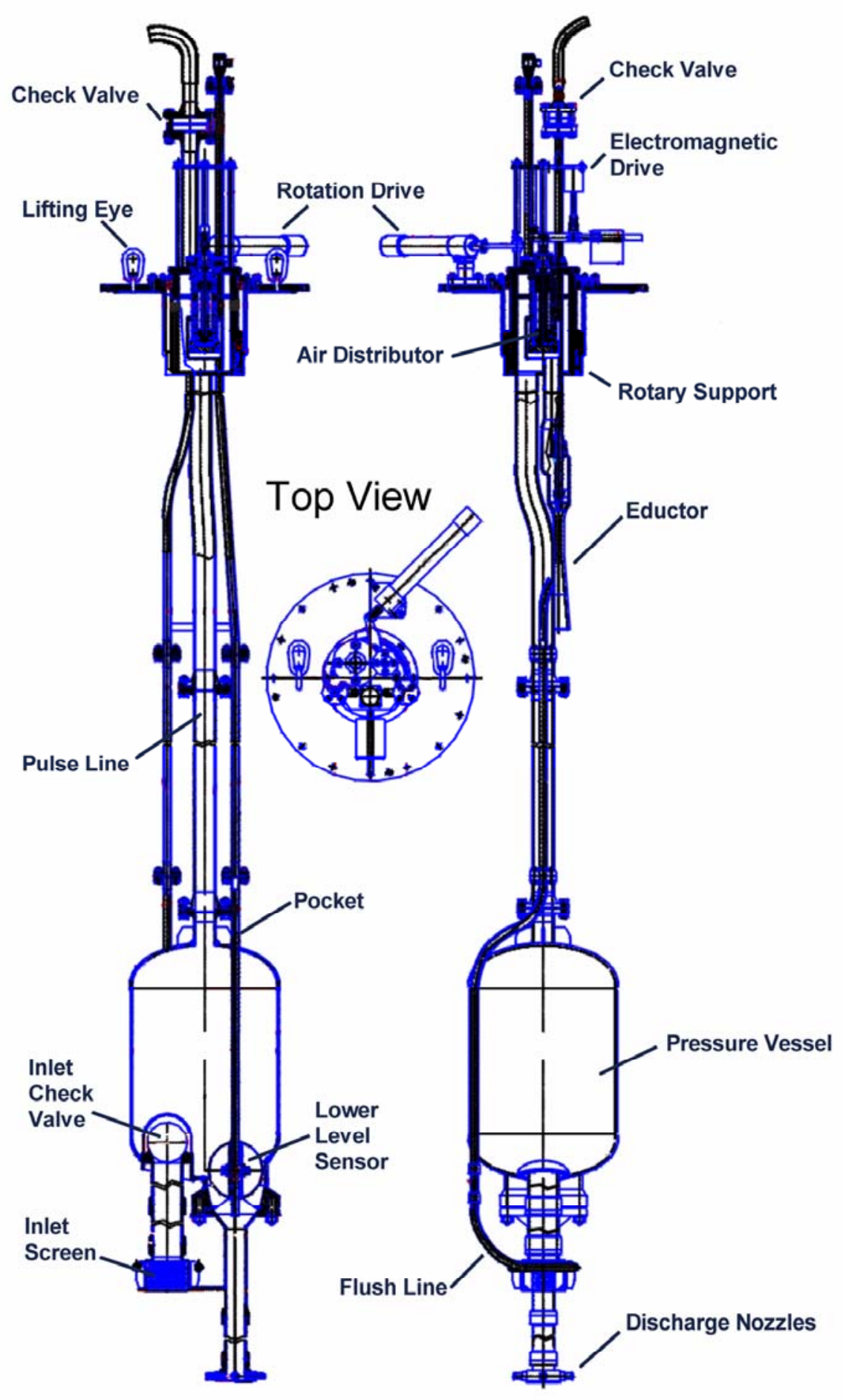

Fig. 1. Russian pulsating mixer pump for use in the Gunite and Associated Tanks remediation. 


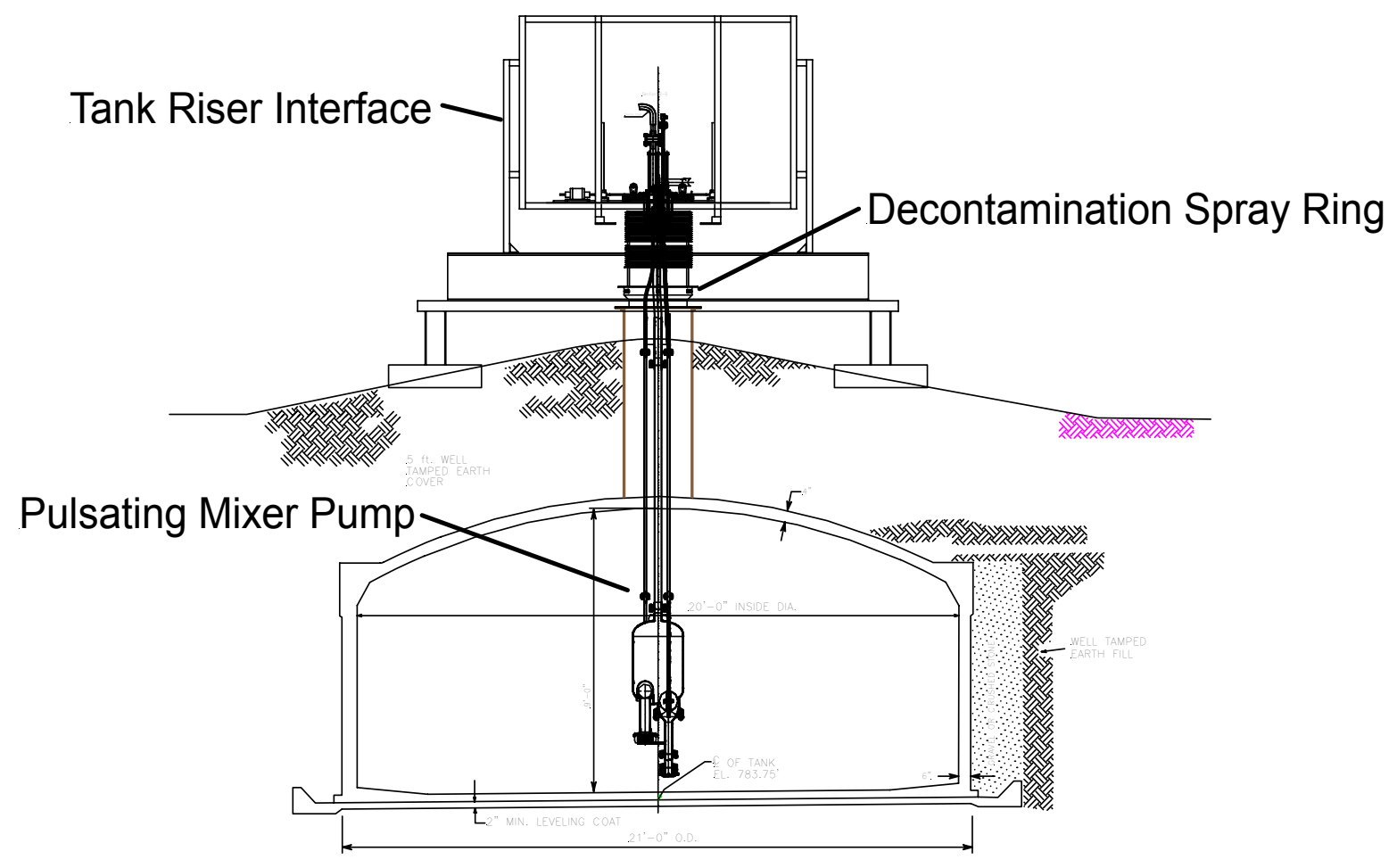

Fig. 2. Sketch of Russian pulsating mixer pump in GAAT TH-4. 

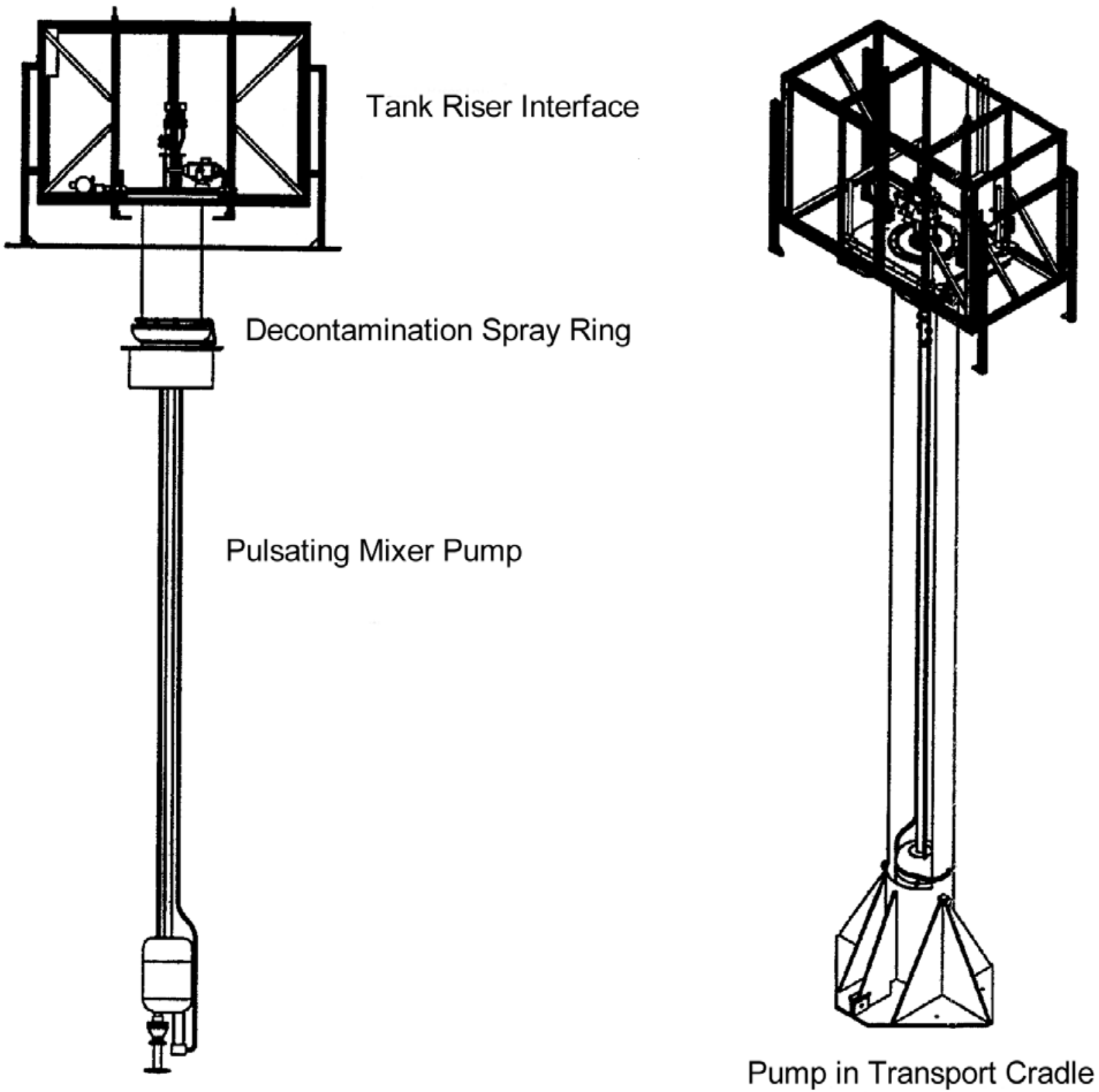

Fig. 3. PMP and TRI mounted in transport cradle. 


\section{COLD TEST OVERVIEW}

The cold tests conducted on the Russian PMP system fall into three distinct groups with unique purposes and goals. The first group of tests consisted of various types of inspections and measurements designed to evaluate the integrity of the equipment. These tests included the following:

- Fabrication shop inspections - On-site visits to the Russian fabrication shop responsible for manufacture of the PMPs.

- Equipment inspections - Detailed review of the equipment fabrication and documentation, focusing on weld integrity and material composition.

- Vibration/oscillation measurements - Measurement and observation of vibrations and oscillations during PMP operation.

- Force measurements - Measurements to allow setting of the slip clutch on the PMP support/drive table to limit the potential force applied to the tank floor. This test was not conducted because of time constraints and the decision to use an alternate means of limiting the force applied to the floor of the tank.

- Hydrostatic pressure tests - Pressure tests to verify the integrity of the Russian fabricated pressure vessel (PV).

A second group of tests was conducted with the PMP installed in the Tanks Technology Cold Test Facility (TTCTF) to check out the functionality of the system components. These tests included the following:

- $\quad$ TRI functionality - Verification of the ability of the TRI to raise, lower, and hold the PMP at a selected elevation.

- DSR functionality - Test the installation and operability of the DSR

- Valves, actuator, sensors, and CS functionality - Verification of the installation of all valves, sensors, and actuators and the ability of the CS to communicate with and operate the system components.

- $\quad$ Support fixture tests - Assessment of the utility and functionality of all rigging and support fixtures needed to install and withdraw the PMP and placement in the TC.

- Contamination control assessment - Assessment of methods of containment of contamination on the PMP upon removal from a tank.

The third group of tests was conducted to assess the mixing and operational performance of the PMP system. These tests included the following:

- DSR performance - Assessment of the ability of the DSR to remove surrogate sludges from the PMP as it is withdrawn from the test tank.

- PMP debris tolerance - Assessment of the tolerance of the PMP to typical debris observed in the GAAT.

- PMP performance with water only - Observation of the operation of the mixer under manual and automatic control at various conditions.

- $\quad$ PMP cleaning radius determination - Determination of the tank-cleaning radius using surrogate wastes.

- $\quad$ PMP performance with sludge surrogates - Determination of the mixing performance and ability of the PMP to mobilize surrogate waste mounds and heavy materials. 
The original intent of the cold test program was to perform test groups one and two on all three PMPs. However, due to time constraints, only one of the three PMP units was completely tested. This PMP unit also underwent group three tests with surrogate sludge materials and was ultimately deployed in ORNL Gunite tank TH-4.

\section{TEST RESULTS AND OBSERVATION}

\subsection{INSPECTIONS AND MEASUREMENTS}

During the design and fabrication of the PMP system a series of special tests was identified. These tests included detailed inspections, vibration measurements, force measurements, and pressure tests. Because of the safety implications, the Russian-made PMP PV was required to undergo stringent weld inspections based on accepted U.S. welding standards.

Inspections of equipment during fabrication and at the conclusion of fabrication are typical U.S. practices. However, for the Russian PMP fabrication, the use of Russian national standards (i.e., standards which have not been approved by an international standards organization) in the design and fabrication of the system components dictated the need for both standard and nonstandard inspections. An effort was made to conduct a top-level comparison and cross mapping between the Russian national standards and recognized U.S. standards. Because of time and budget constraints, detailed cross mapping was not possible. Various acceptance inspections were conducted to (1) assess the general quality of the fabrication, (2) visually check the equipment for damage during shipment, (3) inspect the welds for abnormalities, and (4) verify proper form and fit. In addition, inspections were made during operation to identify any unusual behavior and observe any other abnormalities. ORNL personnel also conducted two separate on-site inspections of the MCC fabrication shop. The initial inspection was conducted at the start of the PMP fabrication, and the second during acceptance testing of PMP units 2 and 3. All U.S.produced equipment, such as the TRI, DSR, and TC were fabricated to U.S. standards and were subjected to periodic routine inspections during the fabrication.

\subsubsection{Fabrication Shop Initial Inspection}

An ORNL representative from UT-Battelle, LLC, visited the MCC fabrication shop in Zheleznogorsk, Russia, on March 3-4, 1999. The purpose of the visit was to inspect the fabrication shop and develop a preliminary assessment of its capabilities and the quality standards to be used in fabrication of the PMPs. This effort was conducted in conjunction with activities for the DOE Nuclear Cities Initiatives program.

The observations from the preliminary assessment and inspection included the following:

1. MCC's fabrication department was staffed with highly qualified managers and engineers, which appeared to exceed the capabilities of most private firms;

2. good organizational structure;

3. machine shop staff appeared to possess the skills necessary to fabricate complex components of high quality;

4. shop equipment was old but appeared to be well maintained and in good operating order;

5. shop areas were kept clean, including areas where work was ongoing; and

6. management ensured that proper training and qualification, requalification was kept up to date and appropriate records were maintained. 
During the inspection, a welding demonstration was conducted on a Russian stainless steel coupon. The work was well performed and the coupon was provided to ORNL as a sample of Russian welding capabilities and their ability to meet U.S. standards. The weld, weld material, and the coupon were inspected by ORNL's Quality Engineering and Inspection (QE\&I) department. The weld was considered acceptable under American Welding Society (AWS) standards with no flaws detected. The weld material was determined to be near type 308 stainless steel and the base material near type 302 .

\subsubsection{Acceptance Test Inspection}

An ORNL representative from Bechtel Jacobs Company, LLC, visited the MCC fabrication shop in Zheleznogorsk, Russia, on November 9-12, 1999, for the purpose of witnessing the acceptance testing of PMP unit 2 and hydrostatic testing of PMP unit 3. The ORNL representative was accompanied throughout the inspection by representatives from ARES. Prior to the inspection, a checklist was prepared based on the requirements given in the internal document, Summary of Proposed Technical Approach for Acceptance of Russian Manufactured Pulsating Mixer Pump, given in Appendix II. The checklist was used to ensure that all fabrication requirements were adequately addressed and satisfied. The observations from the acceptance test inspection included the following:

1. The MCC fabrication department was well organized.

2. The MCC staff was well qualified.

3. Good fabrication practices were conducted.

4. The acceptance tests could not be completed during the November 1999 visit because the flow control valves for the CS had not arrived at MCC. This resulted in manual operation of the PMP unit 2. After receipt of the control valves in December 1999, ARES representatives witnessed the remaining testing, completed the checklist, and video taped the operation of the PMP during the CS tests.

5. The acceptance testing of PMP unit 2 at the MCC was performed in a large rectangular carbon steel tank. The unit was installed in one corner of the tank very near the end and sidewalls. The tank was $\sim 10 \mathrm{ft}$ high with a 6 - by 4 -ft cross section. The standoff distance between the nozzle head and floor of the tank was $\sim 4$ in.

6. The operating conditions for the acceptance tests were as follows:

- 100 psi air supply;

- standard (60 to $100 \mathrm{psi}$ ) water pressure for flushing; and

- $\sim 5 \mathrm{ft}$ of water and kaolin clay $(\sim 1.7 \mathrm{ft}), \sim 121 \mathrm{ft}^{3}$ of material with an approximate specific gravity of 1.03 (calculated).

7. During mixing tests, the PMP quickly mixed the settled waste simulant (clay in water) and performed well.

8. The air eductor on the PMP generated high noise levels above $\sim 100 \mathrm{~dB}$.

9. A vibration occurred at the end of each discharge cycle. Additional concern over the vibration was expressed during a follow-on briefing to ORNL staff. This subject is addressed in Sect. 5.1 .4 of this report.

10. A hydrostatic pressure test on PMP unit 3 was conducted by MCC using the U.S. American Society of Mechanical Engineers (ASME) boiler and pressure vessel (B\&PV) code for pressure testing of vessels and components. The assembled unit was positioned with the PV at 5 degrees above horizontal. The maximum test pressure was 348 psi, in accordance with code requirement for maintaining 1.5 times the maximum allowable working pressure for a period of 10 min without leakage. The unit held the required pressure for a period of $15 \mathrm{~min}$. 


\subsubsection{ORNL Acceptance Tests and Inspections}

Various inspections were performed on all equipment associated with the Russian PMP system. This included the three PMP units, the CS, TRI, DSR, and TC.

\subsubsection{PMP Shipment and Packaging}

The MCC designed and fabricated a total of three PMPs. The MCC also assembled a single PMP CS for use with all three units. Each PMP was fabricated and shipped to ORNL from Russian in its own separate shipping container. The shipping containers were constructed of kiln-dried wood with the individual components held down using metal straps and a fibrous packing material to prevent damage during shipping. The three PMP units were shipped separately and primarily unassembled, with the exception of the AD unit, which was assembled by the MCC. The AD is an intricately designed component that is used to divert pressurized air and vacuum into the pressure chamber. The MCC provided the necessary documentation and drawings for assembly and maintenance of the system. Fig. 4 shows left and right side views of PMP unit 1 strapped in the shipping container with the outside walls of the container removed. Caps (shows as blind flanges in Fig. 4) were installed over the ends of all piping and the PV to prevent the entry of debris and dirt during shipment.
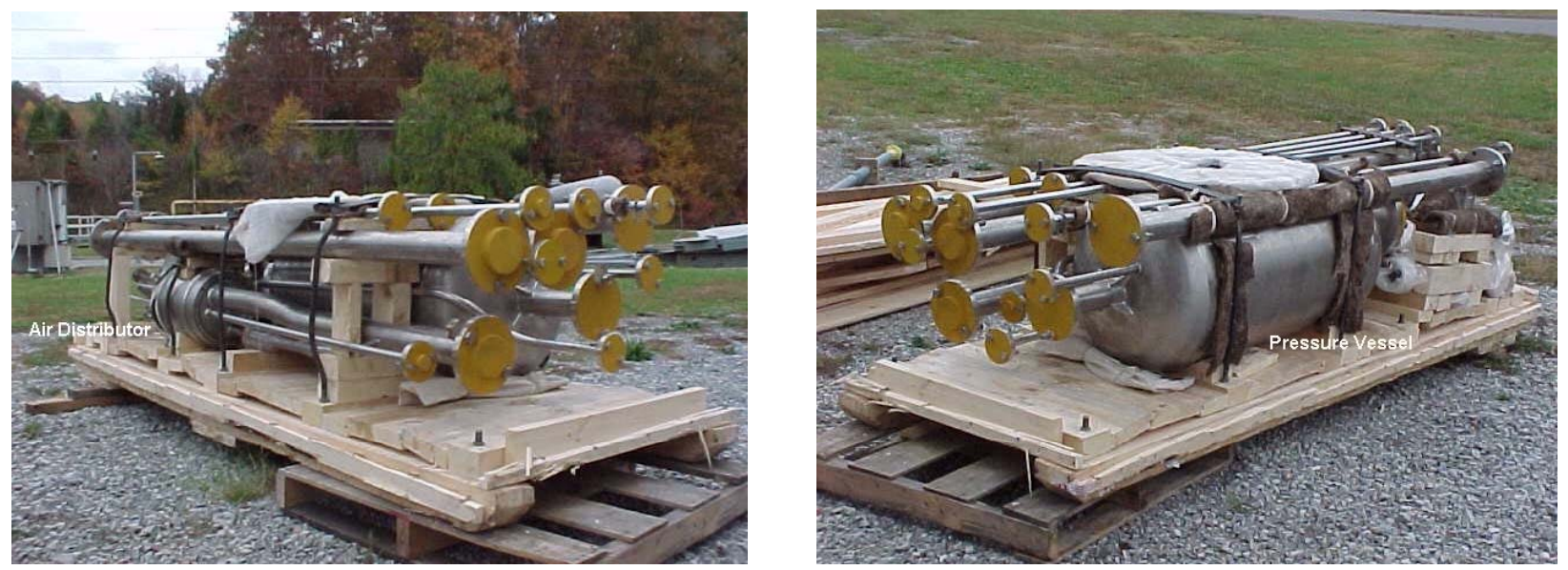

Fig. 4. PMP unit 1 strapped in shipping container with outside walls of container removed.

Visual observations were made for external and internal damage that may have occurred during shipment and none was detected. No visual damage was noted on any of the PMP components with units 1, 2, and 3 , including the CS that was provided with PMP unit 2.

\subsubsection{PMP Materials Analysis}

The design information provided by the Russians indicated that the PMP would be constructed primarily of a type of stainless steel, which is not typical of the type and series of stainless steels used by U.S. and other foreign manufacturers. The ORNL QE\&I department performed nondestructive analysis (NDA) on the PMP construction materials to validate the material composition.

An X-ray fluorescence technique using a portable X-ray analyzer from Texas Nuclear (Metallurgist-XR) was used to assess the composition of the materials used in fabrication of the PMP. The Metallurgist-XR uses two separate radioactive sources to independently expose and introduce X-ray fluorescence into the 
sample being analyzed. The analyzer is calibrated for 21 of the most common alloying elements (e.g., Ni, $\mathrm{Cr}, \mathrm{Mo}, \mathrm{Co}, \mathrm{Cu}$ ) and compares the readings with over 200 identified alloys in its database. The readout from the analyzer indicates whether the sample matches an alloy in the database and also provides the chemical analysis of the sample. Knowledge of metallurgy is not required to operate the analyzer because no interpretation is involved. The analyzer cannot detect elements such as $\mathrm{C}, \mathrm{Mg}, \mathrm{S}, \mathrm{P}, \mathrm{Si}$, and $\mathrm{Be}$, which do not exhibit X-ray fluorescence. Therefore, distinguishing between alloys such as 304 and 304L stainless steel is not possible because the only difference is the carbon content. Table 1, Table 2, and Table 3 provide comparisons of the measured compositions of the Russian materials with standard U.S. stainless steel compositions.

In general, the results from the materials analysis indicated that the majority of the material used to fabricate the PMPs was relatively close to the composition of 321 stainless steel. The bolts used to assemble the PMP 1 were identified as having compositions approximately the same as 440C stainless steel for PMP 1, but this varied for PMPs 2 and 3. The lock washers used on the PMP 3 were composed of a high zinc alloy, which did not match well with any of the alloy compositions in the analyzer database (Table 3), but was identified as being nearest to 304 stainless steel even through the $\mathrm{Zn}$ content of stainless steels are lower than the alloy analyzed that was used for these washers. These washers on PMP unit 1 were brittle and had to be replaced with a 300 series stainless steel during cold testing. The lock washers on PMP unit 2 were closer in composition to types 410 or 416 stainless steel. 
Table 1. PMP 1 construction material composition comparison

\begin{tabular}{|c|c|c|c|c|c|c|c|c|c|c|}
\hline \multirow[t]{2}{*}{$\begin{array}{c}\text { Material } \\
\text { Description }\end{array}$} & \multicolumn{10}{|c|}{$\begin{array}{c}\text { Nominal Composition } \\
(\%)\end{array}$} \\
\hline & $\mathrm{Fe}$ & $\mathrm{Cr}$ & $\mathrm{Ni}$ & $\mathrm{Ti}$ & $\mathrm{Mn}$ & Mo & $\mathrm{Cu}$ & $\mathrm{Sn}$ & $\mathrm{Si}$ & $\mathrm{C}$ \\
\hline U.S. type 321 & $\mathrm{Bal}^{a}$ & 17-19 & $9-12$ & $4^{b}$ & $2(\max )$ & & & & 1 (max) & 0.08 (max) \\
\hline PV & 70.21 & 17.25 & 10.21 & 0.56 & 0.83 & 0.17 & 0.46 & 0.37 & $\mathrm{NM}^{c}$ & NM \\
\hline $\mathrm{AD}$ & 70.23 & 17.3 & 10.64 & 0.57 & 0.61 & 0.15 & & & NM & NM \\
\hline Piping & 69.34 & 16.93 & 11.6 & 0.76 & 1.3 & 0.12 & & & NM & NM \\
\hline 3 in flange & 71.81 & 17.27 & 9.11 & 0.64 & 0.58 & 0.09 & & & NM & NM \\
\hline Nuts & 70.22 & 17.94 & 9.84 & 0.54 & 0.81 & 0.17 & & & NM & NM \\
\hline U.S. type $440 C$ & Bal & $16-18$ & & & $1(\max )$ & $\begin{array}{l}0.75 \\
(\max )\end{array}$ & & & $1(\max )$ & $0.95-1.2$ \\
\hline Bolts & 80.39 & 15.85 & 2.06 & & 1.12 & 0.09 & & & & \\
\hline
\end{tabular}

${ }^{a}$ Balance

${ }^{b}$ Minimum of 5 times the carbon content

${ }^{c}$ Not measured

Table 2. PMP 2 construction material composition comparison

\begin{tabular}{|c|c|c|c|c|c|c|c|c|c|c|c|}
\hline \multirow[t]{2}{*}{$\begin{array}{c}\text { Material } \\
\text { Description }\end{array}$} & \multicolumn{11}{|c|}{$\begin{array}{c}\text { Nominal Composition } \\
(\%)\end{array}$} \\
\hline & $\mathrm{Fe}$ & $\mathrm{Cr}$ & $\mathrm{Ni}$ & $\mathrm{Ti}$ & $\mathrm{Mn}$ & Mo & $\mathrm{V}$ & $\mathrm{Zn}$ & $\mathrm{S}$ & $\mathrm{Si}$ & $\mathrm{C}$ \\
\hline U.S. type 321 & $\overline{\mathrm{Bal}^{a}}$ & 17-19 & 9-12 & $4^{b}$ & 2 (max) & & & & & 1 (max) & 0.08 (max) \\
\hline PV & 70.39 & 16.82 & 10.81 & 0.46 & 0.78 & 0.19 & 0.04 & & & $\mathrm{NM}^{c}$ & NM \\
\hline $\mathrm{AD}$ & 71.02 & 17.27 & 10.49 & 0.49 & & 0.16 & 0.06 & & & NM & NM \\
\hline Piping & 70.87 & 18.74 & 9.29 & 0.66 & & 0.14 & & & & NM & NM \\
\hline Bolts & 89.72 & 16.78 & 11.27 & 0.76 & 0.80 & 0.17 & & & & NM & NM \\
\hline Top Plate & 70.24 & 17.41 & 9.94 & 0.63 & 1.19 & 0.09 & & & & NM & NM \\
\hline U.S. type 410 & Bal & $11.5-13.5$ & & & $1(\max )$ & & & & & $1(\max )$ & 0.15 (max) \\
\hline U.S. type 416 & Bal & $12-14$ & & & $\begin{array}{l}1.25 \\
(\max )\end{array}$ & & & & $\begin{array}{l}0.15 \\
\text { (min) }\end{array}$ & $1(\max )$ & 0.15 (max) \\
\hline Lock washer & 86.84 & 11.37 & & & & & & 1.29 & & NM & NM \\
\hline
\end{tabular}

${ }^{a}$ Balance

${ }^{b}$ Minimum of 5 times the carbon content

${ }^{c}$ Not measured 
Table 3. PMP 3 construction material composition comparison

\begin{tabular}{|c|c|c|c|c|c|c|c|c|c|c|c|c|c|c|}
\hline \multirow[t]{2}{*}{$\begin{array}{c}\text { Material } \\
\text { Description }\end{array}$} & \multicolumn{14}{|c|}{$\begin{array}{c}\text { Nominal Composition } \\
(\%)\end{array}$} \\
\hline & $\mathrm{Fe}$ & $\mathrm{Cr}$ & $\mathrm{Ni}$ & $\mathrm{Ti}$ & $\mathrm{Mn}$ & Mo & $\mathrm{Cu}$ & Sn & $\mathrm{V}$ & $\mathrm{Zr}$ & $\mathrm{Nb}$ & $\mathrm{Si}$ & $\mathrm{Zn}$ & $\mathrm{C}$ \\
\hline U.S. type 321 & $\overline{\mathrm{Bal}^{a}}$ & 17-19 & 9-12 & $4^{b}$ & 2 (max) & & & & & & & 1 (max) & & 0.08 (max) \\
\hline $\mathrm{PV}$ & 69.47 & 17.96 & 10.01 & 0.60 & & 0.15 & & & & & & $\mathrm{NM}^{c}$ & & NM \\
\hline $\mathrm{AD}$ & 69.41 & 18.49 & 9.9 & 0.57 & & 0.17 & & & & & & NM & & NM \\
\hline 3 in Piping & 69.75 & 18.03 & 9.47 & 0.65 & 1.46 & 0.08 & & & 0.06 & 0.1 & 0.02 & NM & & NM \\
\hline 1 in Piping & 71.36 & 16.77 & 9.92 & 0.6 & 0.71 & 0.13 & & & & & & NM & & NM \\
\hline Top Plate & 70.5 & 17.82 & 9.7 & 0.56 & 0.82 & 0.1 & & & & & & NM & & NM \\
\hline Check Valve Basket & 70.54 & 17.79 & 9 & 0.47 & 1.56 & 0.13 & & & & & & NM & & NM \\
\hline Bolt 3 & 67.59 & 19.58 & 8.46 & 0.48 & 0.71 & 0.19 & & 2.49 & & & & NM & & NM \\
\hline Nuts & 69.6 & 19.67 & 9.5 & 0.54 & & 0.18 & & & & & & NM & & NM \\
\hline U.S. type 304 & Bal & $18-20$ & 8-12 & & $2(\max )$ & & & & & & & $1(\max )$ & & 0.08 (max) \\
\hline Lock washer & 35.34 & 6.73 & & & 0.68 & & 1.34 & & & & & NM & 55.41 & NM \\
\hline U.S. type 301 & Bal & 16-18 & $6-8$ & & $2(\max )$ & & & & & & & 1 (max) & & 0.15 (max) \\
\hline Bolts 1 and 2 & 75.62 & 17.52 & 1.98 & & 1.1 & 0.07 & & 2.67 & & 0.06 & & & & \\
\hline
\end{tabular}

${ }^{a}$ Balance

${ }^{b}$ Minimum of 5 times the carbon content

${ }^{c}$ Not measured 
Based upon the results of material type determination, size of the components, and projected material hardness, series 440C stainless steel is considered sufficient to meet the ASME Boiler \& Pressure Vessel (B\&PV) code requirement for fasteners for the listed maximum allowable working pressure of 230 psi. However, as a precaution, the contractor, ARES, procured and provided ORNL with a set of ASME B\&PV code-approved fasteners for use with the PMP prior to installation at GAAT TH-4. Those fasteners were installed on PMP unit 1 at the conclusion of cold testing.

\subsubsection{PMP CS Hardware}

The PMP CS hardware includes the field instrumentation, valves, and piping needed to connect it with the $\mathrm{AD}$ on the PMP. A Micron laptop personal computer was used to automate the operation of the PMP control hardware. All CS hardware, excluding the laptop computer, was shipped with PMP unit 2, which arrived at ORNL in the spring of 2000. An inventory and inspection of the hardware was conducted, which indicated that all the control hardware had been received and was not damaged. Further inspections by ORNL electrical inspectors showed that the wiring of the CS met U.S. electrical code requirements.

\subsubsection{PMP Weld Inspection}

Detailed inspections of the welds on the pressure vessels of the PMPs were conducted to assess the quality of the workmanship. The PMP was fabricated under Russian standards and not specifically to U.S. (ASME) or international standards (International Standards Organization [ISO]) and therefore the welds required inspections to ensure that the Russian welds met or exceeded the minimum standards for U.S. PVs. Russian standards are only accepted and recognized inside Russia. At ORNL, WSS are applied, which require PVs to be fabricated to either U.S. or, in some cases, international standards. ORNL policy also requires that equipment defined as a pressure component (i.e., PMP PV) must meet ORNL WSS for PVs, which are nearly identical to the ASME B\&PV standards.

Each PMP is configured with a PV, which has a capacity of $\sim 200 \mathrm{~L}$ and is $\sim 20$ in diam. During both cold testing and hot deployment, the PV was located below ground inside an enclosure (i.e., the cold test pit or tank TH-4) and was only pressurized during the operational period. This application provided an avenue of exception to the code because the enclosures serve as containment in the event of a failure of the PMP PV.

Consideration was initially given to performing a direct standard-to-standard comparison of the Russian and U.S. standards; however, the difficulty, logistics, funding, and time required made such a comparison impossible. Because MCC is a nuclear facility and is required to comply with Russian nuclear standards, the DOE granted the MCC approval to fabricate the three PMP units under existing Russian standards. Those standards were considered, in principle, to be nearly equivalent to the ASME B\&PV code. The DOE issued an approval letter to ARES, which stated that each unit would be thoroughly inspected upon arrival at ORNL and that those inspections would include weld examinations to ASME B\&PV code prior to placement in service at the TTCTF. ORNL WSS and Quality Assurance policies also required that all equipment of this type must bear a qualified ASME B\&PV code stamp or be qualified at an ORNL facility or approved for service by ORNL officials via an exception policy. In addition, since the PMP was to be operated inside a tank, which would serve as secondary containment in the event of a failure of the system, the anticipated impacts from a possible failure were reasoned to be minimal. An exception letter was written and approved to permit the PMP to be operated at the TTCTF and the GAAT.

The primary concern with the fabrication of the PMPs was the quality of the welding. The design specifications imposed by U.S. standards required that the PMP welds meet or exceed those of the ASME 
B\&PV code prior to being place in service at ORNL. The specifications required visual inspection of all welds and radiographs of $25 \%$ of the PV welds (typical of industry requirement). The radiographic weld examinations performed by MCC were to be made at the critical weld points such as at crosses and difficult to reach areas.

ORNL QE\&I weld specialists inspected each PMP PV upon receipt. Each PMP was shipped with a set of documents and radiographs pertinent to the weld quality of each particular unit. The inspectors were responsible for determining the weld quality using the radiograph film that was supplied by MCC, for performing visual inspections of all welds, and for issuing a written summary of the results of the inspection. The following is a summary of the ORNL weld inspection results for the PVs of each PMP:

1. Weld Inspection Observations on PMP unit 1:

Visual inspections of the PMP unit 1 welds revealed a few areas of incomplete penetration on some of the piping and on the PV. Also, weld slag was observed inside the piping sections and joints for the AD and PV. Three piping legs are used in the PMP design. One pipe serves as an instrument conduit for the PMP level sensor and PV float, another line for the back-flush water line for the PMP's inlet, and the third pipe is used to provide flush water to the AD and PV.

The weld areas where weld slag was observed inside the pipes also showed signs of weld "sugaring" or oxidation, which is normally an unacceptable condition. The slag proved to be a problem upon assembly of unit 1 for installation at the TTCTF. The PMP level sensor could not be fully installed in the PV because of interference from the slag. Also, sharp edges on the slag material located at the flanged joint at the entrance to the AD severed the support cable for the lower portion of the level sensor. The piping on the instrument line was disassembled and the weld slag ground away. This action corrected the problem and allowed the level sensor to be installed and easily positioned to the correct height.

It was also observed that all external welds had been wire brushed after fabrication and prior to shipment. This practice is not allowed under ASME and AWS code. The purpose of the U.S. codes prohibiting wire brushing was a safeguards measure for assuring integrity on the part of the fabricator. Apparently in the past, welders have used the technique of polishing weld surfaces as a means of disguising weld flaws. However, the Russian nuclear standards required polishing of external welds to ease decontamination of the equipment. Understanding this significant difference in philosophy between the two sets of standards was important in assuring weld quality.

The radiograph film and supporting documentation supplied by $\mathrm{MCC}$ was provided to QE\&I for evaluation. An ASME-qualified film reader calibrated per ORNL WSS standards was used to read the radiographs. Unfortunately, the Russian radiograph film was almost, and in most cases, impossible to read on a U.S. film reader. The film density was measured and read to be in the range of 0.8 to 1.1 , which is too light for making a determination of the weld quality. The film density gives an indication of the amount of light transmitted through the film and is determined from the log of the ratio of the intensity of the light incident on the film to the intensity of the light transmitted through the film. The measured density for the Russian radiographs was lower than the ASME code permits, which establishes a film density of 1.8 for the lower limit and 4.0 for the upper limit. MCC was informed of this result and was requested to provide longer exposure times for PMP unit 3. MCC was also provided with a copy of the ASME code requirements for reference. 
Because of the various observations during the initial weld inspection, QE\&I was directed to perform additional radiograph examination of selected PV welds as required by the design specifications and to also perform a $100 \%$ ultrasonic weld examination of the PV. Radiographic examination techniques are excellent for "looking" through a weld while the ultrasonic technique is more suited for locating inclusions. The results of the QE\&I radiograph and ultrasonic weld inspections indicated that the PV welds met code requirements. The ultrasonic inspection, however, did reveal a possible weld inclusion but it was determined to be within the code tolerance.

The weld inspections also showed small areas with less than full penetration on the PV. The thickness of the weld and thickness of material in these areas were measured and code calculations performed to determine the pressure qualification for the PV. The results showed that the fabrication was sufficient to support the required maximum working pressure of $230 \mathrm{psi}$.

2. Weld Inspection Reports on PMP unit 2:

PMP unit 2 arrived on site several months after the arrival of PMP unit 1, and it was immediately apparent that MCC had improved its welding technique, as no slag was observed at any of the welds. However, the radiograph film supplied by MCC had been overexposed in most cases causing the film to be too dark to read. The majority of the film density was measured to be between 4.0 and 6.0 with only a few exceptions of film density as low as 3.5. Based on this finding, the MCC-supplied radiograph film was rejected and MCC informed.

An ultrasonic inspection of $100 \%$ of the welds on PMP unit 2 showed two separate flaws in the PV. These flaws were weld inclusions where a pocket (void) formed and an absence of weld material occurred at those points. The size of the inclusions exceeded the code tolerance, therefore the PV for unit 2 was rejected and the vendor (ARES) notified that they would be required to repair or replace the unit. ARES chose to repair the unit and used a local vendor to make necessary weld repairs. Prior to returning the vessel to ORNL, the vendor had a private, ASME code-qualified firm perform the necessary weld inspections, which included radiographic inspection of the affected area. The weld report and film supplied by the inspection firm indicated the repairs met ASME and AWS code standards.

3. Weld Inspection Reports on PMP unit 3:

PMP unit 3 arrived at the same time as PMP unit 2. Similar observations as noted for unit 2 were also observed for this unit, including high radiographic film density and an inclusion weld flaw in the PV. This unit was rejected and repaired in the same manner as described for unit 2. The weld inspection report for unit 3, after the repairs were competed, indicated that the PV met the necessary code requirements.

\subsubsection{PMP Documentation}

MCC provided detailed documentation with each unit. This documentation typically included a shipping configuration sketch, assembly drawings, drawings for setting up the PMP for performing hydrostatic testing, vendor certification document, materials certifications, and weld inspection data which included a sketch showing the points where radiographic examination were made, and a set of radiographic weld inspection film. The CS documentation was provided with PMP 2. This documentation included an operations manual and wiring diagrams for the CS hardware. 


\subsubsection{PMP Hydrostatic Tests}

Each of the PMPs was hydrostatically tested by the ORNL QE\&I department in accordance with established test procedures. The setup for these tests is shown in Fig. 5.

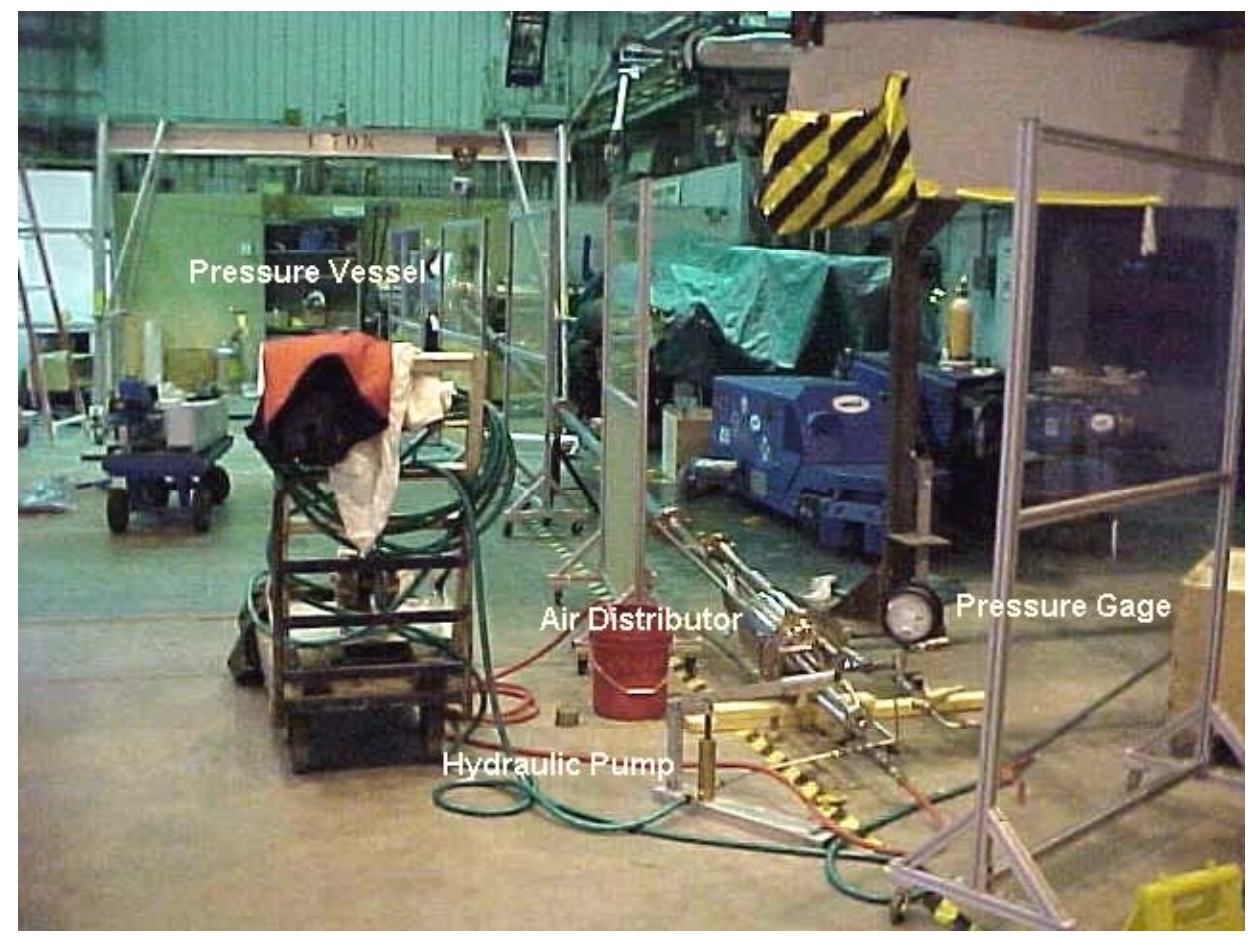

Fig. 5. Russian PMP hydrostatic test setup.

The PMPs were shipped to ORNL unassembled with exception to the ADs. After inspection and inventory of the shipment, a PMP would be partially assembled using only those components that would be exposed to operating pressures in excess of $15 \mathrm{psig}$. These components included the pressure vessel, the $\mathrm{AD}$, and the associated piping between the $\mathrm{AD}$ and the PV. Following assembly, the system was pressurized with air at 5 to 10 psig to check for leaks around pipe connections and flanges using a soap solution. After any air leaks were stopped, the system was vented and prepared for hydrostatic testing.

The PMP assembly was set on supports with the PV end elevated $\sim 5$ degrees above horizontal to permit the displacement of air as the system was filled with water. A small vent line and shut-off valve were attached to the elevated end of the PV.

Design specifications for the PMP indicated the maximum allowable working pressure of $230 \mathrm{psi}$. ASME B\&PV code requires PVs to be tested to 1.5 times the listed maximum allowable working pressure and that the pressure be maintained for a period of $10 \mathrm{~min}$ without leakage. The test pressure for the PMP was 345 psi. Calibrated pressure gages were installed at each end of the PMP and used to measure the applied hydrostatic pressure. The pressure was increased in $\sim 50$ to $100 \mathrm{psi}$ increments. The pressure was held at each increment while the system was checked for leakage. After the test pressure of 345 psi was attained, the system was allowed to sit undisturbed for the required $10 \mathrm{~min}$ while the pressure gages at 
each end of the unit were monitored. Each of the three PMPs successfully underwent independent hydrostatic pressure testing and was able to hold the required pressure for at least $10 \mathrm{~min}$.

\subsubsection{PMP Interface Points}

The piping hardware (e.g., hoses and check valves) required by the design package was to have interfaces that would permit easy crossover from metric components of the PMP to U.S. standard components of the CS. The interfaces points are

1. Air and water supply to the PMP air distributor;

2. Air supply to the air eductor;

3. Water supply to the inlet flush line,

4. Level sensor mounting to the instrument line; and

5. Instrument air to and from the pneumatic actuator.

The air and water supply lines to the air distributor were both equipped with check valves to prevent backflow of any contaminated material from reaching the CS hardware (valves). The PMP interface flanges and pipe connectors were not standard and did not interface well with the procured check valves provided by MCC, which were manufactured in Germany. The U.S. supplied hoses were equipped with standard four-bolt flanges, which were not a one-to-one match with the PMP interface flanges.

Also, a design change had been made on two of the interface points, which was not compatible with the $\mathrm{CS}$ hardware. In the original design, MCC was to supply the PMP with four-bolt standard flanges welded to the piping; however, two of the lines were equipped with combination screwed/O-ring designed fittings. The check valves were mounted on the two lines with this interface and required gaskets to seal the air and water connections. Gasket material was not provided, but an ORNL maintenance shop was able to fabricate appropriate gaskets.

A lesson learned is for internationally composed design teams to permit one side to provide full assemblies with their work. An example would be for the one side only to produce the product that would provide for an easy crossover (i.e., a short extension of weldable pipe). The receiving organization can then readily make the necessary connections without having to perform any equipment modifications. Of course, not all interfaces are piping and all crossover points should be thoroughly discussed prior to fabrication.

\subsubsection{TRI Inspection}

The TRI is a bolted construction framework using extruded aluminum components and mating brackets and fasteners. The TRI serves as the interface between the exterior and interior of the tank, a safety barrier during operation, and to partially protect the equipment from the elements. The TRI comprises a housing, a drive motor, and support table assembly for vertical positioning of the PMP, and shelving for mounting of the PMP CS hardware.

The TRI arrived at ORNL in the summer of 1999. After the unit was delivered to the TTCTF, inspection of the equipment revealed numerous loose connections in the aluminum framework. Many of the fasteners had become loose or fallen out during shipment from Richland, Washington, to Oak Ridge, Tennessee. This failure during shipment caused concern over design reliability, durability, and safety of the TRI for its intended use. Also, the Plexiglas ${ }^{\mathrm{TM}}$ panels that formed the exterior walls of the TRI were warped and, in some cases, broken. The warped Plexiglas panels permitted ingress of rainwater and dust. This rainwater eventually resulted in failure of the upper limit switch used to limit the vertical travel of 
the drive table assembly. The Plexiglas panels were later replaced with 1/8-in. aluminum sheeting. Fig. 6 is a view of the modified TRI at the TTCTF.

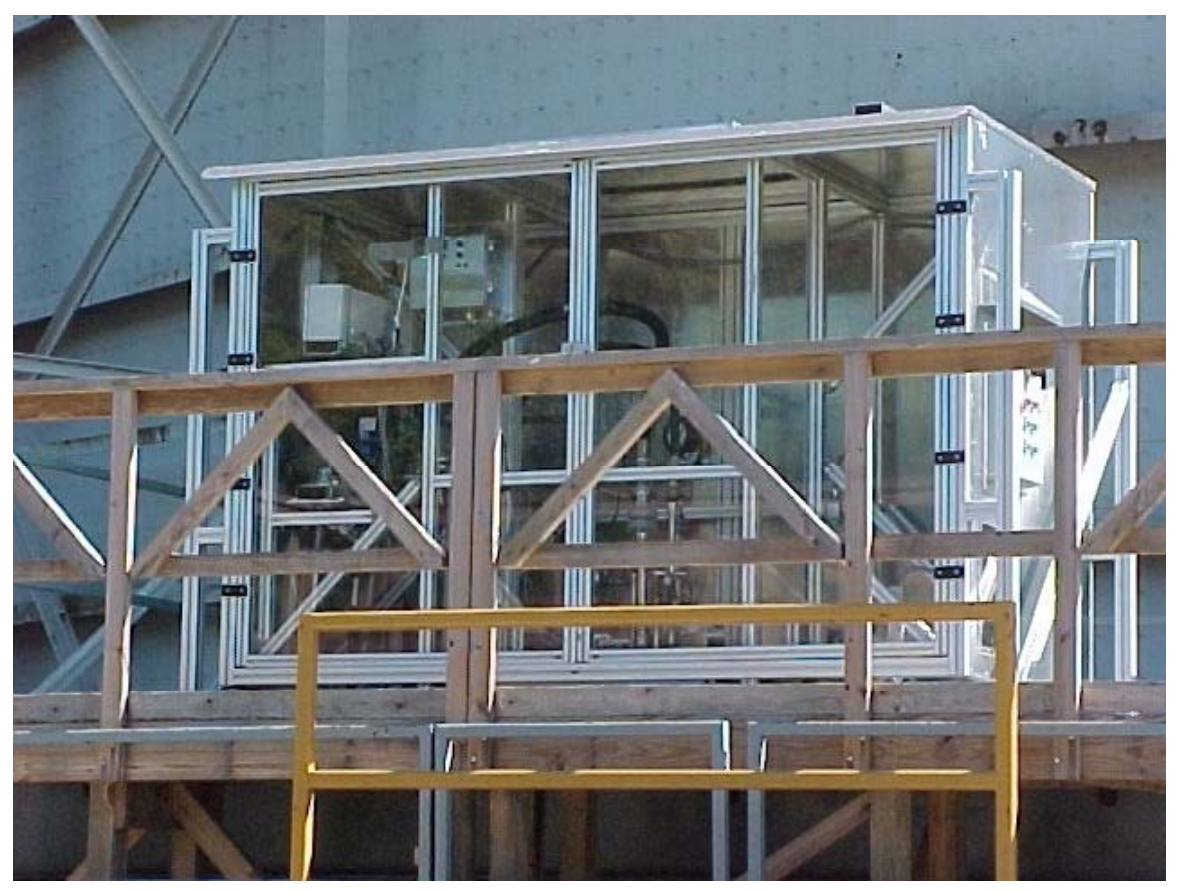

Fig. 6. TRI at the TTCTF after modification.

The side panel where the CS was installed was constructed of a single, continuous panel of Plexiglas, which did not afford easy access to the CS hardware. This panel was replaced with a split panel of aluminum sheeting with a hinged top panel to permit easy access to the CS hardware. This modification was essential to allow access to the hardware and for servicing and adjustment.

The TRI includes two large front doors hinged at each end of the TRI. The doors are constructed of extruded aluminum channels with Plexiglas inserts and are $\sim 4 \mathrm{ft} \mathrm{high}$ and $5 \mathrm{ft}$ wide. The doors proved to be too large and too heavy for the hinges, which resulted in continual sagging. The doors also had to be secured whenever open to prevent gusts of wind from closing the doors with sufficient force to create a safety hazard for personnel. The doors were subsequently reinforced but should be replaced with an improved design or modified to improve operability and safety in future applications. An improved design was developed, which would use two smaller doors at the center front section with two small removable side panels at each end. However, funding and time constraints did not permit modification of the doors, prior to hot deployment.

The TRI was also designed to serve as a lifting fixture for the PMP. By using the TRI as a lift fixture it is possible to deploy and retrieve the TRI and PMP using a single crane versus a two-crane system for management of the PMP alone. Because the TRI is a bolted assembly and the problems with loose fasteners during transport from Richland to Oak Ridge, an evaluation of the TRI as a lift fixture was conducted by the ORNL hoisting and rigging committee. The committee's findings were that the fixture construction was inadequate to meet code requirements for qualification as a lift fixture and was considered a potential risk to personnel and equipment. Eyebolts for use in lifting the assembly were initially located on the top frame member of the TRI. The placement of these eyebolts was considered to be inappropriate and at the recommendation of the hoisting and rigging committee, lifting rings were 
relocated to the more rigid support table, which was constructed of 0.5 -in.-thick carbon steel plate. A structural engineer evaluated the use of the support table as a lift point for the PMP and TRI and determined that relocation of the lift points to the support table would bring the design into compliance with the applicable codes. The PMP is mounted to the TRI support table assembly and held in place by a series of 16 bolts. The support table is securely mounted to the TRI's aluminum framework. The top of the PMP and two of the four lift rings are shown in Fig. 7.

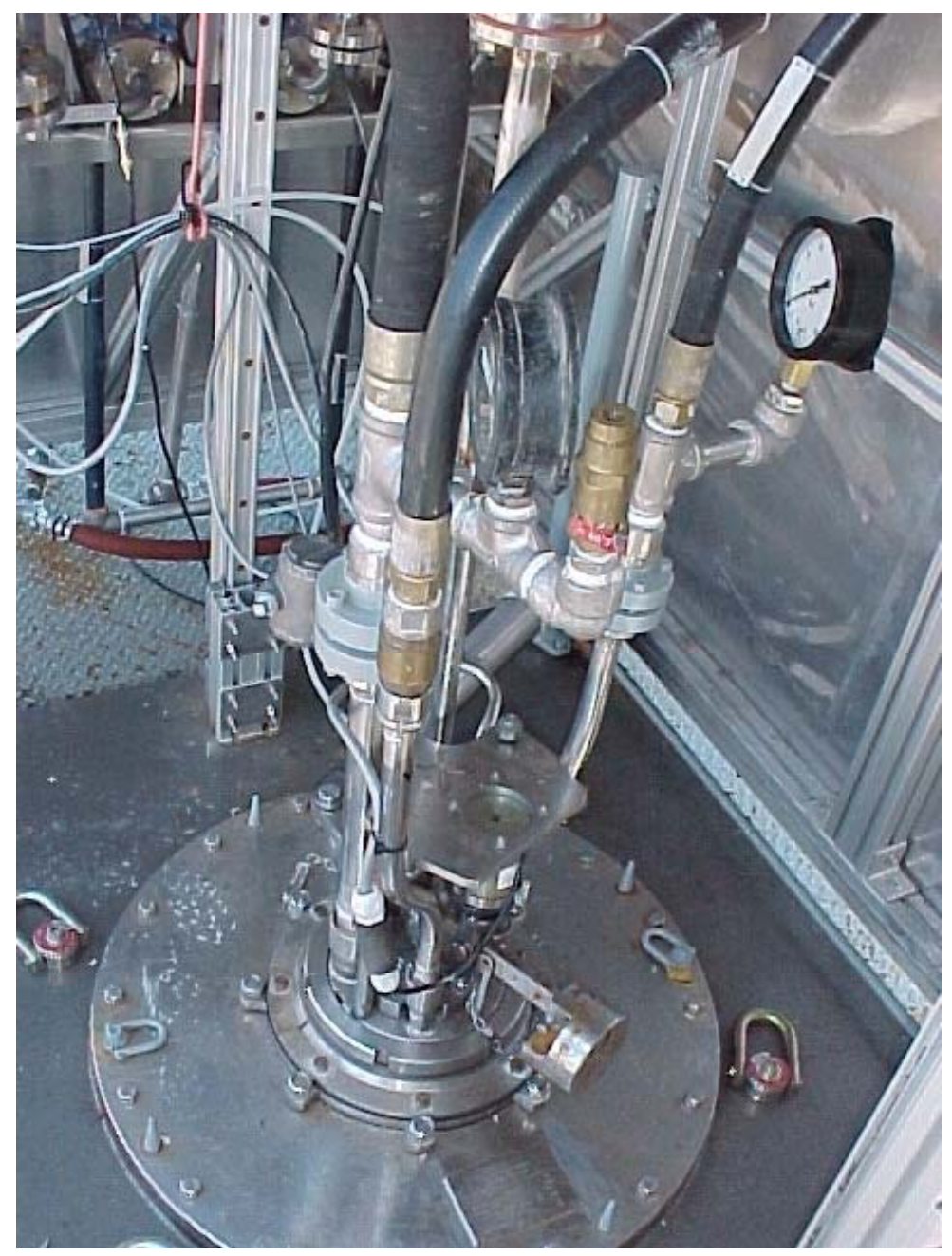

Fig. 7. View of the top of the PMP and drive table inside the TRI.

The TRI is equipped with a drive motor control assembly that includes an electrical disconnect and motor controller, drive motor, electric brake, support table transmission assembly, and limit switches. The assembly was inspected for compliance with National Electrical Code requirements. Deficiencies were found in the components selected for outdoor service and in the wiring diagrams. The wiring diagram supplied with the TRI consisted of a standard off-the-shelf motor controller diagram and was considered to be inappropriate for use as a wiring diagram for the entire TRI motor CS. A wiring diagram of the TRI drive system was generated after completing all necessary wiring requirements (wiring of the electric brake for drive motor) and change out of code deficient components. The code deficient components included the limit switches, the drive motor control switches, and indicator lamps. The limit switches were rated for indoor service and were replaced with outdoor-qualified American National Standards 
Institute (ANSI) switches. The push-button switches and lamps on the door of the electrical disconnect and motor controller were also designed for indoor application and were replaced with ANSI-qualified outdoor components.

Corrosion was observed on the support table, the gear/transmission components, and the support table glide tracks. The corroded areas were cleaned and protected with either a lubricant or paint to prevent further corrosion.

\subsubsection{DSR Inspection}

The DSR was designed to use a pressurized water spray to wash contamination from the PMP as it is withdrawn from a tank. The DSR attaches to the tank riser and is coupled with the TRI via a flexible bellows. The DSR was fabricated from carbon steel and houses six fan-type interchangeable spray nozzles equally spaced about the interior perimeter. Fig. 8 shows a view of the DSR as delivered to ORNL. The DSR was designed to operate at two different pressures $(\leq 100 \mathrm{psig}$ or $\leq 2,500 \mathrm{psig})$. The low-pressure ( $\leq 100 \mathrm{psig})$ design allowed the use of standard car wash type nozzles for applications where the anticipated contamination required only low-pressure water but high volume. The high-pressure $(\leq 2,500 \mathrm{psig})$ design permits operation up to 2,500-psig maximum operating pressure. All of the supporting components were fabricated from materials that were qualified for the higher-pressure application. The design permits change out of the high-pressure nozzles to the low-pressure nozzles without compromising the whole system. The only concern with this application is that the low-pressure nozzles may be inadvertently left in the unit, and operators could incorrectly use these nozzles for highpressure operation.

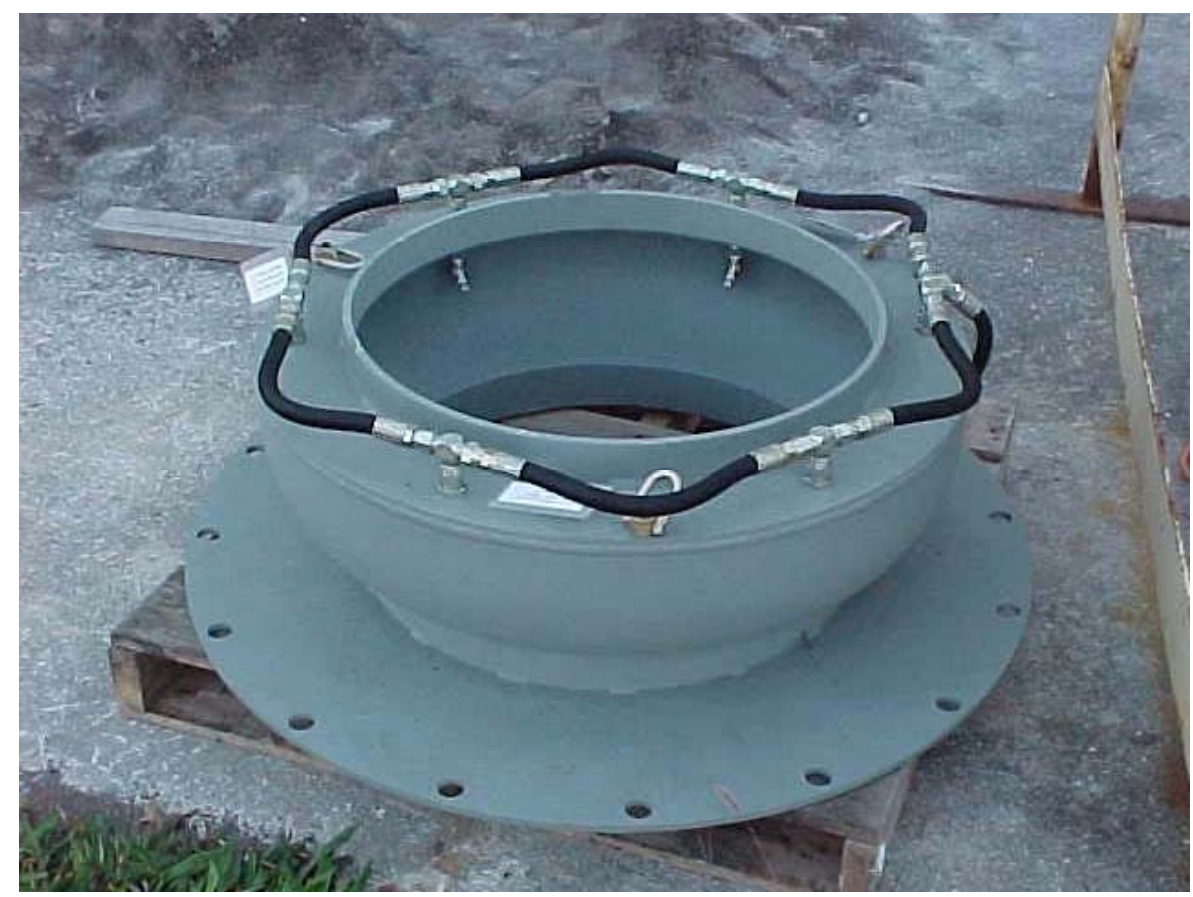

Fig. 8. DSR at the TTCTF prior to installation for cold testing.

The only noted design problem was that the DSR flange is smaller than the tank riser flange to which it was designed to attach. The cause of the error is not clear and could have been a misunderstanding or a mistake in submitting accurate dimensions to the vendor. As a result, the unit had to be clamped to a riser 
flange instead of being bolted to it. This application is an acceptable practice in the low-level contamination site at GAAT TH-4, but would most likely be unacceptable in high-level contamination/radiation applications.

A visual inspection of the welds on the DRS was made to determine any gross flaws. The system was fabricated in the U.S. and was built to ASME codes. The welds appeared to meet the requirements.

\subsubsection{Transport Cradle Inspection}

The transport cradle (TC) is a long cylindrical tube ( 26 in. diam) that is $\sim 25 \mathrm{ft}$ in length and has a hinged base. The base is designed to be bolted to a concrete pad. The top section of the TC has a flange with guide pins for receiving the TRI/PMP. Fig. 9 is a view of the TC at the TTCTF.

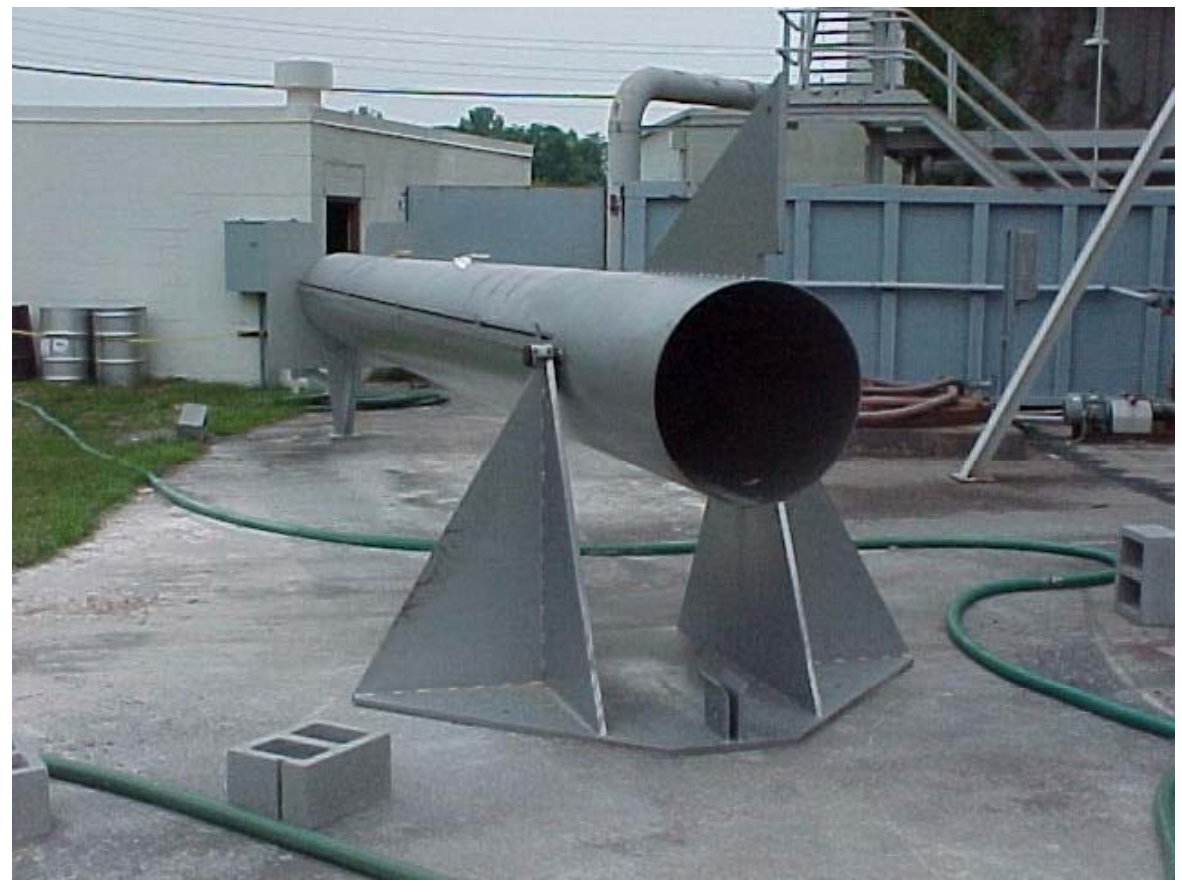

Fig. 9. TC at the TTCTF.

The cradle is hinged at one end and is designed to be up righted and pinned into position to receive the TRI/PMP. A person is elevated to the top of the TC to assist with the transition of the TRI/PMP onto the four guide pins on the TC flange. After it is in place, the TRI/PMP is bolted to the TC flange and then released from the crane hook. The crane hook is then transferred to the TC I-beam, the TC is unpinned at the base, and the entire assembly is lowered to the horizontal position. This permits access to the system for conducting inspections, maintenance, or long-term storage in the event no other work is planned for the unit.

The TC inspection revealed that the hinges and hinge pins were not lubricated and were corroding from exposure to the elements. A concern was expressed that the TC could potentially "lock" in position because of the corrosion. The hinges were not equipped with any grease fittings to allow lubrication of the assembly. The corroded parts were cleaned and the hinge assemblies and hinge pins lubricated. Grease fitting were also installed to allow for future lubrication, as needed. 
Because the TC is open on each end, a concern was raised about secondary containment of contamination if the TRI/PMP were to be stored in the TC for long periods of time. No determination was made as to whether the TC should provide secondary containment for the PMP. However, the requirement was instituted that the PMP be bagged and sealed upon retrieval from a tank.

Inspection of the TC resulted in a safety concern about the intended use of the system. Although the TC was designed to support ease of deployment and retrieval of the hardware, it also posed a potential risk to personnel. If the TRI/PMP assembly experienced any sudden movement it could possibly endanger nearby personnel and equipment with falling parts or by tipping. At the end of the cold test period it was decided that the risks from the use of the TC outweighed the benefits and that it would not be used during hot deployment.

\subsubsection{Vibration Measurements}

Vibration measurements were performed on PMP unit 1 at ORNL as a result of earlier observations made at the MCC test site by an Oak Ridge representative during vendor acceptance testing. During these tests, the PMP was installed in a small rectangular test tank. The U.S. representative noted that during operation the PMP moved in a side-to-side motion, which was described as a vibration. However, after discussions among the U.S. team it was suspected that this observation might have been a result of the configuration of the test tank and the interaction of the PMP jets rebounding off the narrow tank walls. At the ORNL TTCTF, the entire PMP system was observed for vibrations or other abnormalities during the various periods of operation.

Vibration measurements were made near the conclusion of the cold testing of the PMP using accelerometers placed at strategic points on the PMP. Measurement points were placed at the following locations in the $\mathrm{X}$ (horizontal) and $\mathrm{Y}$ (vertical) planes:

- $\quad \mathrm{X}$ - top of PMP mounting plate

- $\mathrm{Y} 1$ - side of AD

- Y2 - approximately 12 in. below bottom of AD on vacuum/pressure supply line to the PV

A baseline measurement was made with the PMP in a stand-by status with no airflow to the PV, no rotation of the PMP, and with water present in the mock tank. After the baseline vibration level was established, the system was started in automatic mode and additional measurements taken. The automatic operating mode allows the PMP to repeat an operating sequence until shutdown. The operating condition for this were as follows:

$\begin{array}{ll}\text { Water Depth } & \text { Water present (depth not recorded). } \\ \text { Discharge header pressure } & 90 \text { psig to AD } \\ \text { Eductor header pressure } & 45 \text { psig } \\ \text { Cycle frequency: } & \sim 1.7 \text { cycles/min } \\ \quad \text { Refill cycle time } & \text { Not recorded } \\ \quad \text { Discharge cycle time } & \text { Not recorded } \\ \text { Rotation angle: } & 45 \text { degrees } \\ \text { Mode of operation } & \text { Automatic } \\ \text { Control system } & \text { New } \\ \text { Nozzle diameter } & 16 \mathrm{~mm}\end{array}$

The PMP was observed to generate a low-frequency vibration when filling the PV. As the tank becomes approximately half full, the unit begins to generate a low-frequency $(<1 \mathrm{~Hz})$ vibration until the tank is 
completely full. It is speculated that the low-frequency vibration may be associated with oscillation of the $\sim 4$-in diam solid titanium ball check valve inside the retaining cage as the PV is filled. Fig. 10 is a view of the check valve and retaining cage before installation in the bottom of the PMP PV. As the PV is filled, the ball check is moved upward above the inlet pipe opening by the flow of incoming material. Fluctuations in the incoming flow may allow the ball check to oscillate inside the retaining cage. The results of the vibration measurements confirmed the belief that the observations made during the MCC acceptance inspection were caused by the interactions of the discharged jet stream with the walls of the test tank and not a result of an inherent design condition of the PMP.

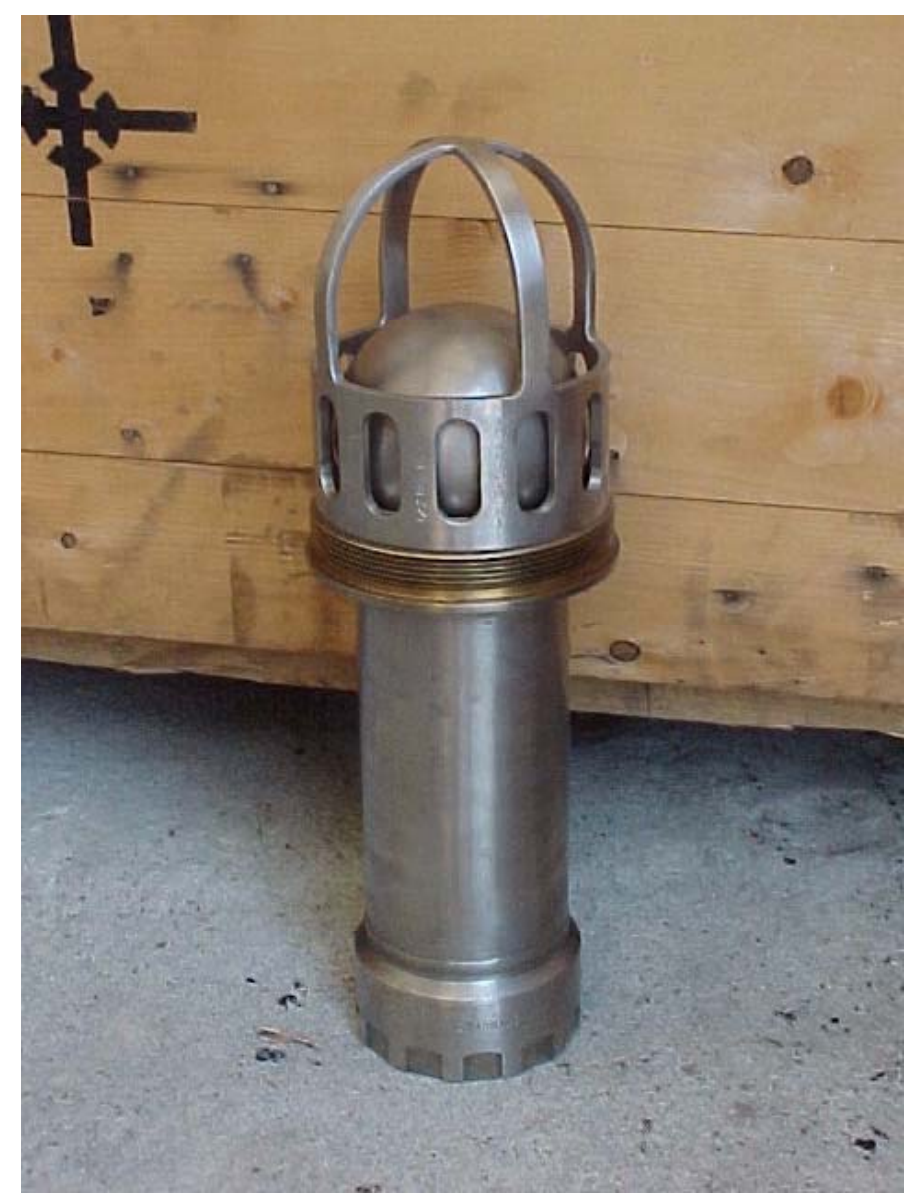

Fig. 10. Check valve assembly before installation in the bottom of the PMP PV.

\subsubsection{Force Measurements}

The cold test plan originally included determination of the minimum amount of force required to raise and hold the PMP in place. This determination was thought to be needed to ensure that the clutch on the support table drive motor in the TRI was set to

1. allow withdrawal of the sludge filled PMP from a tank and

2. slip when resistance was encountered when lowering the unit into a tank.

The TRI has the capability of deploying the PMP to the full depth of the GAAT and potentially contacting the floor of the tank. The concern was that the PMP might be inadvertently driven into the 
floor of the tank and possibly damage either the equipment or the tank floor. As a means of preventing such a problem it was determined that the TRI drive motor slip clutch should be set at a value below the maximum of $400 \mathrm{in}$.-lb to allow slippage in the event of contact with the tank floor or a rigid object in the tank. The tank floor loading limit was specified in the design requirements document for the PMP to be $\sim 750$ psi. $^{2}$ This floor loading would require a force of over $14,000 \mathrm{lb}$ based on the PMP nozzle head diameter of $\sim 5$ in. This test was planned for near the end of the cold test program; however, the user decided to implement alternate means of limiting the force applied to the tank floor and forego the performance of this test in the interest of time. These means included one or more of the following:

1. Ensuring that the stack-up at TH-4 for the PMP system was such that the PMP could not come in contact with the floor of the tank.

2. Monitoring the PMP as it is lowered into the tank and staging the decent to ensure that the PMP could be freely rotated at each elevation change.

3. Loosening the top support flange bolts for the PMP and observing the flange as the unit is lowered. If the PMP touches the bottom of the tank or an obstruction, the support flange will be slightly elevated above the support table in the TRI and the deployment could be stopped before the PMP could be displaced from the drive table.

\subsection{FUNCTIONALITY TESTS}

A series of functionality tests were conducted to verify the operation of individual components, valve operators, sensors, valves, and the associated CS. The specific tests included the assessment of the TRI drive system, DSR spray pattern and seal, CS valve operator responses, the PMP pneumatic actuator, connectivity and calibration of sensors, and operation of the process control software. The functionality tests also included an evaluation of hoisting and rigging (H\&R) requirements and capabilities, structural evaluation of the TRI as a lift fixture, ease of use of the TC, evaluation of the TC for H\&R purposes, and evaluation of contamination control methods for isolating a contaminated PMP from the environment and personnel. This group of tests was subdivided into five distinct tests:

1. TRI functionality tests;

2. DSR functionality tests;

3. Valves, actuators, sensors, and CS functionality tests;

4. Hoisting and rigging and support fixture tests; and,

5. Contamination control test.

\subsubsection{TRI Functionality Tests}

The purpose of this test was to determine the ability of the TRI drive system to properly raise and lower the PMP. The test also included measurements of the overall length of the PMP from the bottom side of the TRI drive table to the tip of the PMP nozzle head. The PMP can be configured for use in various depth tanks by changing the length of pipe between the AD and PV and the inlet and discharge pipe extensions. The ORNL PMP design can be configured from 11.5 to $\sim 29.8 \mathrm{ft}$ in overall length. During cold testing, the length of the PMP was set at $\sim 26.3 \mathrm{ft}$. The results from these tests were used in conjunction with the known geometry of the test pit to establish the available travel for the TRI drive system to avoid driving the unit into the cold test facility floor.

The support table in the TRI is configured with high and low limit switches to permit a travel distance of $\sim 22$ in. The reliability of the limit switches was less than desired making the switches undependable for use in determination of absolute limits of travel. The problem was that the mechanical arm used to trip the switch would not remain in a fixed location, which caused the trip point to change. This problem was 
resolved by attaching a metal tape measure to the guide rails for the support table and having an operator carefully watch the position of the table as the system was lowered into the tank. Future applications should consider using a more reliable device to limit the travel of the support table.

PMP unit 1 was installed in the TRI with the support table elevated to its highest position. The PMP was then lowered to the lowest position of the support table. As the support table was lowered, observations were made for potential and real interferences with other equipment and none were noted. The unit was also elevated to the highest position of the drive table and the same observations were made with no interferences.

A failure of the upper limit switch occurred while returning the PMP and support table to the highest position. Upon examination of the switch it was discovered that water had filled the switch and had frozen. The water ingress had occurred at one of the warped Plexiglas ${ }^{\mathrm{TM}}$ panels on the top of the TRI. Rainwater had apparently traveled down one of the support posts and into the upper limit switch. Failure of the limit switch led to a more detailed evaluation and inspection of the entire electrical system. The inspection revealed that none of the switches and push buttons was qualified for outdoor service. These components were promptly replaced with outdoor service units and no further failures of this nature were observed.

\subsubsection{DSR Functionality Tests}

The DSR components were tested to ensure proper operation. The DSR was designed to perform both low-pressure ( $\sim 100 \mathrm{psi})$ water wash down and high-pressure $(\sim 2,500 \mathrm{psi})$ water wash down. To accomplish this, the spray nozzles for the respective wash down pressure must be installed into the DSR manifold.

The DSR functionality tests included tests using each type of nozzles separately. With no equipment in the path of the DSR a low-pressure water supply was attached to the supply line to the DSR. The maximum measured water supply to the DSR was $\sim 11 \mathrm{gpm}$ at a pressure of $\sim 60$ psi. The jet array was designed and configured to cause overlap of the coverage area of each spray nozzle. The DSR performed as designed.

The high-pressure tests required change-out of the low-pressure nozzles with the high-pressure $(2,500$ psi) rated nozzles and the use of a high-pressure water pump. The high-pressure water pump used at TTCTF has a capability of $\sim 12$ gpm up to 10,000 psi water pressure. Safety relief devices were installed on the pump to limit its operating pressure to that of the DSR maximum allowable working pressure $(2,500 \mathrm{psi})$. All the equipment was carefully inspected to verify that only components rated for operation at pressures above $2,500 \mathrm{psi}$ were installed on the DSR prior to operation. The first operating pressure was $500 \mathrm{psi}$ and the jets performed well but made a light mist. The pressure was then raised to 1,000 psi and the mist became wider and broader above the spray ring. Because of the total equivalent orifice area of the six spray nozzles, the maximum pump pressure that could be maintained was 1,500 psi. The spray pattern was good, but the mist was dominant during the high-pressure tests. During hot operations the mist from the DSR will be contained inside a flexible bellows connecting the top of the DSR to an attachment ring on the bottom of the TRI. Fig. 11 is a view of the mist formed above the DSR during one of the high-pressure tests. Observations from these tests indicted that the DSR would perform well at either operating pressure range. 


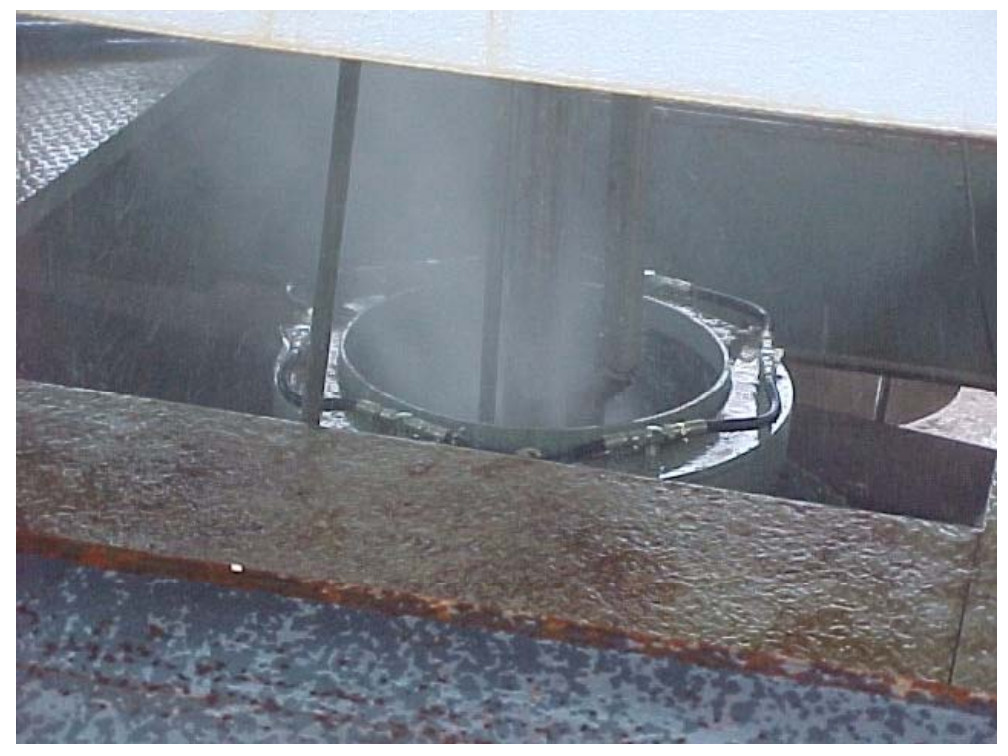

Fig. 11. Mist above DSR operating at the TTCTF.

\subsubsection{Valves, Actuators, Sensors, and CS Functionality Tests}

In this series of tests, the various components that the CS comprised were tested for proper installation and operation. The CS components were assembled, tested, and initially operated in Russia by MCC. The CS comprised four electrically actuated valves, one Bimba ${ }^{\mathrm{TM}}$ pneumatic actuator, a Trombetta ${ }^{\mathrm{TM}}$ solenoid valve, a pressure sensor, a level sensor, a Micron ${ }^{\mathrm{TM}}$ personal computer, FieldPoint ${ }^{\mathrm{TM}}(\mathrm{FP})$ computer interface hardware, and LabView ${ }^{\mathrm{TM}}$ based control software.

The electrically actuated valves were procured from Jamesbury ${ }^{\mathrm{TM}}$ Valve, Inc. and supplied to MCC by ARES. The valves operate on $120 \mathrm{~V}$ at $6 \mathrm{~A}$. Each valve is a standard off-the-shelf ball valve with an actuator replacing the valve handle. The valve utilizes a cam mechanism to set limits of travel for the valve stem. The cam includes a set of positioners that establish the actual travel range. If the system overdrives the cam, the valve can lose its position and operation can become erratic. This occurred in the initial test phase but was corrected. The failure was attributed to a load mismatch between the valves and the CS FP computer interface hardware. The FP modules were rated for 3 A service, while the valves were rated at $6 \mathrm{~A}$. It was necessary to install a set of relays between each valve actuator and the respective FP module to prevent overloading the modules. This change corrected the problems associated with overdriving the valves.

The PMP system uses a pneumatic actuator that is capable of rotating the PMP assembly through a 90degree arc. The actuator was supplied by Bimba, Inc., and uses two small solenoid valves for supplying and exhausting air to and from the unit. The CS software is configured to specify the range of motion of the Bimba up to a 90-degree arc by utilizing the actuator's feedback positioning sensor. As a signal is received from the CS to move the actuator to a predetermined position, air is supplied to the actuator and the feedback sensor provides the necessary position information to the CS. After reaching the desired position, the CS turns off the solenoid valves, effectively trapping the supplied air in the actuator. The air is released upon command of the CS to open the solenoid valves and return the PMP to its starting position. The small solenoid valves are three-way ported valves, which supply air to the actuator and release it to the atmosphere. The arrangement allows air to be used to drive the actuator forward or backward. While one solenoid is applying pressure, the other is exhausting. The Bimba actuator 
operated as intended but was initially plagued with erratic motion. To correct this problem, a set of small needle valves was installed on the air lines to the solenoid valves to smooth the operation of the actuator. The Bimba successfully operated through the required 90-degree range of rotation.

The PMP is equipped with two primary sensors. One sensor is used to measure the absolute pressure in the PV, and the other to measure the fluid level inside the PV. The absolute pressure sensor is mounted on top of the PMP's AD. This sensor provides a signal to the CS for monitoring purposes only. The signal from the pressure sensor is processed by the CS and is displayed as a pressure readout. The pressure signal data are also used to produce on-screen graphs of the fill and discharge pressure cycles for the PMP. The functionality of the sensor was tested, and the appropriate signal was received at the CS monitor.

The PMP PV is equipped with a level sensor to provide high- and low-level indications for the contents of the PV. The level sensor is comprised of magnetic sensors separated by spacers and weights, which are attached to a steel support cable. The steel support cable is attached to an end cap located on top of the PMP. The end cap and steel support cable are used to support the sensor elements and take the load off of the electrical cable running from the sensor elements to an interface connector in the end cap. The length of the sensor is predetermined based upon the particular application. A sealed conduit running from the top of the PMP to the bottom of the PV houses the level sensor and provides protection from contamination and contact with the contents of the PV. A stainless steel float with a central magnetic core surrounds the level sensor conduit inside the PV. The float is free to raise and lower as the level of material inside the PV changes. When the float passes over the area of the conduit containing a sensor element, an electrical signal is transmitted to the CS to indicate either a high- or low-level condition.

Prior to installing the level sensor into the PMP instrument conduit, the sensor was connected to the computer FP module, and the float was passed across each sensor to verify proper operation. The FP module correctly indicated a high or low signal depending upon placement of the float across the respective sensor elements.

During functionality testing, the sensor experienced very erratic behavior after installing the float into the PMP instrument conduit. The CS software used to operate the PMP would display the high and low indications as if the sensor were signaling these events. After several efforts to determine the problem, two things were discovered that contributed to the confusion. First, the CS software would simulate the fill and discharge cycle even when a signal was not being received. A graphical simulation of the PV during the fill cycle was started each time the low-level sensor was tripped. The software would continue to simulate operation until a timeout occurred. When the CS software was started and the tank would supposedly fill, it appeared that the float was actually indicating a high-level alarm status. The time-out period is hard coded into the CS software (i.e., $60 \mathrm{~s}$ for the fill time). The solution to this problem was to develop a new control program, which did not include the graphical simulation of the PV fill and discharge cycles.

Second, it was discovered that the sensor was not fully deployed to the bottom of the instrument conduit. Careful measurements of the overall sensor length and height of the PMP confirmed this problem. The sensor had become lodged near the entrance to the PV on weld slag inside the instrument conduit near a flange connection. After all weld slag was removed from the internal segments of the instrument conduit, the sensor could pass into the tank and reach the bottom of the conduit. After correctly positioning the level sensor and modifying the CS software, the level indicator worked as required.

The CS was constructed to permit both local and remote operation of the PMP. This was accomplished by providing cabling of sufficient length to establish a remote operations point at the TRI. In this case, 
the cabling was $300 \mathrm{~m}$ in length but was operated at a distance of $\sim 150 \mathrm{~m}$. A short pigtail connector located inside the FP module housing provided the local operations capability. To operate the system locally, the remote connector was disconnected and the CS computer connected directly into the FP hardware using the short pigtail connector. Both local and remote operations were successfully demonstrated.

\subsubsection{Hoisting and Rigging and Support Fixture Functionality Tests}

A variety of tests were conducted to assess the H\&R functionality of the various components of the PMP system. These tests focused on the ability of the PMP, TRI, and TC to be safely lifted and handled.

\subsubsection{PMP Lift}

The PMP is equipped with two lift eyes, which are attached to the top PMP mounting flange. The PMP was installed at the TRI using a two-crane lifting method. Initially there was concern that the PMP could be damaged using the two-crane lifting method if the two crane lifts were not synchronized. It was speculated that the pipes between the AD and the PV could be bent or warped if the unit was improperly lifted. However, ORNL has an experienced H\&R crew, which after evaluation of the lift requirements for the unit successfully lifted it into position. When the cold test program was complete, the unit was also removed from the TRI via the two-crane method. The sequence of photographs in Fig. 12 show the PMP as it was lifted from the TRI at the end of cold testing. View 1 of Fig. 12 shows the PMP inside the TRI with the front doors and top hatch open to allow access. Views 2 through 8 show the PMP as it is lifted from a vertical orientation to horizontal. With careful job planning, an experienced H\&R crew can safely manage a unit such as the PMP.

\subsubsection{TRI Lift}

The TRI was removed from the transport vehicle via a large forklift truck and was placed onto the TTCTF work platform by a crane. Before installation of the PMP and CS hardware, the TTCTF work platform had to be elevated approximately an additional $2 \mathrm{ft}$ to accommodate the installation. When this was performed, the TRI minus the PMP and CS hardware was lifted using the original lift eyes on top of the TRI. The TRI was designed to serve as a lift fixture for the TRI and PMP as a single unit. This design option was selected to reduce the number of cranes required for deployment and retrieval of the system from two to one. The TRI, as noted previously, was constructed of extruded aluminum beams, which are bolted together with small fasteners. After detailed inspection of the TRI, several concerns arose about the capability and qualification of the system during H\&R actions. The ORNL hoisting and rigging committee and TTCTF engineers performed an inspection and assessment of the proposed H\&R procedures for the TRI. The results of this assessment were noted previously in Sect. 6.1.3.8. In summary, the as-built TRI was thought to be too unstable to be used as a lift fixture. To improve the stability of the system, the TRI lift points were relocated from the top of the TRI to the PMP support table inside the TRI. The number of lift points was also increased from two to four. The four smaller lift rings provided the same load capability as the two larger ones, but provided more flexibility, maneuverability, and stability during a lift. 


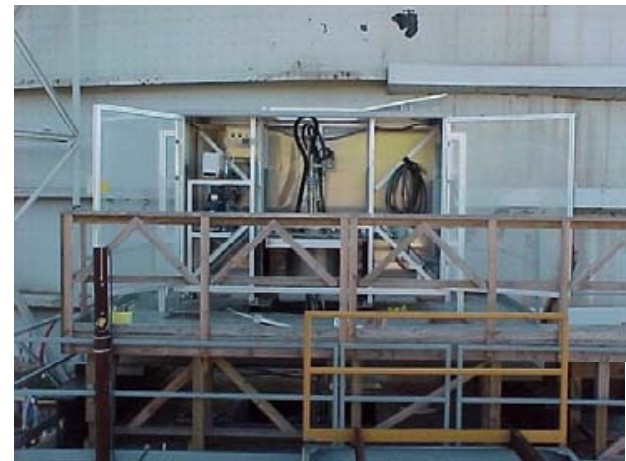

2
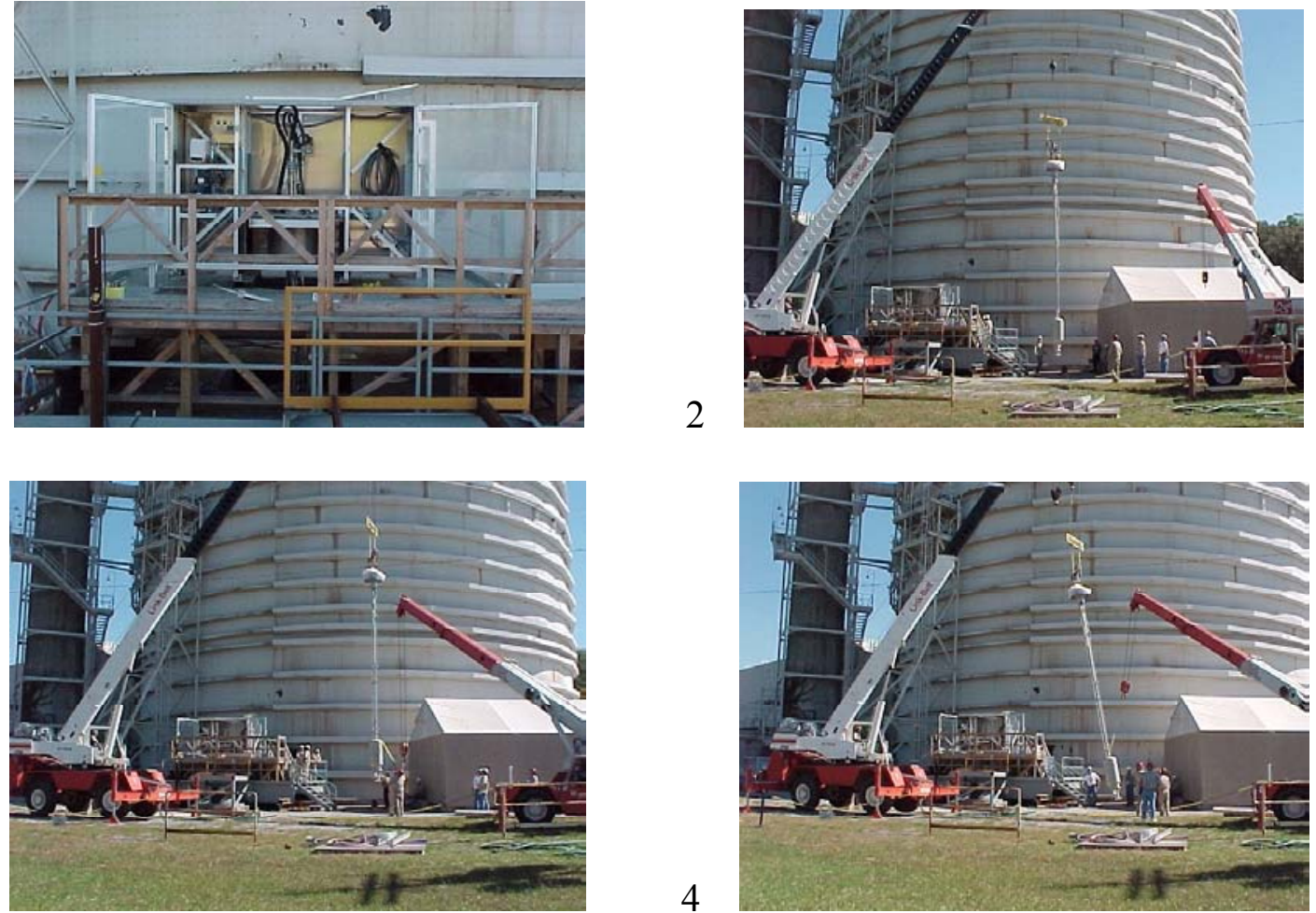

4
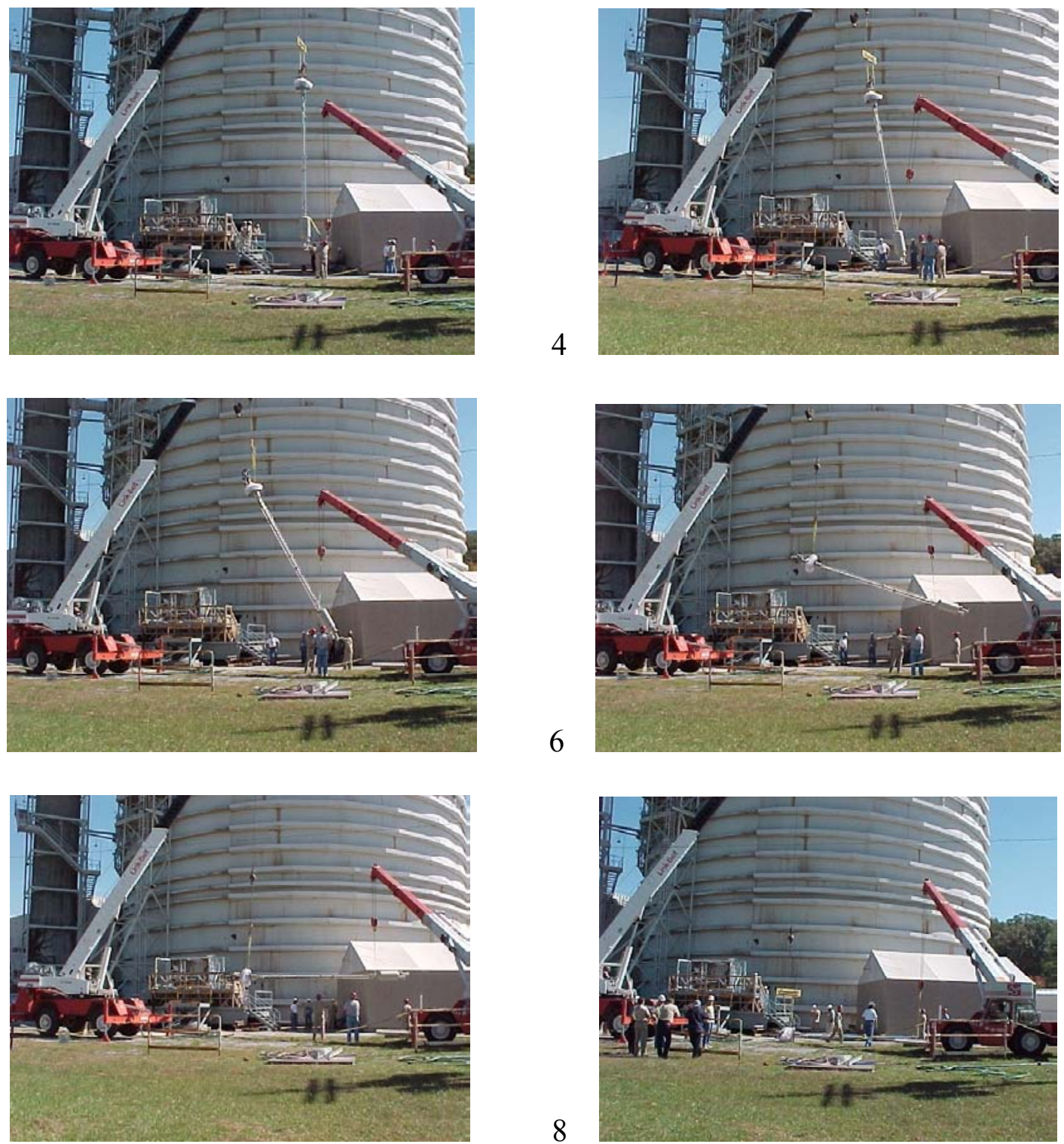

Fig. 12. Sequence of views of two-crane lift of PMP from TTCTF. 


\subsubsection{TC Lift}

The TC was designed to receive and store the TRI with the PMP attached. The TC serves to minimize the number of cranes required for the deployment or retrieval of the TRI/PMP and also as a storage tube. The storage component of the design permits staff to perform any necessary maintenance and either return the unit to service or provide long-term storage of the system.

To prepare the TC to receive the TRI/PMP, the base of the unit is anchored in place. The clamshell lid is unbolted and removed using a crane. The crane is then connected to the I-beam at the top of the TC and the latch pin securing the TC in the horizontal position is removed. The crane then lifts the TC to the vertical position, at which point personnel lock the unit using a steel latch pin. After the TC is securely latched in place, a person is elevated to the top of the TC to release the crane hook. The crane then is connected to the TRI/PMP assembly. The TRI/PMP is removed from its platform and then transferred to the TC. The TRI/PMP assembly must be carefully positioned onto four guide pins located on the top support flange of the TC. After the TRI/PMP assembly is in position on the guide pins, the unit is secured using four bolts located on the TC support flange. The crane is then released from the TRI/PMP assembly and secured to the TC I-beam. Following this procedure, the latch pin at the base of the TC is removed, and the unit is then lowered into the horizontal position where it is repinned.

When preparing the TC for the lifting demonstration, it was noted that the empty TC flexed slightly when positioning the unit into the vertical position. Because no load was applied to the TC during this demonstration, this flexing was a safety concern for the operators and support personnel. The concern was that if the TC experiences an off-balanced load or the load shifts slightly, sufficient flexure might occur that would allow the TC to become unstable and lead to a hazardous situation for the personnel near the top of the TC and on the ground. During the lift demonstration, the TRI/PMP was lifted from the TTCTF platform, positioned onto the TC flange, and secured in place. At this point the demonstration was stopped for the following reasons:

1. The TRI/PMP assembly is an off-balance load for the TC, and the risk of failure during positioning the TC from vertical to horizontal was considered too high to proceed (the TRI became an off-center load after the addition of the CS hardware);

2. Observation of the procedures used to place the TRI/PMP assembly onto the TC support flange indicated a potential personnel safety issue as the assembly was guided into place,

3. The TRI/PMP was not fully seated on the TC support flange frame because the TRI drive table was not elevated and interfered with the longer guide pins on the TC support flange.

The TRI/PMP assembly was removed from the TC and returned to the TTCTF to conclude the test. The findings from this demonstration led to the decision not to use the TC for the proposed hot application at tank TH-4.

The TC design was considered to have potential benefit in reducing the risks of handling equipment requiring multiple crane lifts. However, the TC design should be improved to allow proper handling of off-balance loads, to minimize use of personnel for off-ground management of the equipment, and eliminate potential pinching hazards during positioning of the TRI/PMP onto the TC flange. 


\subsubsection{Contamination Control Test}

The purpose of this test was to demonstrate possible methods of containing the PMP during withdrawal and reinstallation into contaminated waste tanks. General areas planned for study included:

1. Techniques for containment of the PMP when removed from the waste tank.

2. The ability of the containment bag to withstand the handling operations necessary for placement and removal of the PMP in the TC.

After review of the plans for deployment of the PMP, the decision was made that this test would not be required. This decision was based on the following assertions:

1. The experience of the deployment team with containment control with similar equipment was sufficient to properly manage the PMP.

2. The PMP was only required for use in one waste tank at ORNL.

3. The TC was not required for a single tank deployment effort.

Containment of the PMP appeared to be more awkward than most other types of equipment because of the following:

1. The PMP can only be bagged while it is being lifted from the tank.

2. It must undergo a decontamination spray down while being lifted from the waste tank, which poses potential problems from (a) risk to personnel due to load path issues; and (b) back spray from the DSR that could cause exposure to the environment and personnel.

\subsection{PERFORMANCE TESTS}

Performance tests were conducted as a means of proving the capabilities of the system. A series of tests were performed which included the following:

1. Capability of the DSR to effectively remove material from the PMP upon retrieval from the tank,

2. Tolerance of the PMP system to various types of debris that may be encountered during operations,

3. General observation of the operation of the PMP in a water only test,

4. Determination of the cleaning radius of the PMP in relation to a 20 -ft-diam tank, and

5. Performance testing of the PMP system using a sludge simulant.

To better simulate the tank geometry for the planned hot deployment, a mock-20-ft diam cylindrical tank was constructed in the TTCTF test pit by dry stacking 12-in cinder blocks to form a 5-ft-high wall on the floor of the test pit (Fig. 13). The floor of the test pit and the inside walls of the mock tank were painted with green and orange fluorescent stripes to assist in data analysis and observation of mixing performance. The stripe layout was in concentric circles at 5-ft intervals from the center of the mock tank and radial lines on the floor and tank wall at 45-degree intervals. A plastic liner was added to the mocktank later in the test program.

Many of the performance tests described in Sect. 6.3 were attempted using the original CS, which, because of problems with both the software and hardware, allowed for only sporadic operation of the PMP. A decision was made to develop a new control program and to modify the hardware to improve 
reliability. After those improvements were completed, testing and operation of the PMP proceeded smoothly. Unfortunately, automatic data logging with the as-received CS was not practical because of the frequent interruptions. Data obtained with the as-received CS were recorded manually in the form of observations and periodic instrument readings. Automatic data logging for most of the performance tests was only accomplished after completion of the CS software and hardware modifications.

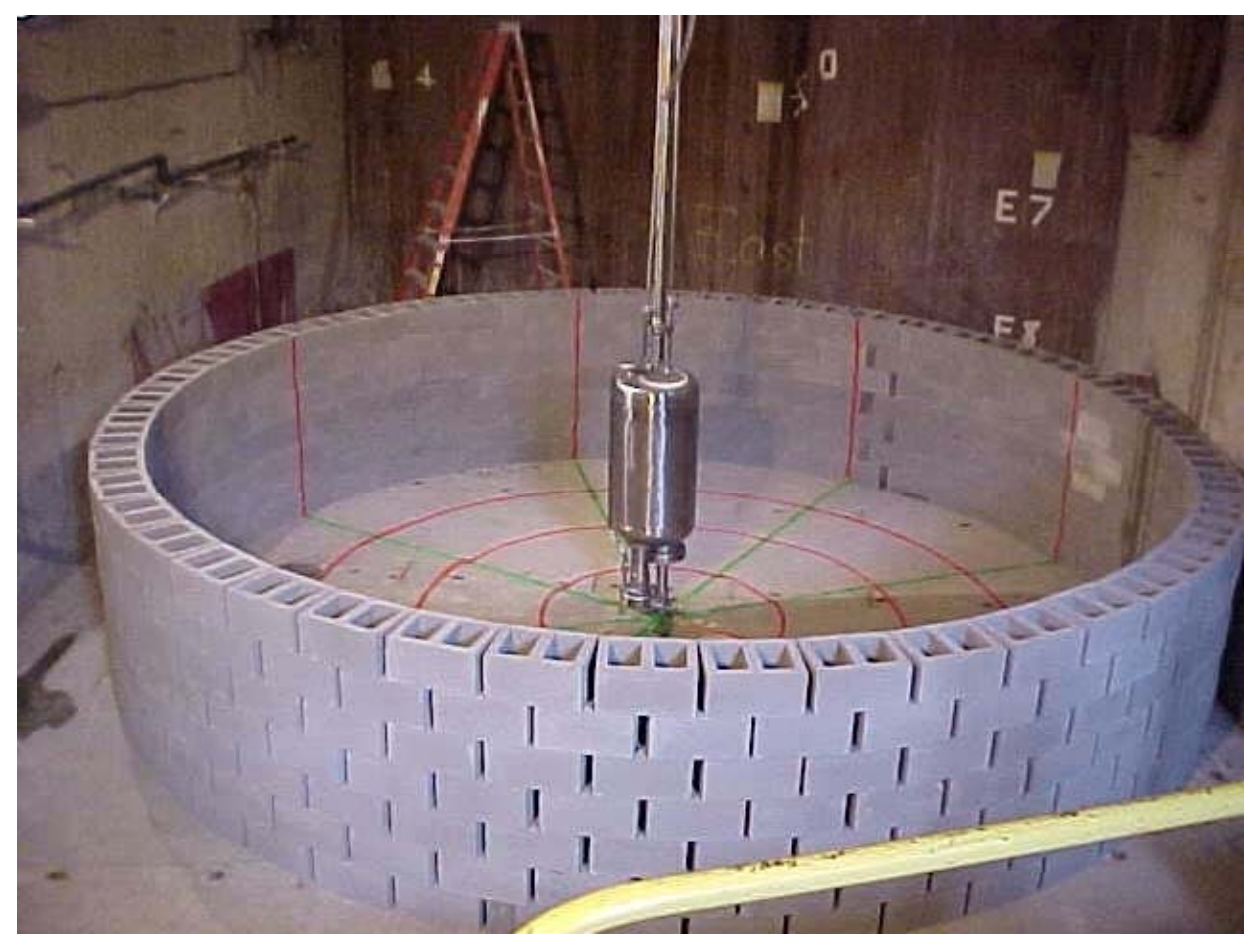

Fig. 13. Mock tank in TTCTF before addition of plastic liner.

\subsubsection{DSR Performance Tests}

The DSR is designed to deliver $\sim 16$ gpm of water at pressures up to $2,500 \mathrm{psi}$. The high-pressure water pump used at TTCTF has a capability of $\sim 12 \mathrm{gpm}$ at pressures up to 10,000 psi. Safety relief devices were installed on this pump to limit its operating pressure to that of the DSR maximum operating pressure of 2,500 psi. Also, because the equivalent orifice size of the six nozzles was greater than that required to achieve an output of 10,000 psi, the system was self-limiting, and the maximum pressure that could be generated with this configuration was $\sim 1,500$ psi.

Both wet and dry simulants were used to assess the effectiveness of the DSR. To prepare the PMP for the DSR test, simulant material (consisting of kaolin clay and water) was spread across all of the piping extending into the TTCTF (Fig. 14). This material was allowed to dry approximately two months prior to the removal of the unit. It was not necessary to apply any simulant to the lower portions of the PV as this occurred naturally as the lower third of the PMP and associated inlet piping and discharge piping and nozzles were submerged into the material throughout most of the performance test period.

The DSR performance test was performed during the functionality test, which required the PMP to be removed from the platform and located onto the TC. As the TRI/PMP lift began, the DSR system was activated at $500 \mathrm{psi}$ and a $\sim 12 \mathrm{gpm}$ water flow. The test pressure was increased in 500-psi increments until the maximum operating pressure of $1,500 \mathrm{psi}$ was achieved. The water spray-down was instantly 
capable of removing material at the spray ring and also as the water from the nozzles flowed down the piping onto the remainder of the below-grade components.

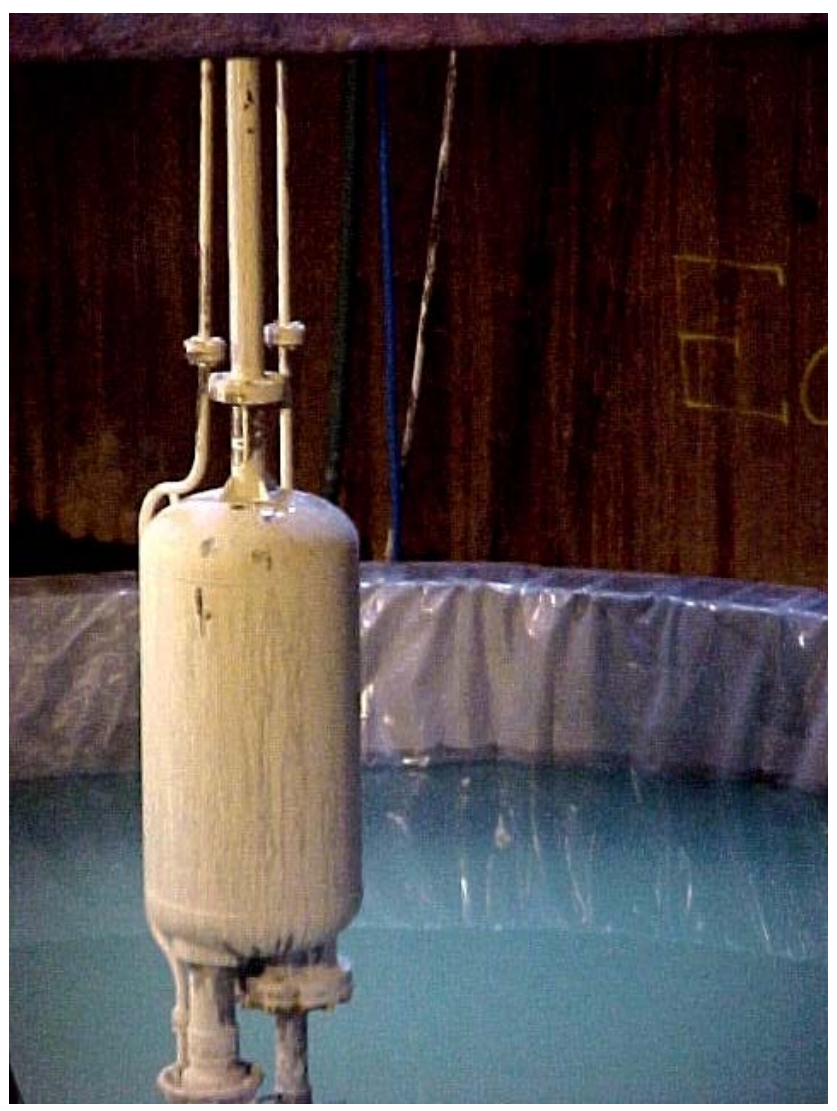

Fig. 14. View of waste simulant on the PMP PV at the TTCTF.

At operating pressures of 1,000 and $1,500 \mathrm{psi}$, a significant quantity of mist and over spray was observed. The TTCTF is not connected to an off-gas system, as was the case for the hot deployment of the system. The negative pressure produced inside the waste tank from the operation of an off-gas system should ensure an inflow of air to the tank. Air inflow through the tank riser should serve to reduce the amount of over spray migration in the direction of the TRI. For the two-month-old dry kaolin clay simulant, it is important to note that a 500-psi decontamination spray supply pressure was adequate for cleaning the equipment. Also, GAAT operators determined that 500-psi water pressure should be adequate for providing effective decontamination when the PMP is withdrawn from the waste tank.

The mist created by the DSR operation made it difficult to observe the PMP's position relative to the tank riser during the test. This scenario poses a potential risk to the equipment because the PMP could catch on the edge of the riser as it is being removed. A possible solution would be to mount a camera with a radio frequency transmitter on either the TRI or the base of the AD to observe the position of the equipment as it is removed from the tank.

Wet simulant material is readily removed by ordinary plant water pressure $(\sim 100 \mathrm{psi})$. However, the capability to remove material from hard-to-reach crevices on the equipment may require higher water supply pressures ( $>100 \mathrm{psi})$. The PMP is designed such that very few locations exist where waste material can become lodged. Furthermore, the majority of the PMP piping and hardware is never in 
contact with the waste. Only the PMP PV and associated suction and discharge lines are typically in contact with the waste.

\subsubsection{PMP Debris Tolerance Test}

Debris can create significant problems for tank waste retrieval systems. Retrieval systems with moving components and/or suctions inlets can become blocked or damaged by in-tank debris. Various types of debris have been observed in the waste tanks at ORNL and at other DOE sites, including the following:

- Electrical and vinyl tapes,

- Wire,

- Rope and string,

- Large metal floats,

- Plastic bags,

- Rubber or vinyl gloves,

- Metal tapes for depth measurements, and

- Piping.

Systems that are sensitive to debris interference must be protected either by use of physical guards or by operational schemes, which prevent blockage by debris. Because the PMP uses a vacuum to draw waste slurry into the PV through a 4-in.-diam inlet port, it was considered that certain types of debris might present a problem for the operation of the PMP. Therefore, a series of debris tolerance tests were conducted to assess the performance of the system in the presence of various types of debris. The debris used in this test consisted of the following items:

- 4 clear, large plastic bags ( $\sim 30$ gal capacity);

- 12 pair of rubber gloves;

- 4 50-ft lengths of nylon rope;

- 100 12-in. long plastic wire wraps;

- $\quad 12$ 3-ft lengths of electrical wire, including wire gauges of 10, 12, 14, 18, 22, 24, 28; and

- 12 2-ft strips of yellow vinyl tape.

The initial plan was to test each of the debris items separately; however, after reevaluation, the decision was made to simultaneously test all of the debris items. Each item of debris exhibits unique characteristics and behaves relatively independently of the others. Fig. 15 is a photograph of some of the debris used in these tests. Prior to the start of the tests, the debris was placed directly beneath the PMP inlet near the discharge nozzles while other debris floated near the PMP. The test was performed for a total of $\sim 2.5 \mathrm{~h}$ to observe the interaction of the debris with the system. The operating conditions for the test were as follows:

$\begin{array}{ll}\text { Water depth } & 26 \mathrm{in} . \\ \text { Discharge header pressure } & 90 \mathrm{psig} \\ \text { Eductor header pressure } & 32 \mathrm{psig} \\ \text { Cycle frequency } & \sim 1.7 / \mathrm{min} \\ \quad \text { Discharge cycle time } & \sim 30 \mathrm{~s} \\ \quad \text { Refill cycle time } & \sim 7 \mathrm{~s} \\ \text { Rotation angle } & 90 \text { degree } \\ \text { Mode of operation } & \text { Automatic } \\ \text { Control system } & \text { As received } \\ \text { Nozzle diameter } & 16 \mathrm{~mm}\end{array}$




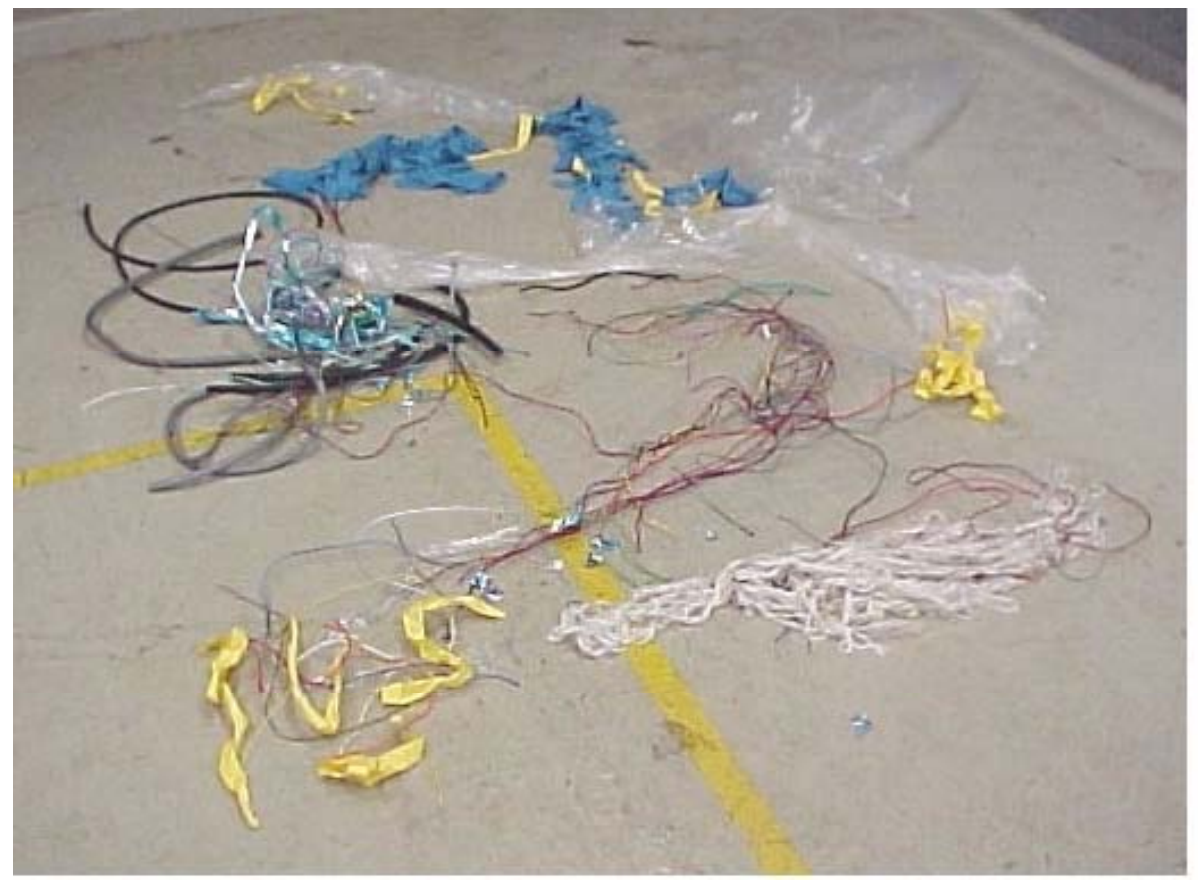

Fig. 15. Debris used in cold testing of the PMP.

The first $1.5 \mathrm{~h}$ of testing were conducted with the PMP discharge nozzles positioned $\sim 1$ in. off the floor of the test tank. It was expected that certain types of debris, such as the floating debris (large plastic bags, tape, gloves) would migrate toward the PMP inlet and would be drawn onto the PV inlet screen to block the inflow of material. Therefore, the last $1 \mathrm{~h}$ of testing was conducted with the PMP elevated $\sim 12$ in. off the floor of the test tank. At this elevation, the top of the inlet screen was $\sim 2$ in. below the surface of the water. This orientation was selected to increase the opportunity for floating debris to attach to the inlet screen. The floating debris did migrate toward the inlet but never became attached to the inlet. This was due to the amount of turbulence created by the PMP during the discharge cycles. The short cycle times $(\sim 1.7 / \mathrm{min})$ allowed the tank fluid to remain in motion even during the fill cycles. The circulatory flow created by the PMP in the 20-ft-diam test tank during operation caused the floating debris to move toward the PMP during the discharge cycle while submerged debris would be pushed away from the PMP. This appears to be a result of the placement of the PMP discharge nozzles near the floor of the tank and inlet port $\sim 8$-in. above the discharge nozzles. The material discharged from the submerged nozzles mobilized the material close to the floor of the tank in the direction of the exterior wall of the waste tank. The mobilized materials would then contact the tank wall, rebound, and travel in a surface layer back toward the PMP. Floating debris such as plastic bags were drawn to the PMP inlet during the fill cycle but were pushed away by the next discharge cycle. The PMP was operated so that at the end of each discharge cycle a small amount of air was released into the tank as illustrated by the sequence of photographs in Fig. 16. The air discharge created a significant amount of turbulence and disrupted the forward motion of any floating materials approaching the PMP. 


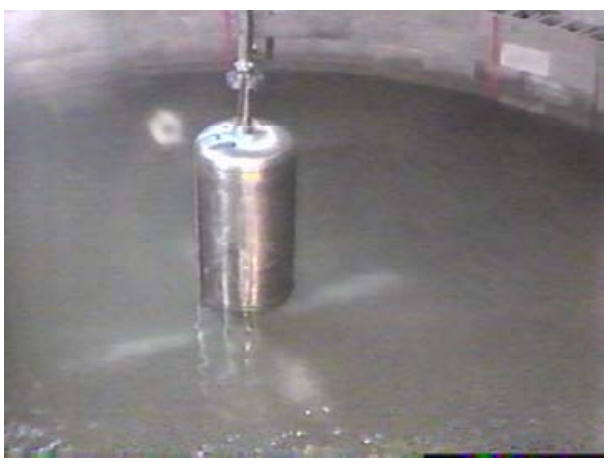

(1)

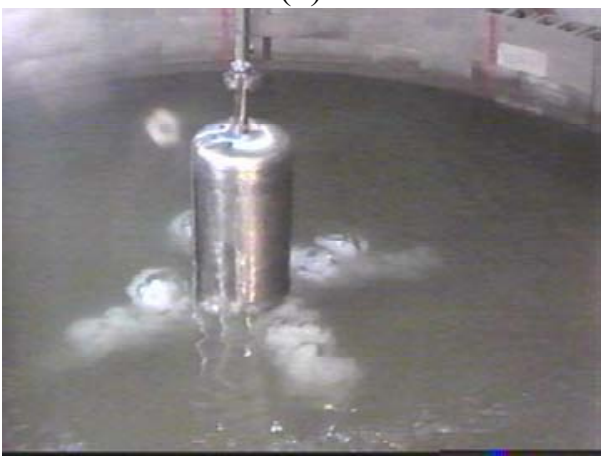

(3)

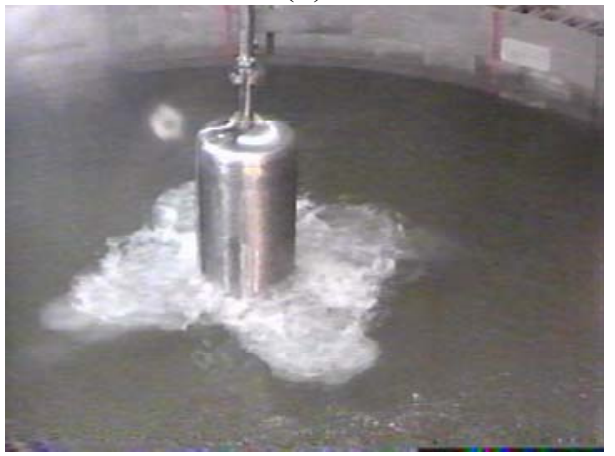

(5)

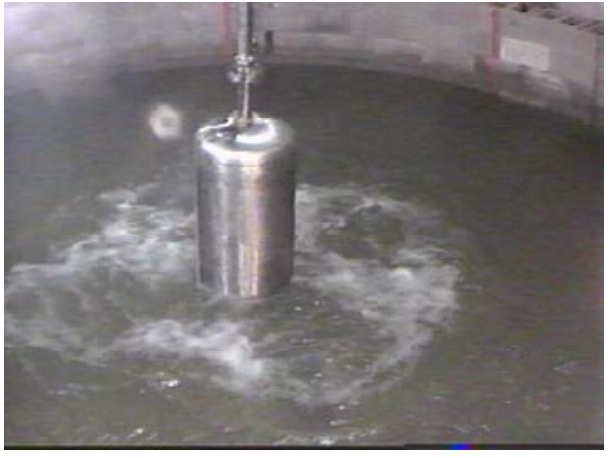

(7)

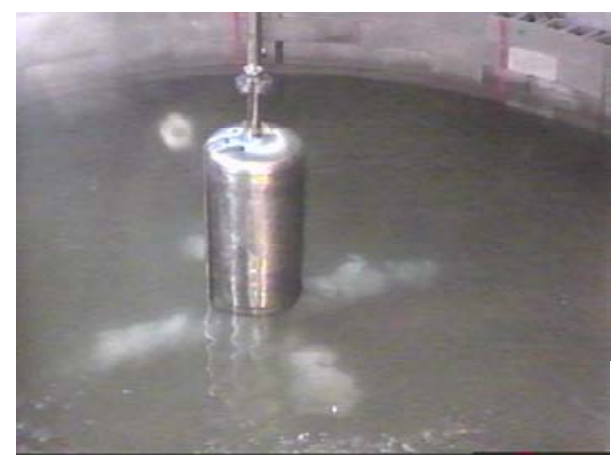

(2)

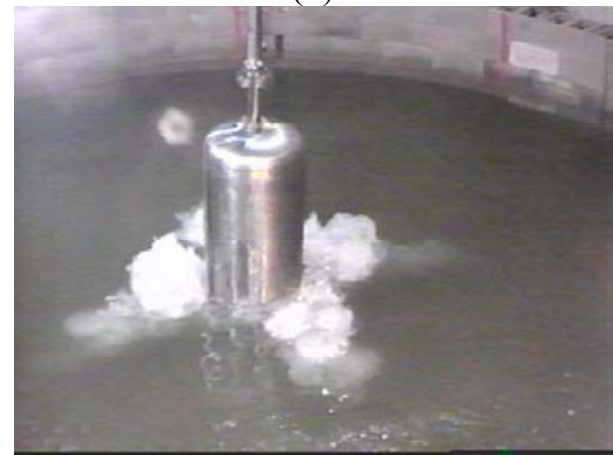

(4)

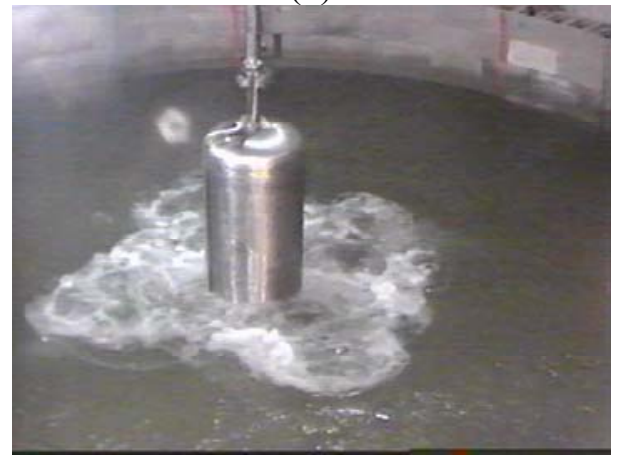

(6)

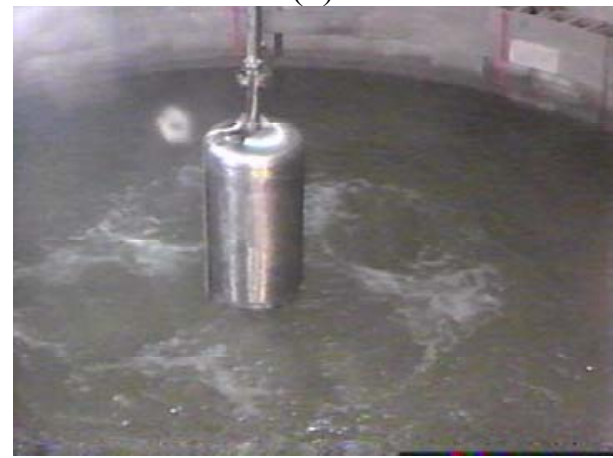

(8)

Fig. 16. Air release at end of discharge cycle. 
Additionally, a perforated metal screen was used to limit the size of material that could be drawn into the PV through the inlet port. The screen is $\sim 6 \mathrm{in}$. diam and $\sim 4 \mathrm{in}$. high and is constructed of perforated ( 0.25-in.-diam holes) metal plate (Fig. 17). No material became caught in the perforations during cold testing.

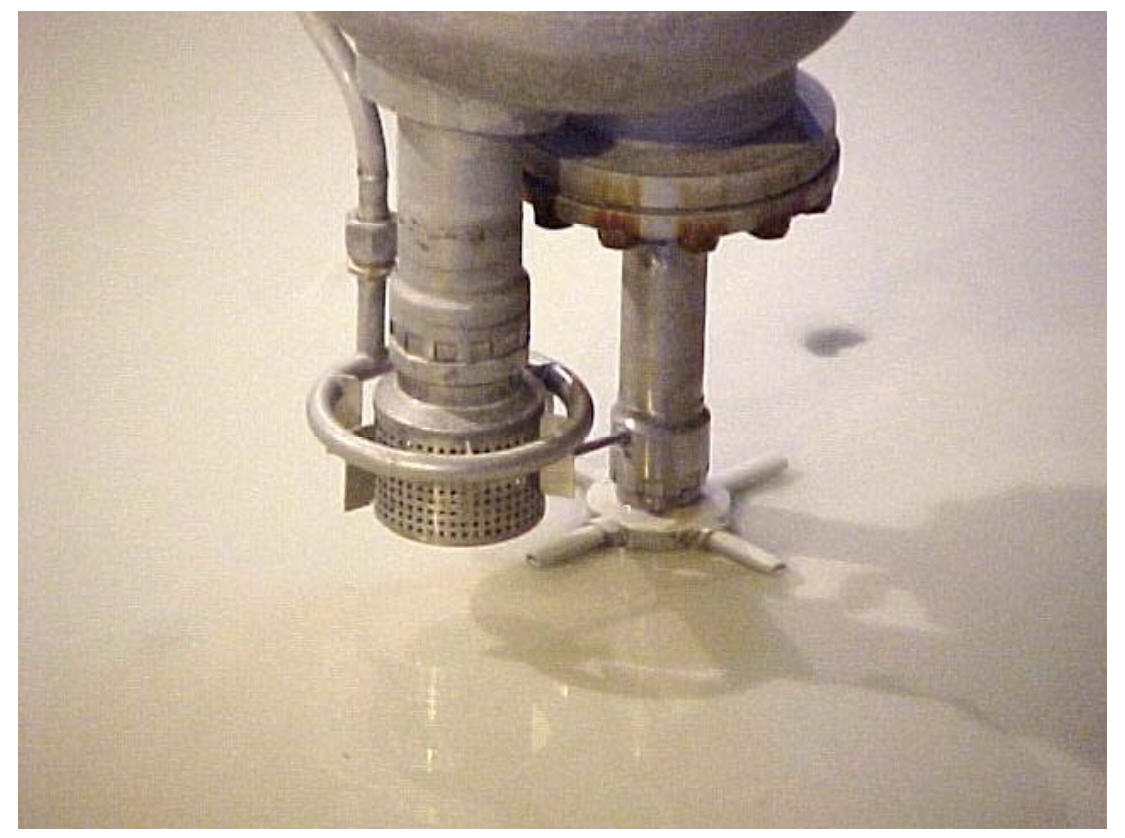

Fig. 17. View of the bottom of PMP showing the orientation of the screened inlet port relative to the discharge nozzles.

Most of the wires, rope, wire-wraps, and gloves were pushed to the outer edge of the tank floor and remained there throughout the test. Occasionally some of the rubber gloves would circulate between the PMP and tank wall. The observations from these tests indicate that the PMP should be able to operate effectively in the presence of the expected range of debris types in waste storage tanks.

\subsubsection{PMP Performance Test with Water Only}

A series of tests was conducted in the TTCTF with the test area filled with $\sim 2$ and $4 \mathrm{ft}$ of water and no other waste simulants. These tests were the first tests conducted to assess the qualitative performance of the integrated system, including the CS, PMP, and support equipment, and to determine effects of variations in operational parameters. Baseline monitoring and measurement of the noise levels generated by the PMP air eductor were also accomplished during these initial performance tests.

\subsubsection{Nominal Pressure Test}

The PMP was designed for a maximum operating pressure of $230 \mathrm{psig}$; however, for the intended application, the available air supply pressure was $\sim 90$ psig. Therefore, 90 psig was selected as the nominal operating pressure for the cold test program. The following operating conditions were used for this test: 


$\begin{array}{ll}\text { Water depth } & \sim 26 \text { to } 34 \mathrm{in} . \\ \text { Discharge header pressure } & \sim 90 \mathrm{psig} \\ \text { Eductor header pressure } & \sim 32 \mathrm{psig} \\ \text { Cycle frequency } & \sim 1.8 / \mathrm{min} \\ \quad \text { Refill cycle time } & \sim 26 \mathrm{~s} \\ \quad \text { Discharge cycle time } & \sim 7.5 \mathrm{~s} \\ \text { Rotation angle } & 0 \text { degree } \\ \text { Mode of operation } & \text { Automatic } \\ \text { Control system } & \text { As received } \\ \text { Nozzle diameter } & 16 \mathrm{~mm}\end{array}$

The use of the unmodified, as-received CS resulted in several interrupted tests as various problems with the CS hardware and software were experienced. Some of these problems included the following:

1. The CS software frequently dropped out of automatic mode for no apparent reason.

2. Timeout errors on start-up would cause the CS software to stop running.

3. The CS software logic was cumbersome and resulted in sluggish operation and logic errors, which contributed to CS failures.

4. Occasional signal mismatches between the software and hardware resulted in system failure, which could have been the result of either a hardware or software problem. A variety of hardware problems also caused the CS software to shut down (i.e., failed FP module).

5. The timer mode failed and the system could not be started using the CS software.

6. The CS software included graphical simulations of the fill and discharge cycles, which were not directly tied to the actual operating cycles. Processing the graphical information placed an excessive burden on the CS software and resulted in decreased performance and sluggish operation.

In addition to the difficulties with the CS, problems were also encountered with the air supply system for the PMP. Air was supplied to an air distribution manifold, which was connected to the air eductor and $\mathrm{AD}$ at the PMP. The air eductor line from the manifold was operated at a pressure of $\sim 37 \mathrm{psig}$. Because of line losses between the manifold and the eductor, the gage pressure at the eductor was only $\sim 27 \mathrm{psig}$. The AD leg of the manifold was operated at a pressure of $\sim 90$ psig. During the discharge cycle, a significant pressure drop was observed in both legs from the air distribution manifold. The air pressure in the line to the $\mathrm{AD}$ decreased from 90 to $\sim 53$ psig during the discharge cycle when the Trombetta ${ }^{\mathrm{TM}}$ solenoid opened the AD distribution valve on the PMP to admit pressurized air to the PV. A Rosemount ${ }^{\mathrm{TM}}$ pressure sensor was used to measure the absolute pressure in the PV; however, problems with water accumulation in the sensor head and faulty wiring made the instrument unreliable. The observed decrease in air supply pressure to the PV from 90 to $\sim 53$ psig was a result of line losses and competition from the air eductor supply line. Air is constantly supplied to the eductor used to generate the vacuum for refilling the PV; however, the $\mathrm{AD}$ distribution valve blocks the vacuum source to the PV during the discharge cycle. The pressure loss problem was later improved by the installation of an air accumulator tank in the air feed line to the PMP. With the 90-psig air supply pressure and no air accumulator tank, the average refill and discharge times for the PMP were $26.1 \mathrm{~s}$ and $7.5 \mathrm{~s}$, respectively. Observation of flow patterns during the discharge cycle indicated that the discharge pressure was sufficient to expel the water from the PV through the four discharge nozzles and rebound off the walls of the mock tank.

Fig. 18 is a representative absolute pressure-time curve for a typical fill and discharge cycle for the PMP operating with a 90-psig air supply pressure. 


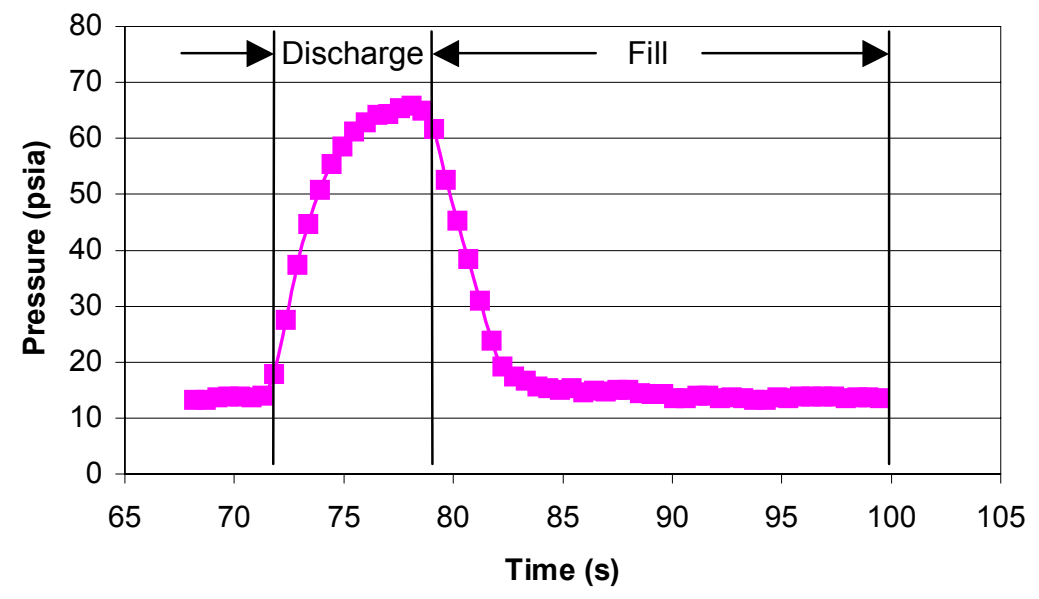

Fig. 18. Typical pressure time curve for the fill/discharge cycle using a 90 psig air supply.

The air eductor used to evacuate and refill the PV during the fill cycle generated noise levels $\geq 100 \mathrm{~dB}$ at or very near the PMP support platform. The noise level was measured to be $\sim 85 \mathrm{~dB}$ at $\sim 50 \mathrm{ft}$ from the support platform, which is the maximum allowable noise level for personnel without hearing protection. As a result of this finding, a 4-ft-long, 2-in.-diam extension was added to the discharge of the air eductor. The extension was long enough to allow the eductor to discharge below grade level and into the TTCTF test pit. Additional sound measurements showed that the operational noise level in the above ground work area had been reduced to the point that hearing protection was only required when working beneath the support platform and when the TRI doors were open.

\subsubsection{Low Pressure Test}

Since the available air supply pressure for the PMP application at ORNL was limited to $\sim 90$ psig, a brief test was conducted to observe the performance of the system under less than nominal conditions. The following operating conditions were used for this test:

$\begin{array}{ll}\text { Water depth } & \sim 26 \mathrm{in} . \\ \text { Discharge header pressure } & \sim 45 \mathrm{psig} \\ \text { Eductor header pressure } & \sim 25 \mathrm{psig} \\ \text { Cycle frequency } & \sim 1.6 / \mathrm{min} \\ \quad \text { Refill cycle time } & \sim 28.8 \mathrm{~s} \\ \quad \text { Discharge cycle time } & \sim 9 \mathrm{~s} \\ \text { Rotation angle } & 0 \text { degree } \\ \text { Mode of operation } & \text { Automatic } \\ \text { Control system } & \text { As received } \\ \text { Nozzle diameter } & 16 \mathrm{~mm}\end{array}$

Typical refill and discharge cycle times for the PMP during this $\sim 2$-h test were $28.8 \mathrm{~s}$ and $9 \mathrm{~s}$, respectively. The system performed reasonably well during this short duration test. The refill time was $\sim 10.3 \%$ longer and the discharge time $\sim 20 \%$ longer than the times observed during the 90 -psig tests described in Sect 6.3.3.2. These observations are consistent with the decreases in discharge and eductor header pressures. 


\subsubsection{High Pressure Test}

A test was planned to operate the PMP with an air supply pressure of $150 \mathrm{psig}$. However, a suitable airsupply system, which could meet the air pressure (150 to $230 \mathrm{psig}$ ) and volume requirements ( $\sim 70$ to $100 \mathrm{cfm}$ ) was not readily available. It is desirable to test the system to its maximum allowable working pressure of $230 \mathrm{psig}$. Additional tests at higher operating pressures are needed to fully explore the capabilities of the PMP system for possible applications in larger diameter tanks and for mobilization of higher density materials.

\subsubsection{High Pulsation Frequency Test}

Attempts were made to operate the PMP under high pulsation frequency conditions. These tests were to be accomplished by placing the CS in the timer mode of operation and setting the time-to-fill and the time-to-discharge to coincide with an approximate pulsation frequency of 4 cycles per minute. The normal pulsation frequency using 90 psig supply air is $\sim 1.8$ cycles per minute. Using a pulsation frequency of 1.8 allows the PV to be completely filled prior to discharge and requires a nominal fill time of $\sim 25$ to $30 \mathrm{~s}$ and a discharge time of $\sim 7$ to $9 \mathrm{~s}$ with slurry densities in the range of 1 to $1.1 \mathrm{~kg} / \mathrm{L}$. To accomplish a pulsation frequency of 4 cycles per minute, the timer mode was selected and the fill time set to $\sim 12.5 \mathrm{~s}$ and the discharge time to $\sim 5 \mathrm{~s}$. Under this operating scenario, it was expected that a higher degree of agitation using smaller volumes of solution would be attained. The initial efforts to complete this test using the unmodified, as-received CS system failed because of the software and hardware problems previously mentioned. Furthermore, because of higher priority test requirements, the continuing problems with the as-received CS, and the need to eventually release the system for field operation, this test was not completed.

\subsubsection{Rotation Angle Test}

This test was conducted to assess the ability of the PMP to repeatably rotate through a set arc of travel. The PMP can be rotated through a $90^{\circ}$ arc via a pneumatic actuator, which is manufactured by Bimba, Inc. The Bimba actuator is a position feedback unit that contains a linear resistive transducer (LRT) mounted in the cylinder head. The LRT, which has a resistive element on one side and a collector strip on the other, is inside the cylinder rod. A wiper assembly is installed in the piston. As the piston moves, an electrical circuit is created between the resistive element and collector strip. The output voltage is proportional to the wiper position on the resistive element, which allows the cylinder position to be determined.

The accuracy of the LRT is determined by three factors: resolution, linearity and repeatability. The Bimba LRT has a high degree of resolution but is stroke sensitive (i.e., the longer the stroke, the less the resolution). The linearity is listed as $\pm 1 \%$ of stroke, and the repeatability is listed as $\pm 0.001 \mathrm{in}$. The maximum speed is $50 \mathrm{in} . / \mathrm{s}$ at a pressure of $150 \mathrm{psi}$. The available air pressure at the cold test facility was $<100$ psig.

The associated hardware required to support the operation of the Bimba included a CYLCON 5030 signal tracking controller system for controlling cylinder motion in response to a voltage or current stimulus and two three-way Herion ${ }^{\mathrm{TM}}$ solenoid valves. One valve supplies pressurized air to the extend port and the other to the retract port. 
The following operating conditions were used for this test:

$\begin{array}{ll}\text { Water depth } & \sim 30 \mathrm{in} . \\ \text { Discharge header pressure } & \sim 90 \mathrm{psig} \\ \text { Eductor header supply } & \sim 32 \mathrm{psig} \\ \text { Cycle frequency } & \sim 1.7 / \mathrm{min} \\ \quad \text { Refill cycle time } & \sim 30 \mathrm{~s} \\ \quad \text { Discharge cycle time } & \sim 6 \mathrm{~s} \\ \text { Rotation angle } & 90 \text { degree } \\ \text { Mode of operation } & \text { Automatic } \\ \text { Control system } & \text { As received } \\ \text { Nozzle diameter } & 16 \mathrm{~mm}\end{array}$

A total of $\sim 257$ cycles were completed during a $\sim 151$ min operating period. The PMP rotated through the apparent 90-degree arc throughout the operating period. Prior to performance of this test, it was noted that the rotary motion of the PMP was not uniform. This unsteady motion was traced to variations in the air feed to the Bimba pneumatic actuator. The installation of small $(1 / 8$-in.) needle valves in the air feed lines to the Bimba served to properly throttle the airflow and stabilize the travel.

The Bimba pneumatic cylinder is mounted to the PMP top flange with the cylinder arm attached to the PMP AD. As air pressure is supplied to the inlet, the actuator rotates the PMP up to a maximum of 90 degrees. The desired rotation angle is input to the CS (in degrees) as one of the operating parameters. After the actuator has completed its initial stroke, air pressure is once again supplied to the retract solenoid valve, and the actuator returns to its starting position of 0 degrees. As the air is being supplied to one solenoid valve, the other is used to vent and vice versa. The actuator can be set to operate at rotation angles up to 90 degrees in 1-degree intervals.

Under fully automatic operation, the CS software is programmed so that rotation begins at the time the discharge cycle occurs and returns to the 0 degree position upon completion of the cycle. The use of a four-nozzle configuration and a 90-degree rotation range on the discharge of the fluid from the PV provides $\sim 360$-degree coverage of the floor of the tank. The only exception is operating the PMP in local mode, and in that scenario the discharge and rotation cycles do not necessarily operate simultaneously.

Because of the continuing problems with the as-received CS, automatic data storage was not possible during this test. However, after development of new CS software, subsequent tests were conducted, during which automatic data storage was used to record the rotational angle of the PMP. In each of these tests, the rotational angle was set to 90 degrees and a variety of operating conditions employed. The test data from July-September 2000, in which the new CS software was used, showed that the actuator was not extending to a full 90 degrees but was in the range of 80 to 89 degrees. The 80 -degree result may have been an outlier because only one test was operated at that condition. Most of the other tests resulted in a maximum stroke between 87 and 89 degrees. The reasons that the unit did not extend to a full 90 degrees were (1) the extend/retract period was set to align with the AD Trombetta solenoid on/off rate and (2) no effort was made to precisely tune the position indicator on the Bimba.

The Bimba extend/retract rate was synchronized with the Trombetta solenoid to more effectively mobilize and mix the waste material as the $\mathrm{AD}$ distribution valve is activated to discharge the material collected in the PV. However, it may be important to more precisely tune the Trombetta and Bimba operation to allow the Bimba to extend the full stroke of 90 degree to maximize the mobilization and mixing effort. Further testing is needed to determine if such a modification would be beneficial. 
Fine tuning of the position indicator and compensation for the mechanical linkage would have also improved the resolution but would have required some nonlinear corrections to account for the loose tolerances in the mechanism. Fine tuning of the system was not done because the initial visual observations of the operation of the system did not indicate a problem with control of the rotational angle and the subsequent CS data indicated near completion of the 90-degree rotation.

\subsubsection{Baseline Cleaning Radius Tests}

A series of baseline tests were conducted with $\sim 18$ in. of water and a 2-in. layer of medium-grain sand on the bottom of the mock tank to serve as a waste surrogate. These tests were conducted to provide an initial estimate of the cleaning radius for the PMP and to assess the effect of nozzle diameter on the cleaning radius.

Tests were performed using a sand simulant with various size discharge nozzles. Four sets of nozzles with four different diameters were provided with the PMP. The four nozzle diameters were $10 \mathrm{~mm}, 12$ $\mathrm{mm}, 14 \mathrm{~mm}$, and $16 \mathrm{~mm}$. Tests were originally planned for all four sets of nozzles; however, time constraints limited the testing to the 10- and 16-mm-diam nozzles.

A medium-grain, unwashed sand (1 to $2.4 \mathrm{~mm}$ ) was used as a waste simulant for these tests. In future tests, all sand surrogates should be prewashed to remove fine materials and decrease the settling time. Use of the unwashed sand resulted in extended periods of reduced visibility because of the presence of fine particles in suspension. The sand surrogate was an inexpensive and reasonable surrogate for the waste present in the ORNL GAAT. Sand density typically ranges from $\sim 90$ to $105 \mathrm{lb} / \mathrm{ft}^{3}$. A $\sim 2$-in.-deep layer of sand was placed on the floor of the mock tank. About 3 tons of sand was used in these tests. About 1 ton of Kaolin clay was used in the subsequent tests along with existing inventories of clay.

The PMP was lowered to a position where the centerline of the nozzles was $\sim 1$ in. off the tank floor. Because the floor of the TTCTF is not level, the PMP had to be positioned such that bottom of the system would not contact the floor during rotation. This meant that one side of the PMP nozzle head would be slightly higher than the other by $\sim 0.25 \mathrm{in}$. Under ideal conditions, the nozzle head is $\sim 0.375 \mathrm{in}$. off the floor when the nozzle centerline is $\sim 1$ in. off the floor. During these tests, the distance between the nozzle centerlines and tank floor varied from 1 to 1.25 in. off the floor because of the unleveled floor.

\subsubsection{16-mm Nozzle Test}

An $\sim 2$-in.-deep layer of medium-grain sand was spread across the tank floor of the mock tank. A small amount of the sand was removed immediately beneath the base of the PMP nozzle head to allow the PMP to be lowered into position with the nozzle centerline $\sim 1$ in. off the floor surface, as previously described. After the PMP was positioned, water was carefully added so as not to disturb the sand. The operating conditions were as follows:

$\begin{array}{ll}\text { Water depth } & \sim 18 \mathrm{in} . \\ \text { Discharge header pressure } & \sim 90 \mathrm{psig} \\ \text { Eductor header pressure } & \sim 35 \mathrm{psig} \\ \text { Cycle frequency } & \sim 1.4 / \mathrm{min} \\ \quad \text { Refill cycle time } & \sim \text { Not recorded } \\ \quad \text { Discharge cycle time } & \sim \text { Not recorded } \\ \text { Rotation angle } & 0 \text { degree (initially) } \\ \text { Mode of operation } & \text { Manual (initially) } \\ \text { Control system } & \text { As received }\end{array}$


Refill and discharge times were not recorded because of continuing difficulties with the as-received CS. The PMP was initially operated without rotating for one or more fill/discharge cycles to produce distinctive patterns in the layer of sand on the floor of the test tank. At the conclusion of each operating period and after the sand had settled, measurements were taken of the patterns formed in the sand by the action of the discharge nozzles. Operating periods of $1,4,5,5$, and 5 cycles were conducted without rotating the PMP. The amount of time required for full development of the PMP cleaning radius was determined from the pattern measurements at the end of each operating period. Measurements were made at the locations shown in the sketch in Fig. 19. The jet pattern in the sand (surrogate waste) was clearly defined after the initial operation of the PMP and did not change significantly during the follow-on tests. The general shape of the jet pattern produced in the sand by the four jet nozzles on the PMP is that of a four-lobbed propeller. As a result of the depth of sand used and the motivational force of the jet, a distinct three-dimensional pattern is formed at each lobe of the pattern. Sand is pushed to the outer edges of the propeller-shaped pattern deposits near the wall of the tank beginning at location $\mathrm{C}$, as indicated in Fig. 19. The distance from the center of the PMP to location $\mathrm{C}$ is defined as the minimum cleaning radius and the distance to location $\mathrm{B}$, the maximum cleaning radius. A characteristic mound is formed beginning at point $\mathrm{C}$ and reaching a maximum depth as indicated by dimension $\mathrm{E}$ at location $\mathrm{B}$. A small beach area of depth D typically forms behind the mound, beginning at location A and continuing to the tank wall.

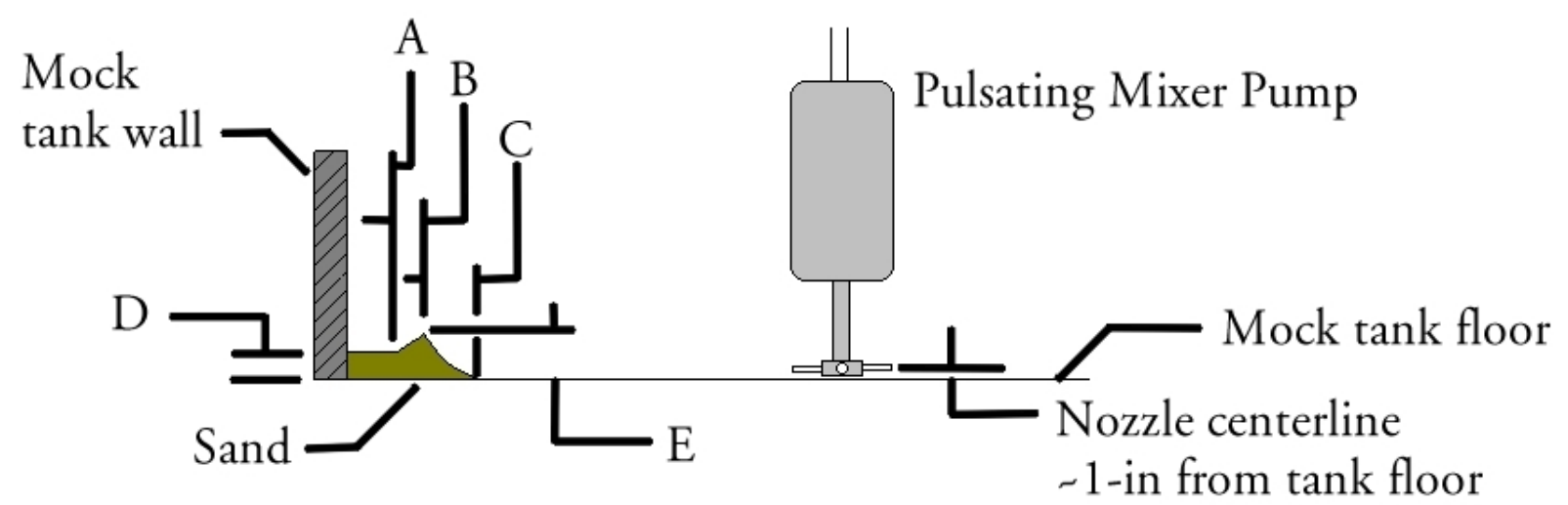

Fig. 19. Cross section of mock tank showing the measurement points for the sand displacement patterns observed during the cleaning radius tests.

From the turbulence observed in the mock tank, it was evident that the jet streams from the PMP discharge nozzles were rebounding off the mock tank wall, which was a distance of $\sim 10 \mathrm{ft}$ from the center of the PMP. The rebounding jet streams appear to enhance the mixing effect, as the material striking the tank wall rebounds back into the jet stream of a following cycle to increase turbulence.

Fig. 20 shows the growth of the minimum cleaning radius for the 16-mm-diam nozzles to a maximum measured value of 84.5 in. during the static tests. After completion of these tests, the sand was redistributed to a $\sim 2$-in. layer on the bottom of the test tanks and a test was conducted with the PMP rotating from 0 to 90 degrees under automatic control. All other operating conditions were the same as for the static test. After two or three false starts by the CS, the PMP was operated for a 30-min period and shut down. The sand was allowed to settle and measurements of the dynamic cleaning radius made every $\sim 45$ degrees around the PMP. An irregularly shaped zone (Fig. 21), which was free of sand, was formed around the PMP. The average minimum cleaning radius for the dynamic test was $\sim 65.8 \mathrm{in} . \pm 1.2 \mathrm{in}$. The average radial distance to the maximum sand depth (maximum cleaning radius) for the dynamic tests was 78.6 in. \pm 1.9 in. The cleaning radius observed during the dynamic test was much less than that in the 
static tests because of disbursement of the jet energy over a wider area. During the dynamic tests, the discharge cycle occurred as the PMP began to rotate from the 0 degree position to the 90 degree position and was completed before the PMP returned to the zero position. This type of operation is typical and allows each nozzle to discharge over a quadrant of the floor of the tank and thus scour the entire floor of the tank. The fill cycle began near the end of the PMP rotation back to the 0 degree position. As soon as the fill cycle was completed, the discharge cycle would begin automatically.

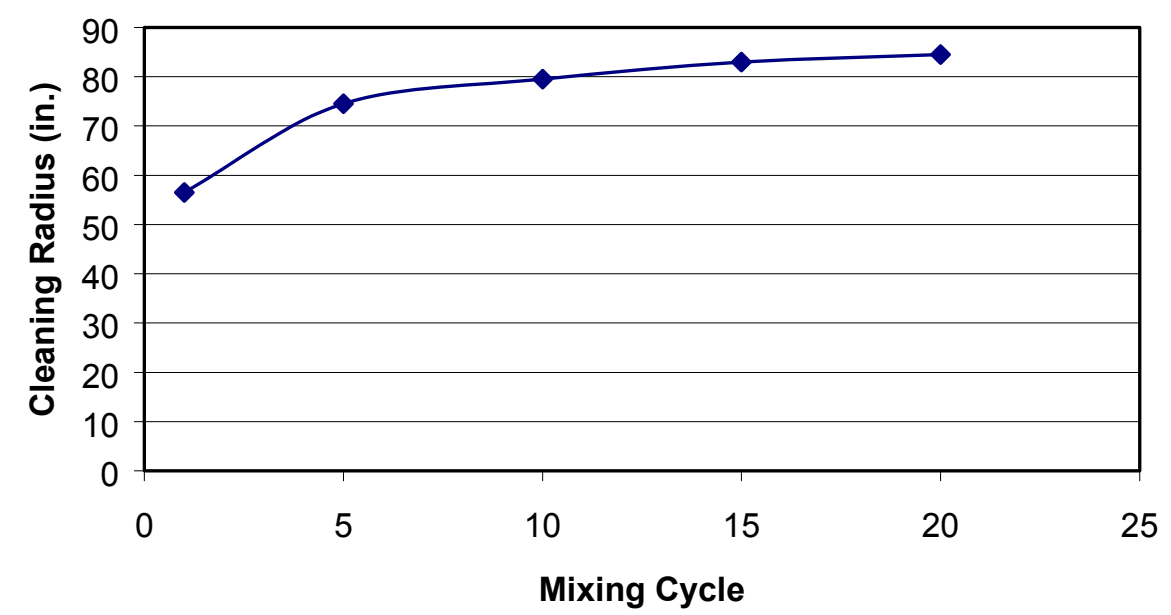

Fig. 20. Minimum cleaning radius growth for $16 \mathrm{~mm}$ diameter nozzles.

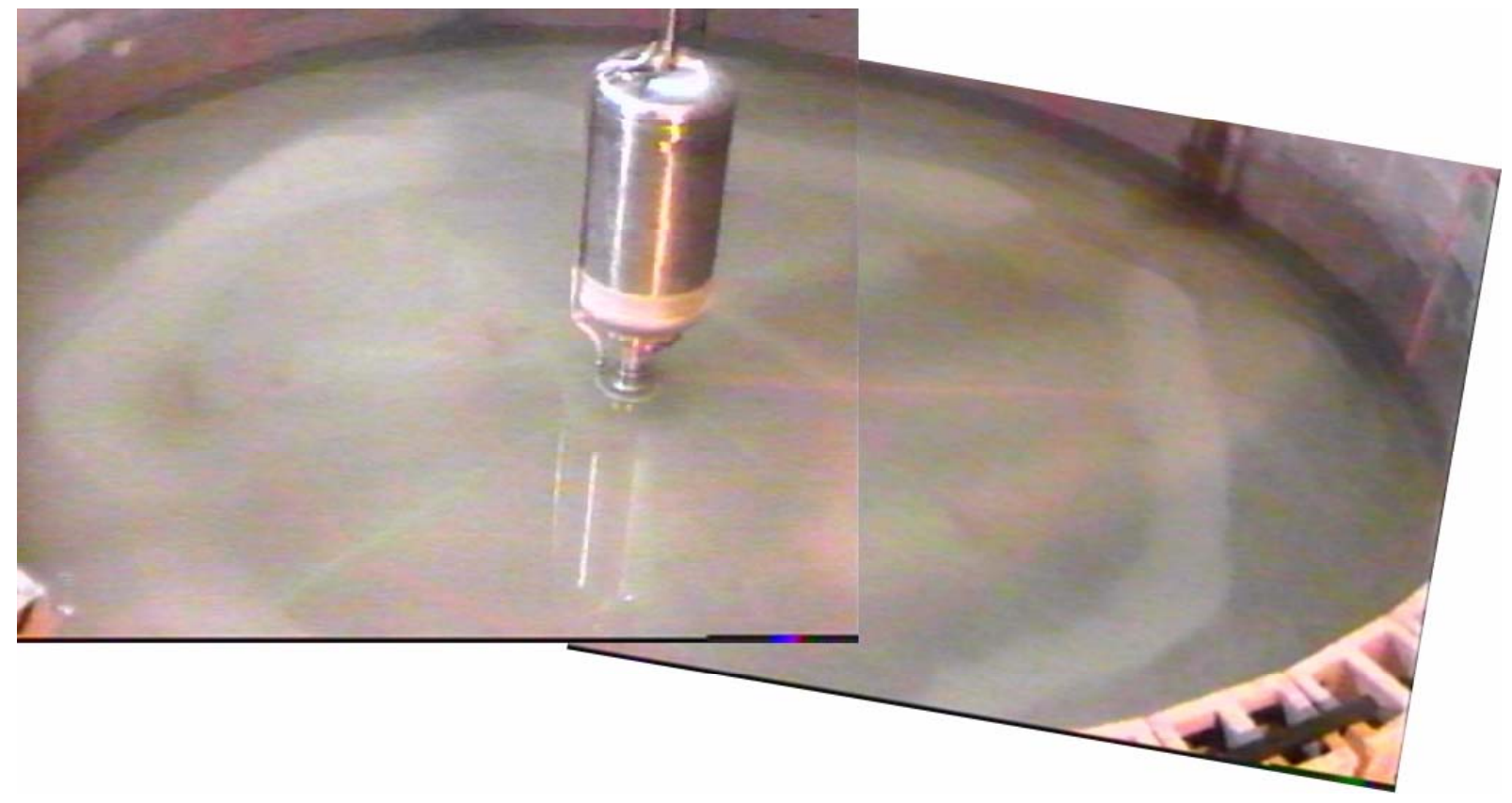

Fig. 21. Composite photo of sand displacement pattern after dynamic cleaning radius tests with 16-mm-diam nozzles. 


\subsubsection{10-mm Nozzle Test}

At the conclusion of the 16-mm nozzle cleaning radius tests 10 -mm diam nozzles were installed on the PMP. Static and dynamic cleaning radius tests were then conducted using the 10-mm diam nozzles with the following operating conditions:

$\begin{array}{ll}\text { Water depth } & \sim 18 \text { in. } \\ \text { Discharge header pressure } & \sim 90 \text { psig feed to AD } \\ \text { Eductor header pressure } & \sim 37 \mathrm{psig} \\ \text { Cycle frequency } & \sim 1.0 / \mathrm{min} \\ \quad \text { Refill cycle time } & \sim 42 \text { to } 48 \mathrm{~s} \\ \quad \text { Discharge cycle time } & \sim 18 \text { to } 13 \mathrm{~s} \\ \text { Rotation angle } & 0 \text { degree (initially) } \\ \text { Mode of operation } & \text { Manual (initially) } \\ \text { Control system } & \text { As received }\end{array}$

These tests began with an $\sim 2$-in.-deep layer of sand on the bottom of the mock tank. Fig. 22 shows the growth of the static minimum cleaning radius for the 10 -mm-diam nozzles with a maximum of 85 in. after 45 operating cycles.

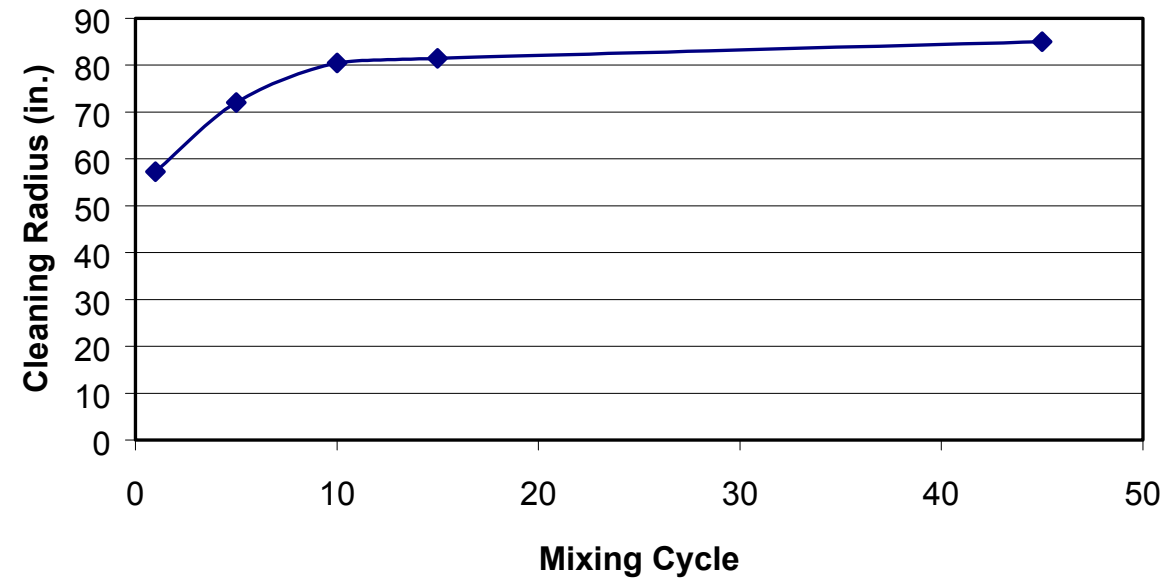

Fig. 22. Minimum cleaning radius growth for 10-mm-diam nozzles.

A dynamic test was also conducted using the 10-mm-diam nozzles and, as observed in the 16-mm-diam nozzle tests, a characteristic irregular shaped zone, which was free of sand, was formed around the PMP. Problems with the as-received CS continued to interfere with the operation of the PMP and completion of the cold test program. After several attempts to operate the PMP in automatic mode for the dynamic cleaning radius test, hardware problems were detected in the FP modules located inside the TRI near the PMP. Problems associated with operations in a high humidity environment may have led to failure of one of the control modules. In order to complete this test, circuitry was installed to allow local manual operation of the PMP. The system was operated for $\sim 30$ min to complete the test. The approximate observed minimum cleaning radius for the $10-\mathrm{mm}$-nozzle test was $64 \mathrm{in}$. The approximate radial distance to the maximum sand depth (maximum cleaning radius) for this test was $76 \mathrm{in}$. 
The results from the static and dynamic 10-mm-nozzle tests were similar to those observed for the 16mm-nozzle tests. Because of the similarity of these results, further testing using intermediate size nozzles was not conducted. At the completion of these tests, the 16-mm-diam nozzles were reinstalled on the PMP and used throughout the remainder of the cold test program. Although plugging problems were not observed during the cold test, it was thought that the larger diameter nozzles would in general be less susceptible to plugging.

\subsubsection{Performance Tests with Sludge Surrogates}

A series of tests were performed to aid in understanding the capabilities of the PMP to displace and mobilize a variety of simulated sludge materials. These tests extended the observations from the baseline cleaning radius tests described in Sect. 6.3.4 and included tests with sand, gravel, kaolin clay, and mixtures of these components. Tests were conducted to observe the performance of the PMP for displacement of (1) mounds of sand, (2) mounds of gravel in sand, and (3) mounds of kaolin clay and sand.

Tests were also conducted to (1) measure the variation in the solids concentration profile at a fixed location in the test tank with time and (2) observe and measure the solids concentration profile while simultaneously retrieving material from the test tank. A kaolin clay-sand simulant was used in these tests. The data from these tests provided insight to the mixing capability of the unit and was also beneficial in understanding the operation of the PMP.

\subsubsection{Sand Mound Displacement Tests}

For the initial sand mound displacement test, two conical mounds of sand were placed within $\sim 8 \mathrm{ft}$ of the centerline of the PMP with the mound centerlines $\sim 6 \mathrm{ft}$ from the centerline of the PMP and oriented 180 degrees apart. The sand mounds were constructed from the sand previously used in the cleaning radius tests. The initial test duration was $\sim 36 \mathrm{~min}$. A second test was also conducted with the sand mounds positioned $\sim 2.5 \mathrm{ft}$ from the centerline of the PMP. As a result of the continuing problems experienced with the as-received CS, a modification was made to implement a set of mechanical timers to control the clockwise and counterclockwise rotation time for the PMP. The operating conditions for the initial test were as follows:

Water depth
Discharge header pressure
Eductor header pressure
Cycle frequency
$\quad$ Refill cycle time
Discharge cycle time
Rotation angle
Mode of operation
Control system

\author{
$\sim 30$ in. \\ $\sim 90$ psig feed to $\mathrm{AD}$ \\ $\sim 37$ psig \\ $\sim 2 / \mathrm{min}$ \\ Not recorded \\ Not recorded \\ 90 degree \\ Modified automatic \\ As received with mechanical timers for rotation control
}

The results show that the mounds of sand were quickly displaced to the outer edges of the mock tank wall during the $\sim 36$-min operating period for the initial test. The sand mounds before and after the initial test can be seen in Fig. 23 beneath the water in the mock tank. During this test, the PMP was rotated with a 3s clockwise and 3-s counterclockwise cycle for the first 14 min followed by 6-s clockwise and 6-s counterclockwise cycle for the remaining 21 min of operation. 


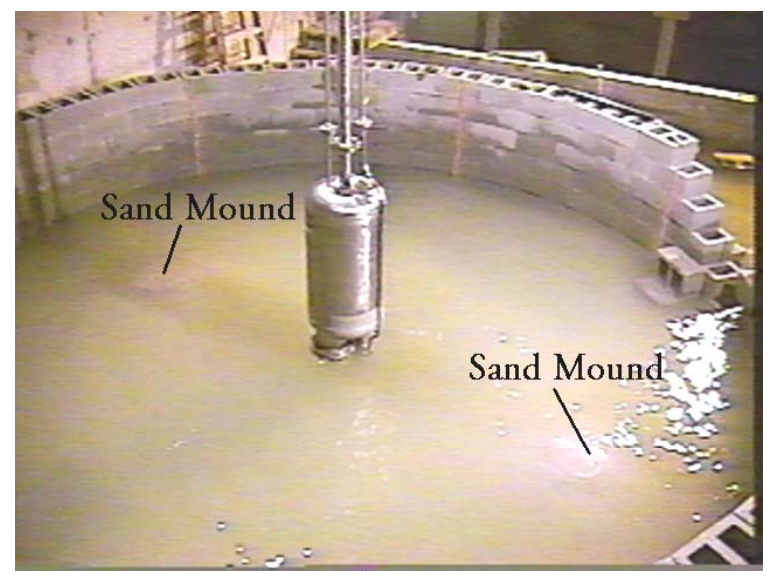

Before

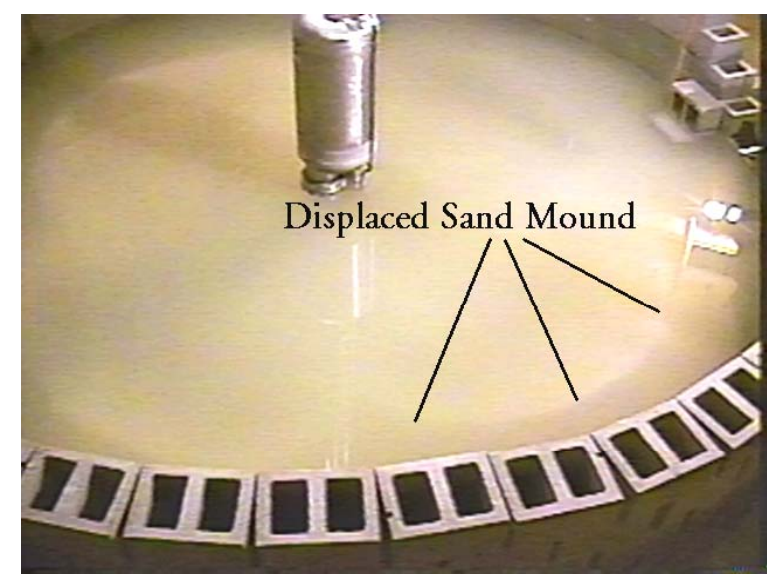

After

Fig. 23. Typical sand mound test observations before and after testing.

The conical sand mounds were displaced to the outer wall of the mock tank into the shape of an arc as shown in Fig. 23. The water was drained from the mock tank and measurements made, which showed a minimum cleaning radius of $\sim 67 \mathrm{in}$. and is consistent with the previous dynamic cleaning radius observations given in Sect. 6.3.4.1. The operating conditions for the second test were the same as for the initial test with the exception of (1) the position of the sand mounds were $\sim 2.5 \mathrm{ft}$ from the center of the mock tank, (2) the rotation arc was reduced from 90 to 75 degrees, and (3) the clockwise and counterclockwise rotation cycle times were held at $\sim 6 \mathrm{~s}$ each. The decreased rotation arc was used to better focus the discharge from the PMP on the sand mounds. The cumulative test duration was $\sim 30$ min, although the test was interrupted near the start to observe the progression of the sand mound displacement. The minimum cleaning radius for this test was $\sim 75.5 \mathrm{in}$. The larger cleaning radius is indicative of the effect of the reduced rotation arc.

\subsubsection{Modified Control System Tests}

As a result of the problems encountered in controlling and operating the PMP using the as-received CS, the decision was made to develop completely new CS software and make the necessary changes and modifications to the hardware to improve the reliability and simplicity of operation of the system. These changes included the following:

1. Development of new software to simplify the program logic to allow easier modification and more efficient operation

2. Elimination of unnecessary graphical simulations to provide better response time by the process control computer

3. Elimination of nonessential calculations to improve the response time of the process control computer

4. Installation of solid-state relays to prevent damage to the FP hardware due to inductive spikes from the valve actuator motors

5. Correction of wiring errors in the cable between the FP computer and the process control computer

6. Modification of the data logging routines to log parameters of interest

7. Documentation of the CS software changes and preparation of a users' manual 


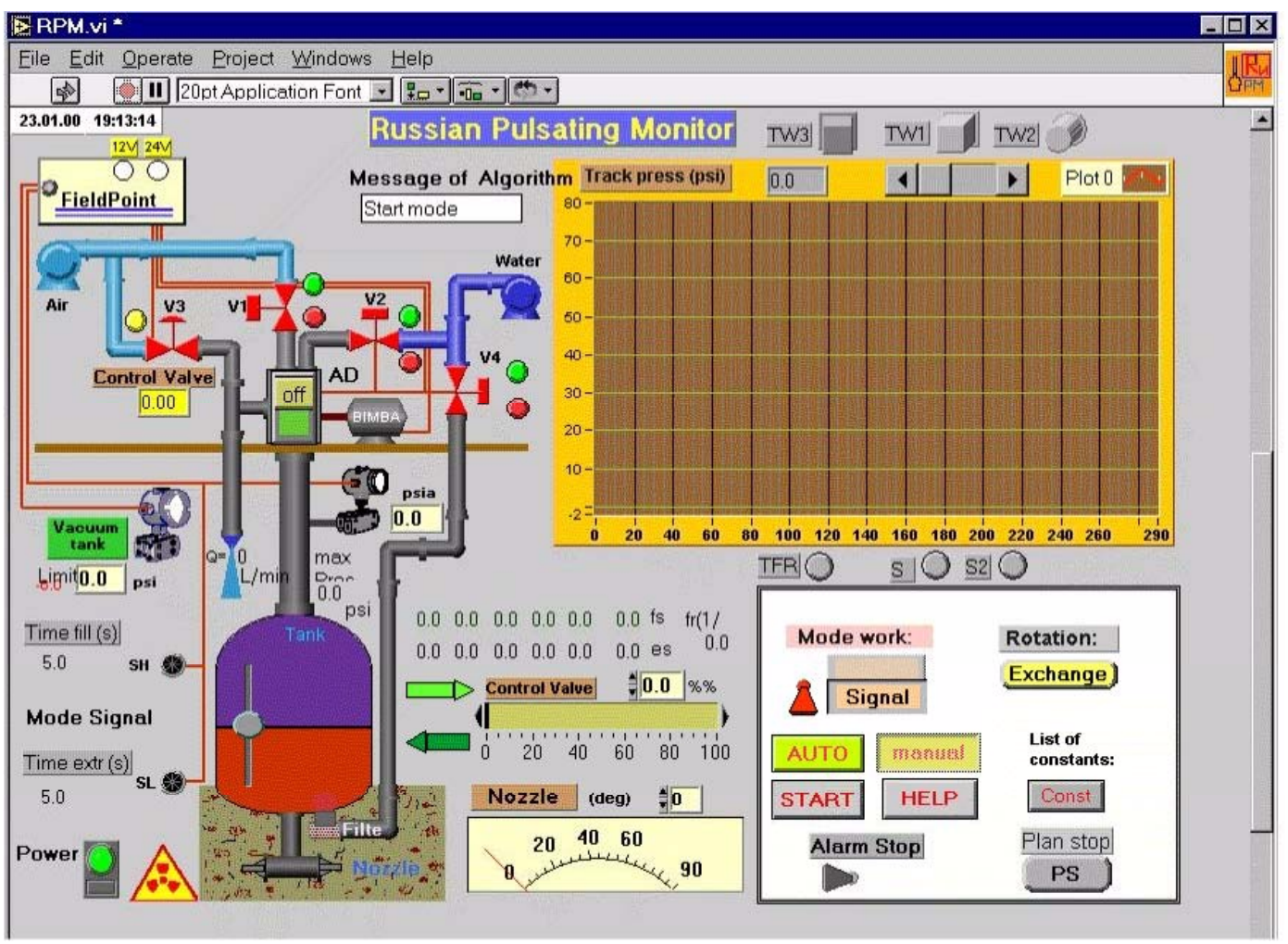

As-received screen view

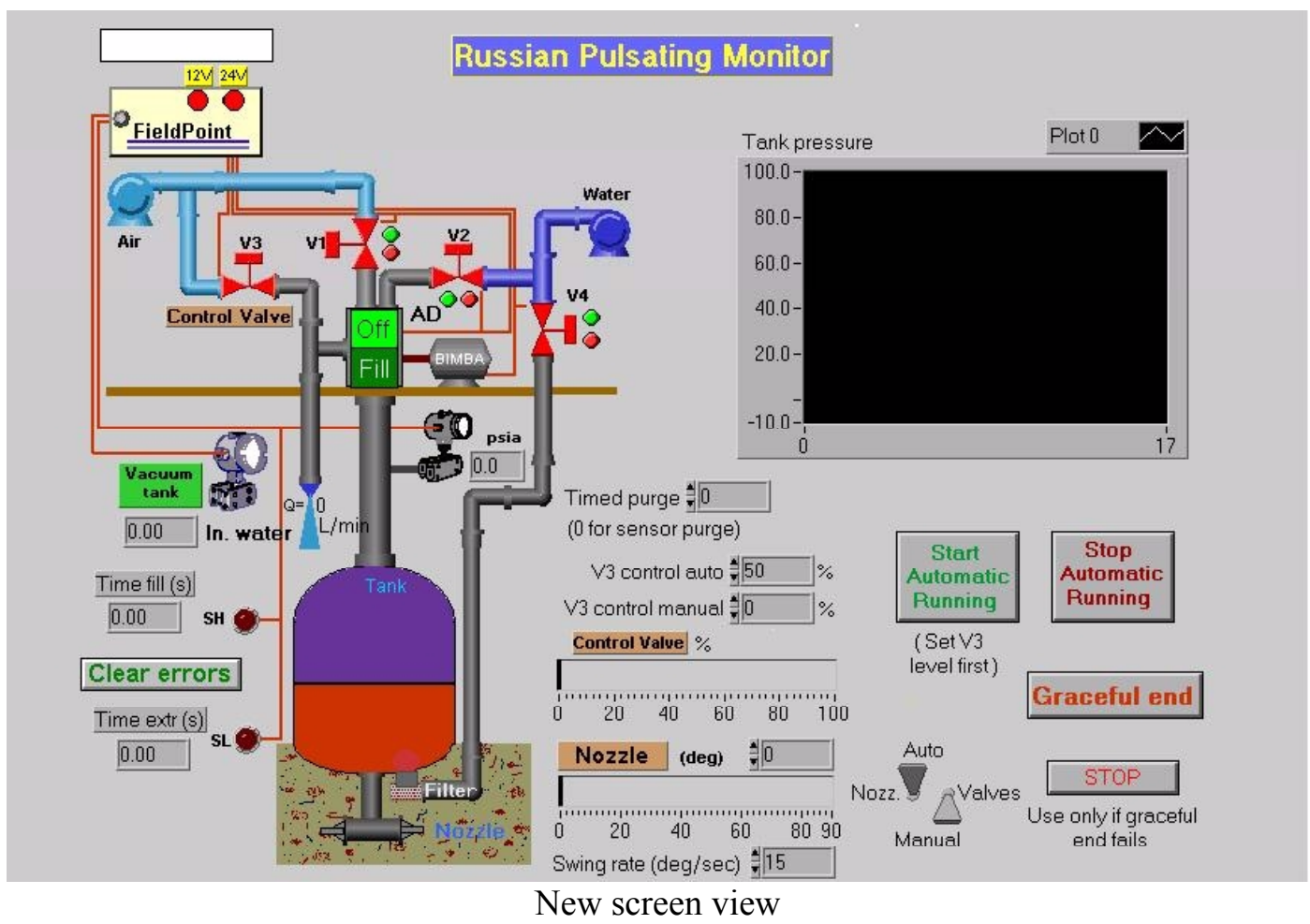

Fig. 24. Screen views from the as-received and new control systems. 
The majority of these changes were made over about a two-week period after completion of the sand mound displacement tests. Views of the CS screens from the as-received and new CS are shown in Fig. 24. Most of the functionality of the interface capability of old as-received CS was retained in the new CS. Each system includes the following common features:

1. graphical representation of the PMP piping and valve layout to indicate the system status;

2. data window to show real-time pressure and time curve for pump and refill cycles;

3. air control valve-stem position;

4. PMP position;

5. operating mode switches;

6. data readouts for various pressures, flows, and times;

7. FP power up indicators;

8. high- and low-level indicators for PV; and

9. message window.

A variety of short and long duration tests up to $\sim 6.5 \mathrm{~h}$ in duration were conducted to debug and evaluate the performance of the new CS and PMP hardware. An extended $6.5 \mathrm{~h}$ operation was conducted under the following conditions:

$\begin{array}{ll}\text { Water depth } & \sim 30 \text { in. } \\ \text { Discharge header pressure } & \sim 90 \text { psig feed to AD } \\ \text { Eductor header pressure } & \sim 30 \text { to } 45 \text { psig } \\ \text { Cycle frequency } & \sim 1.4 \text { to } 1.9 / \mathrm{min} \\ \quad \text { Refill cycle time } & \text { Not recorded } \\ \quad \text { Discharge cycle time } & \text { Not recorded } \\ \text { Rotation angle } & 90 \text { degree } \\ \text { Mode of operation } & \text { Automatic } \\ \text { Control system } & \text { New }\end{array}$

With the new program and hardware modifications in place, the system operated very well over an extended period of time. Additional modifications were made to the CS software to add data collection capabilities and continue to improve performance during subsequent tests.

\subsubsection{Gravel Displacement Tests}

The gravel displacement tests used limestone rock up to $\sim 0.5$ in. diameter. About 20 gal of gravel was used to make two small ( $\sim 10$ gal) mounds. The mounds were placed 180 degrees apart $\sim 2.5 \mathrm{ft}$ from the PMP centerline and in line with two of the PMP discharge nozzles. The sand from the previous test was not removed prior to this test, but was redistributed to a uniform layer $\sim 2$ in. thick across the bottom of the test tank. The test was conducted over a two-day period with an initial $\sim 108$ min operating period followed by an $\sim 25 \mathrm{~min}$ operating period on the second day. Problems were experienced with the shutdown cycle for the new CS software at the end of the first day of operation. Modifications were made to the CS software to correct the problem and allow normal shutdown on the second day of operation. The following general operating conditions were used:

$\begin{array}{ll}\text { Water depth } & \sim 10.7 \mathrm{in} . \\ \text { Discharge header pressure } & \sim 90 \mathrm{psig} \text { feed to AD } \\ \text { Eductor header pressure } & \sim 45 \mathrm{psig} \\ \text { Cycle frequency } & \sim 2 / \mathrm{min}\end{array}$




\begin{tabular}{ll}
\multicolumn{1}{c}{ Refill cycle time } & Not recorded \\
Discharge cycle time & Not recorded \\
Rotation angle & 90 degree \\
Mode of operation & Automatic \\
Control system & New
\end{tabular}

At the end of the test, the water was drained from the mock tank, and measurements were taken to determine the degree of displacement of the gravel. The estimated minimum cleaning radius for displacement of gravel by the PMP was $\sim 95.4 \pm 8.2 \mathrm{in}$. The gravel had all been displaced to the sand area and was $<30$ to 35 in. from the wall of the test tank as shown in Fig. 25. The gravel was distributed around the entire test tank perimeter area. No gravel was observed in the $\sim 35$-in.-wide zone from the wall of the test tank. This test shows the capability of the system to readily displace a heavy material.

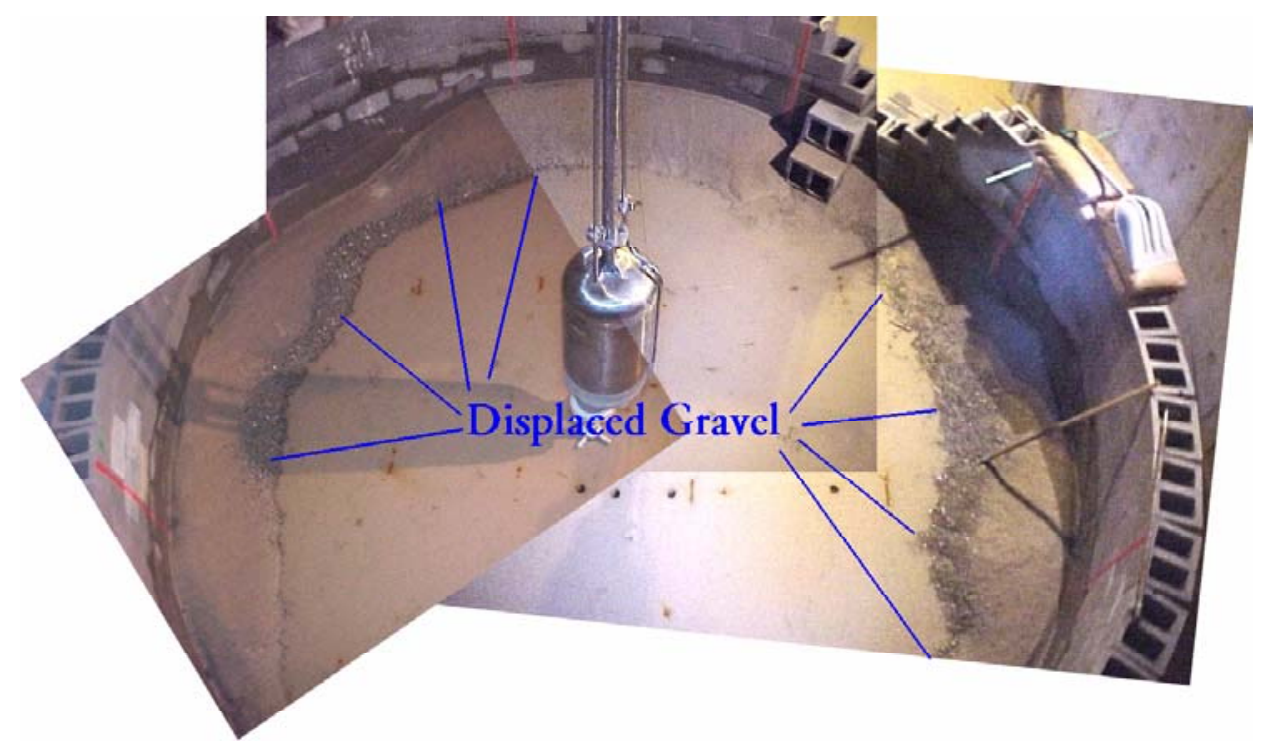

Fig. 25. Composite overview of mock tank floor after the gravel displacement test.

\subsubsection{Dual Clay-Sand Mound Displacement Test}

A test was conducted to assess the displacement of two kaolin clay mounds on a bed of sand from previous tests. This test was conducted following the gravel displacement test described in Sect. 6.3.5.2. Most of the sand and gravel were removed from the mock tank at the end of the gravel displacement test, which resulted in $\sim 500 \mathrm{lb}$ of sand remaining on the bottom of the tank. A small quantity of gravel from the previous test remained mixed with the sand. The sand was spread in a 1 to $2 \mathrm{in}$. layer on the bottom of the mock tank prior to adding $\sim 800 \mathrm{lb}$ of kaolin clay to the tank. The clay was heaped into two mounds $\sim 180$ degrees apart with $\sim 6$-ft-diam bases and protruding $\sim 3$ to $4 \mathrm{in}$. above the surface of the water in the mock tank. The mounds were placed $\sim 3$ to $4 \mathrm{ft}$ from the center of the mock tank as indicated in Fig. 26. 


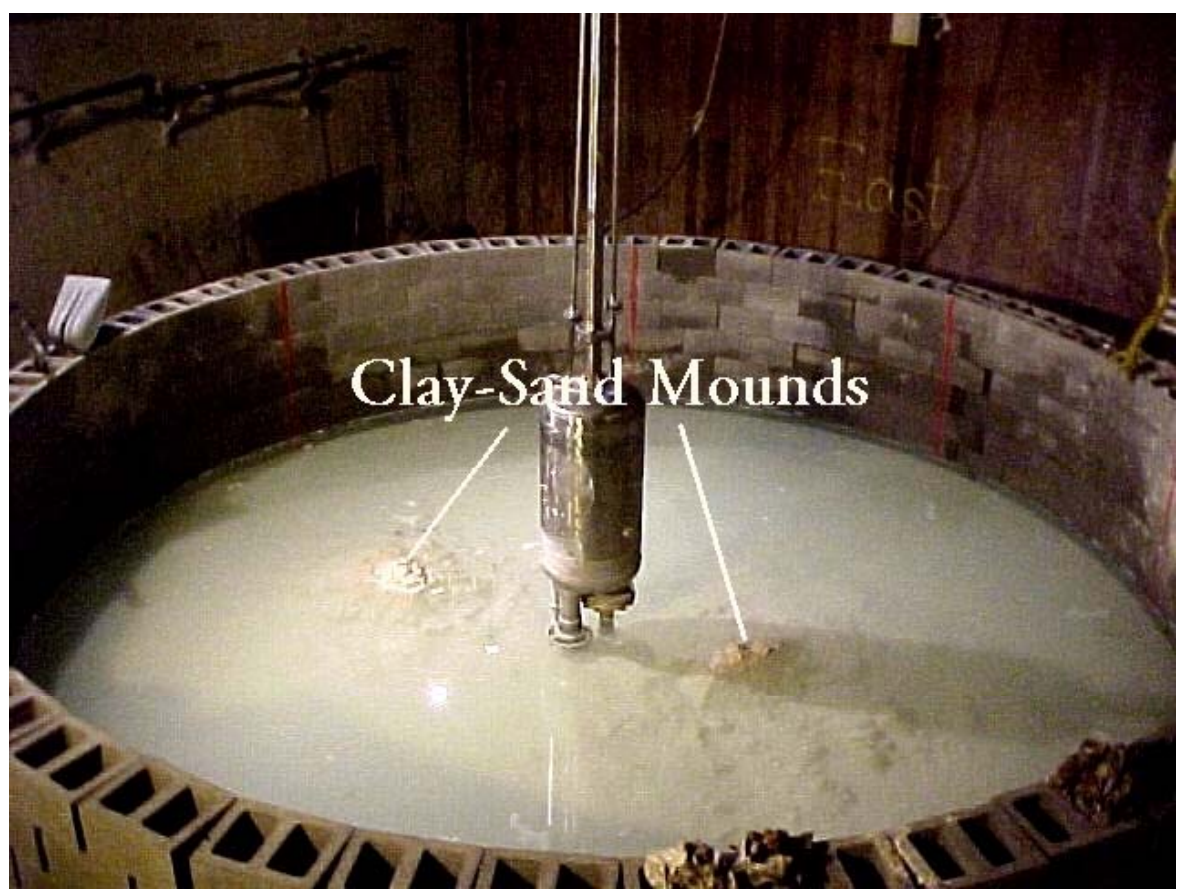

Fig. 26. Clay-sand mounds in mock tank before mixing.

During construction of the mounds, a small amount of the sand from the bottom of the tank was mixed with the clay. The following operating conditions were used in this test:

$\begin{array}{ll}\text { Water depth } & \sim 10.5 \text { to } 11 \text { in. } \\ \text { Discharge header pressure } & \sim 90 \text { psig feed to AD } \\ \text { Eductor header pressure } & \sim 45 \mathrm{psig} \\ \text { Cycle frequency } & \sim 1.8 / \mathrm{min} \\ \quad \text { Refill cycle time } & \sim 24 \\ \quad \text { Discharge cycle time } & \sim 8.8 \mathrm{~s} \\ \text { Rotation angle } & 90 \text { degree } \\ \text { Mode of operation } & \text { Automatic } \\ \text { Control system } & \text { New }\end{array}$

The PMP was operated for a total of $\sim 3 \mathrm{~h}$ during two separate operating periods on July 19,2000 . At the end of the test, the solids were allowed to settle, and the liquid was pumped out of the test pit to allow measurement of the clay-sand pattern. At the end of the 3-h mixing test, the estimated minimum effective cleaning radius was $87.6 \pm 4.1 \mathrm{in}$. The clay was dispersed around the periphery of the tank in a pattern similar to that observed during the gravel displacement test. An overview of the mock tank at the end of the test is presented in Fig. 27. A relatively thin layer of kaolin clay was present on the floor of the mock tank between the PMP and the displaced bank of clay and sand near the tank wall. The amount of claysand near the mock tank wall varied from 3 to 6 in. and had an average depth of $3.8 \pm 1.4 \mathrm{in}$. 


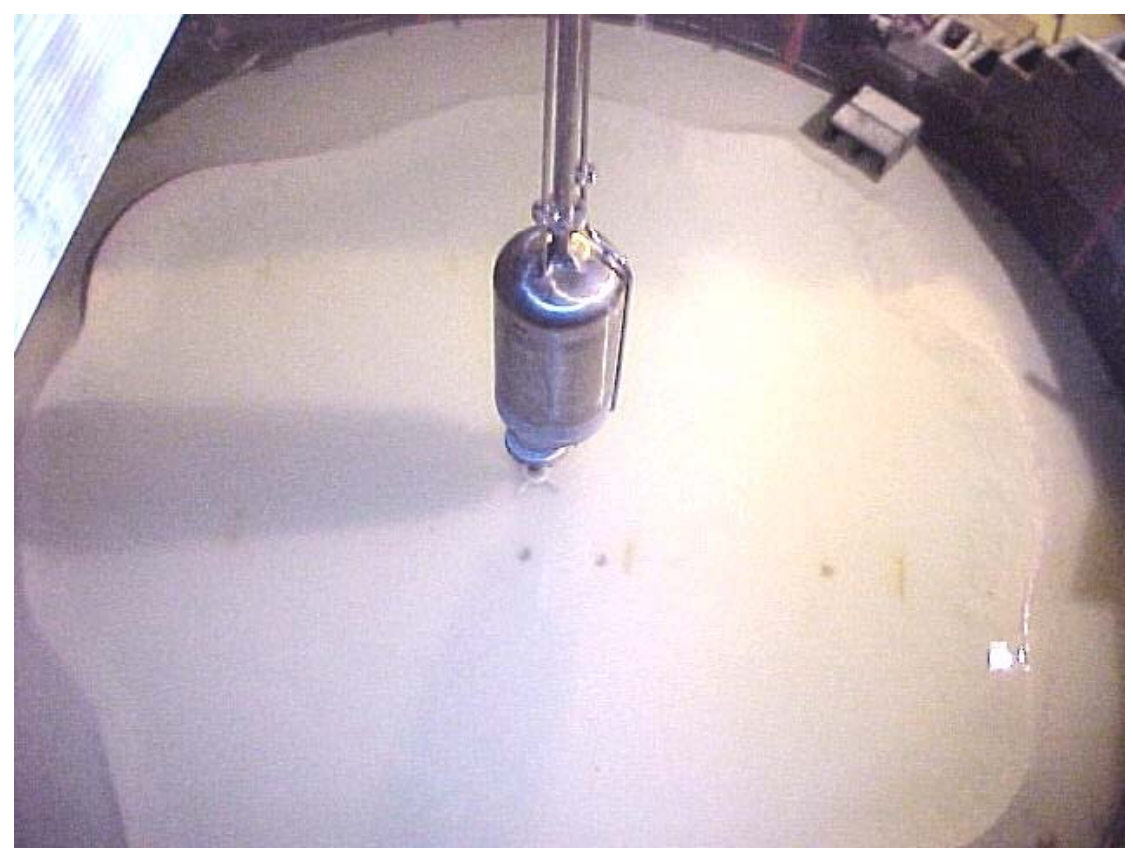

Fig. 27. Overview of mock tank after the dual mound clay-sand displacement test.

\subsubsection{In-Line Clay-Sand Mound Displacement}

Two tests were conducted to observe the performance of the PMP when installed into a mound of sludge surrogate. A mixture of $\sim 500 \mathrm{lb}$ of sand and $2,450 \mathrm{lb}$ of kaolin clay was placed in the center of the mock tank to form a single clay-sand mound. The PMP was elevated about $2 \mathrm{ft}$ above the floor of the mock tank while the material was added to the tank. Fig. 28 shows the setup before completely filling the mock tank with water. The clay-sand mound for the first test was $\sim 6 \mathrm{ft}$ diam at its base and $\sim 18 \mathrm{in}$. tall with its centerline aligned with the centerline of the PMP. The operating conditions for this test were as follows:

$\begin{array}{ll}\text { Water depth } & \sim 20 \mathrm{in} . \\ \text { Discharge header pressure } & \sim 90 \mathrm{psig} \text { feed to AD } \\ \text { Eductor header pressure } & \sim 45 \mathrm{psig} \\ \text { Cycle frequency } & \sim 1.9 / \mathrm{min} \\ \quad \text { Refill cycle time } & \sim 23.5 \mathrm{~s} \\ \quad \text { Discharge cycle time } & \sim 7.8 \mathrm{~s} \\ \text { Rotation angle } & 90 \text { degree } \\ \text { Mode of operation } & \text { Automatic with manually decreasing depth } \\ \text { Control system } & \text { New }\end{array}$

The test was conduced over two 1.5-h operating periods. The test was started by first lowering the PMP to within 12 in. of the floor of the mock tank. With the centerline of the mound aligned with the centerline of the PMP, the discharge nozzles were just touching the side of the clay-sand mound. The system was operated in this location for $\sim 15 \mathrm{~min}$ and then lowered to within 8 in. of the floor of the mock tank. After 15 min of operation at this location, the PMP was lowered to within 4 in. of the floor of the mock tank. After another 15-min operating period the PMP was lowered to within $1 \mathrm{in.}$ of the floor of the mock tank and operated for $\sim 30$ min. The position of the PMP was set by measuring the change in elevation of the support table inside the TRI. The system was shut down and the test pit drained at the 
end of the 30-min operating period to allow measurement of the clay-sand displacement patterns. The minimum effective cleaning radius after the initial 1.5 -h cumulative operating period was $95.6 \pm 7.5$ in. The depth of clay-sand near the mock tank wall varied from 3 to $5.5 \mathrm{in}$. and had an average depth of $3.8 \pm$ 1.2 in.

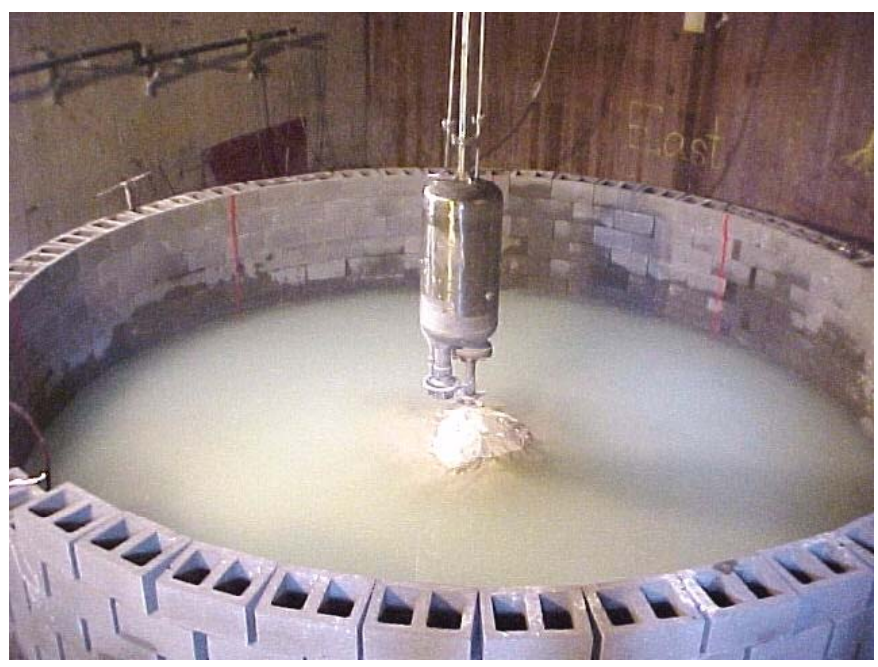

Fig. 28. View of clay-sand mound before mixing and filling of mock-tank.

The test was resumed the following day by refilling the test pit to the initial water level and continuing the operation of the PMP with the discharge nozzles $\sim 1$ in. off the floor of the mock tank. The system was operated for an additional $1.5 \mathrm{~h}$ before it was shut down and clay-sand displacement measurement taken. At the end of this operating period, the PMP had been operated for a total of $3 \mathrm{~h}$. The minimum effective cleaning radius at the end of the $3 \mathrm{~h}$ cumulative operating period was $94.1 \pm 1.9 \mathrm{in}$, which was within $0.5 \mathrm{in}$. of the value after $1.5 \mathrm{~h}$ but with significantly less variation. The amount of clay-sand near the mock tank wall varied from 4 to $6 \mathrm{in}$. and had an average depth of $5.2 \pm 1 \mathrm{in}$. This clay-sand depth indicates that essentially all the sludge surrogate had been displaced to the outside wall of the tank during the test. Fig. 29 shows views of the mock tank after mixing.

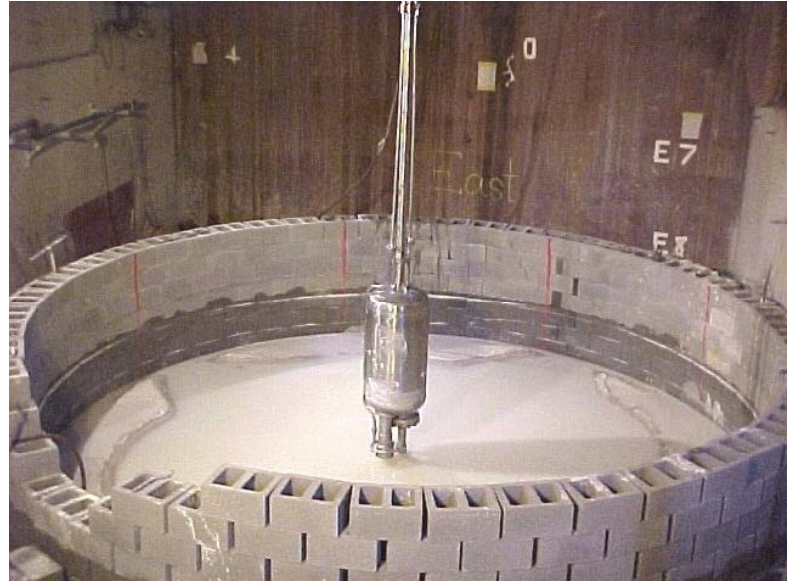

After $1.5 \mathrm{~h}$

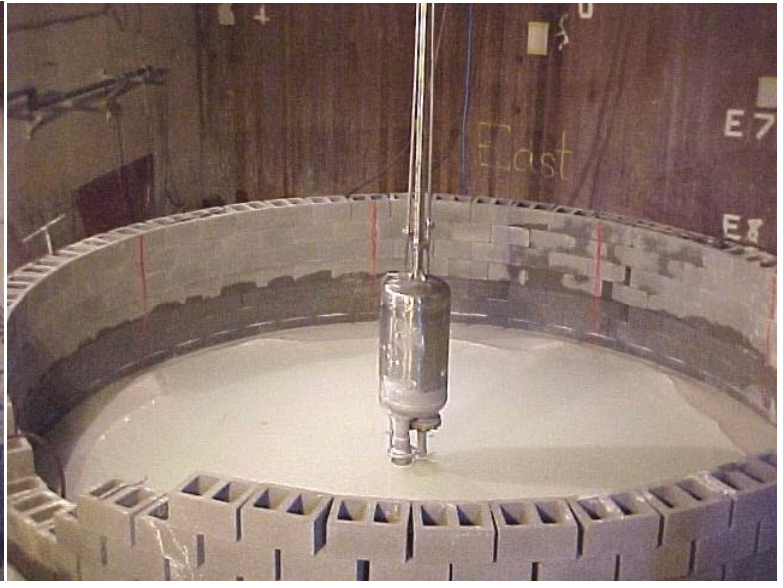

After $3 \mathrm{~h}$

Fig. 29. View of mock-tank after mixing a single in-line clay-sand mound. 
A second test was conducted using the same materials as in the initial test. The fully hydrated clay-sand mixture was collected in the center of the mock tank to form a mound $\sim 7 \mathrm{ft}$ in diam at the base and $\sim 5.5$ in. tall. Although the same material was used in this test as was used in the first test, the volume of material was significantly reduced as a result of hydration and losses through the joints in the walls of the mock tank. About $42 \%$ of the initial clay-sand volume was available for the second displacement test. The operating conditions for this test were as follows:

$\begin{array}{ll}\text { Water depth } & \sim 16 \mathrm{in} . \\ \text { Discharge header pressure } & \sim 100 \mathrm{psig} \text { feed to AD } \\ \text { Eductor header pressure } & \sim 40 \mathrm{psig} \\ \text { Cycle frequency } & \sim 1.8 / \mathrm{min} \\ \quad \text { Refill cycle time } & \sim 25.3 \mathrm{~s} \\ \quad \text { Discharge cycle time } & \sim 7.9 \mathrm{~s} \\ \text { Rotation angle } & 90 \text { degree } \\ \text { Mode of operation } & \text { Automatic } \\ \text { Control system } & \text { New }\end{array}$

This test was conducted during a 3 -h cumulative operating period consisting of a $1-\mathrm{h}$ period followed by a 2-h period. At the end of the initial 1-h operating period, the pit was drained and measurements taken that indicated a minimum effective cleaning radius of $90.1 \pm 5.0 \mathrm{in}$. The depth of clay-sand near the mock tank wall varied from 3 to $6 \mathrm{in}$. and had an average depth of $3.9 \pm 1.1 \mathrm{in}$. The test pit was refilled with water and the test continued for an additional 2-h period. The minimum effective cleaning radius at the end of the 3 -h cumulative operating period was $86.0 \pm 3.4$ in., which is statistically similar to the value observed after $1 \mathrm{~h}$ of operation. The depth of clay-sand near the mock tank wall varied from 3 to 5 in. and had an average depth of $3.3 \pm 0.7 \mathrm{in}$.

\subsubsection{Summary of Sludge Surrogate Cleaning Radius Test Results}

Operating conditions used in each test were similar with only minor variations in supply pressure and cycle frequency. The sludge surrogates used consisted of various quantities of sand, gravel, and kaolin clay in water. Table 4 lists the name of the test, minimum cleaning radius, types of surrogates used in each test, approximate quantity of surrogate used, and the section of the report that gives additional information. 
Table 4. Summary of cleaning radius test results

\begin{tabular}{|c|c|c|c|c|}
\hline Name & $\begin{array}{l}\text { Section } \\
\text { number }\end{array}$ & $\begin{array}{l}\text { Cleaning } \\
\text { radius (in.) }\end{array}$ & $\begin{array}{l}\text { Description } \\
\text { of } \\
\text { surrogate }\end{array}$ & Quantity of surrogate \\
\hline $\begin{array}{l}\text { Baseline cleaning radius - } \\
\text { 16-mm nozzle }\end{array}$ & 6.3 .4 .1 & $65.8 \pm 1.2$ & Sand & 2-in depth on bottom of mock tank \\
\hline $\begin{array}{l}\text { Baseline cleaning radius - } \\
10-\mathrm{mm} \text { nozzle }\end{array}$ & 6.3.4.2 & $64^{a}$ & Sand & 2-in depth on bottom of mock tank \\
\hline Sand mound displacement & 6.3.5.1 & 67 & Sand & $\begin{array}{l}2 \text { mounds } \sim 8 \mathrm{ft} \text { from centerline of mock } \\
\text { tank }\end{array}$ \\
\hline Sand mound displacement & 6.3.5.1 & 75.5 & Sand & $\begin{array}{l}2 \text { mounds } \sim 2.5 \mathrm{ft} \text { from centerline of mock } \\
\text { tank }\end{array}$ \\
\hline Gravel displacement & 6.3.5.3 & $95.4 \pm 8.2$ & $\begin{array}{l}\text { Sand } \\
\text { Gravel }\end{array}$ & $\begin{array}{l}\text { 2-in depth of sand on bottom of mock } \\
\text { tank } \\
210 \text {-gal mounds of gravel } \sim 2.5 \mathrm{ft} \text { from } \\
\text { center of mock tank }\end{array}$ \\
\hline $\begin{array}{l}\text { Dual clay-sand mound } \\
\text { displacement }\end{array}$ & 6.3.5.4 & $87.6 \pm 4.1$ & $\begin{array}{l}\text { Sand } \\
\text { Gravel } \\
\text { Clay }\end{array}$ & $\begin{array}{l}\text { I 500 lb sand on bottom of mock tank } \\
\text { Incidental amounts of gravel from } \\
\text { previous tests } \\
2400 \text {-lb mounds of clay } \sim 3 \text { to } 4 \mathrm{ft} \text { from } \\
\text { center of mock tank }\end{array}$ \\
\hline $\begin{array}{l}\text { In-line clay-sand mound } \\
\text { displacement }\end{array}$ & 6.3.5.5 & $\begin{array}{l}95.6 \pm 7.5^{b} \\
94.1 \pm 1.9^{c}\end{array}$ & $\begin{array}{l}\text { Sand } \\
\text { Gravel } \\
\text { Clay }\end{array}$ & $\begin{array}{l}7500 \mathrm{lb} \text { sand on bottom of mock tank } \\
\text { from previous test } \\
\text { Incidental amounts of gravel from } \\
\text { previous tests } \\
2,450 \mathrm{lb} \text { clay in mound in center of mock } \\
\text { tank }\end{array}$ \\
\hline $\begin{array}{l}\text { In-line clay-sand mound } \\
\text { displacement }\end{array}$ & 6.3.5.5 & $\begin{array}{l}90.1 \pm 5.0^{b} \\
86 \pm 3.4^{c}\end{array}$ & $\begin{array}{l}\text { Sand } \\
\text { Gravel } \\
\text { Clay }\end{array}$ & $\begin{array}{l}\sim 500 \mathrm{lb} \text { sand on bottom of mock tank } \\
\text { from previous test } \\
\text { Incidental amounts of gravel from } \\
\text { previous tests } \\
\sim 42 \% \text { of clay used in previous test }\end{array}$ \\
\hline
\end{tabular}

${ }^{a}$ Only two measurements were recorded

${ }^{b}$ First operating period

${ }^{c}$ Second operating period

\subsubsection{Concentration Profile During Mixing Test}

A test was conducted to assess the variation in solids concentration with time during mixing. This test was conducted using the available sand and clay from the previous tests, which included $\sim 2,450 \mathrm{lb}$ kaolin clay and $\sim 500 \mathrm{lb}$ of sand. A small quantity of gravel was mixed with the sand from previous testing. Because of safety concerns, personnel were not allowed inside the test pit during operation of the PMP. To sample the slurry during operation, a long-pole sampling tool (Fig. 30) was constructed to allow remote sampling of the slurry in the mock tank. The sampling tool consisted of four sample vials attached to the end of a $\sim 25$-ft-long, 1-in-diam metal pole as shown in Fig. 30. The sampler was lowered into the mock tank through an opening in the top of the test pit. Samples were taken during operation of the PMP by simultaneously pulling stoppers from the sample vials using the attached steel cables. After 
the four sample vials were filled, the sampling tool was removed from the tank, caps placed on the vials, the vials removed from their holders, and the samples analyzed to determine the solids content. Each sample vial contained an average of $\sim 52 \mathrm{~mL}$ of slurry.

Samples were taken every $\sim 15 \mathrm{~min}$ of operation during the first $2 \mathrm{~h}$ of mixing and then about every 30 min for the remainder of the $\sim 6$-h test. The samples were taken at elevations of $\sim 4.5,14.5,24.5$, and 34.5 in. above the floor in the east quadrant of the mock tank. The operating conditions for this test were as follows:

$\begin{array}{ll}\text { Water depth } & \sim 36 \mathrm{in} . \\ \text { Discharge header pressure } & \sim 100 \mathrm{psig} \text { feed to AD } \\ \text { Eductor header pressure } & \sim 38 \mathrm{psig} \\ \text { Cycle frequency } & \sim 2.1 / \mathrm{min} \\ \quad \text { Refill cycle time } & \sim 20.2 \mathrm{~s} \\ \quad \text { Discharge cycle time } & \sim 7.9 \mathrm{~s} \\ \text { Rotation angle } & 90 \text { degree } \\ \text { Mode of operation } & \text { Automatic } \\ \text { Control system } & \text { New }\end{array}$

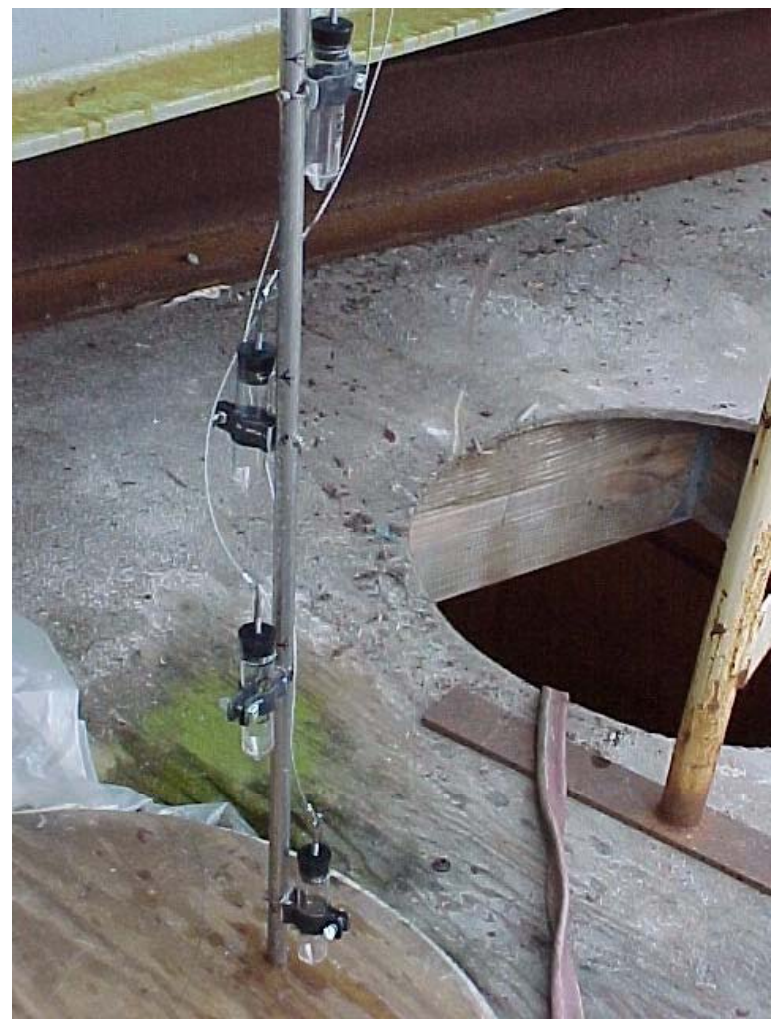

Fig. 30. End of long-pole sampling tool, showing sample collection vials.

The raw data from this test are shown in Fig. 31. Although a significant amount of scatter occurs in the data, the data show that the solids concentration is generally highest during the first 30 to 90 min of mixing and tends to decrease with longer mixing periods. This assertion is consistent with the observed 
operation of the PMP during the displacement tests where the surrogate sludges were pushed away from the center of the tank and tended to settle and accumulate near the mock tank walls. Because of the scatter in the data, little can be determined about the variation of solids content relative to the distance from the floor of the tank.

\subsubsection{Concentration Profile During Pump Down Test}

This test was conducted to assess the variation in solids concentration during pump down of the test pit and to determine the amount of material that may remain in a tank at the end of a transfer operation. The mock tank was lined with plastic sheeting prior to the start of this test to minimize the loss of waste simulant through gaps between the cinder block walls of the tank. A significant portion of the sand-clay surrogate had transferred through the mock tank walls during previous tests. The majority of the clay and a small portion of the sand outside the mock tank walls was collected and returned to the mock tank for this test. An air accumulator tank was also added to provide additional air capacity during discharge and refill cycles for the PMP. Two air diaphragm pumps were used to retrieve the slurry mixture from the mock tank. Each pump had a capacity of $\sim 100$ gpm; however, because of air supply limitations, the pumps were only operated at $\sim 25 \%$ of capacity. The pump intake was through a 2 -in.-diam flexible hose attached to a 6-in.-diam, 6-in.-tall screened inlet head. The inlet head prevented particles $>0.5$ in. in diam from entering the pump. During the test, the pump was operated with a suction lift of $\sim 6 \mathrm{ft}$ and a discharge head of $\sim 12 \mathrm{ft}$.

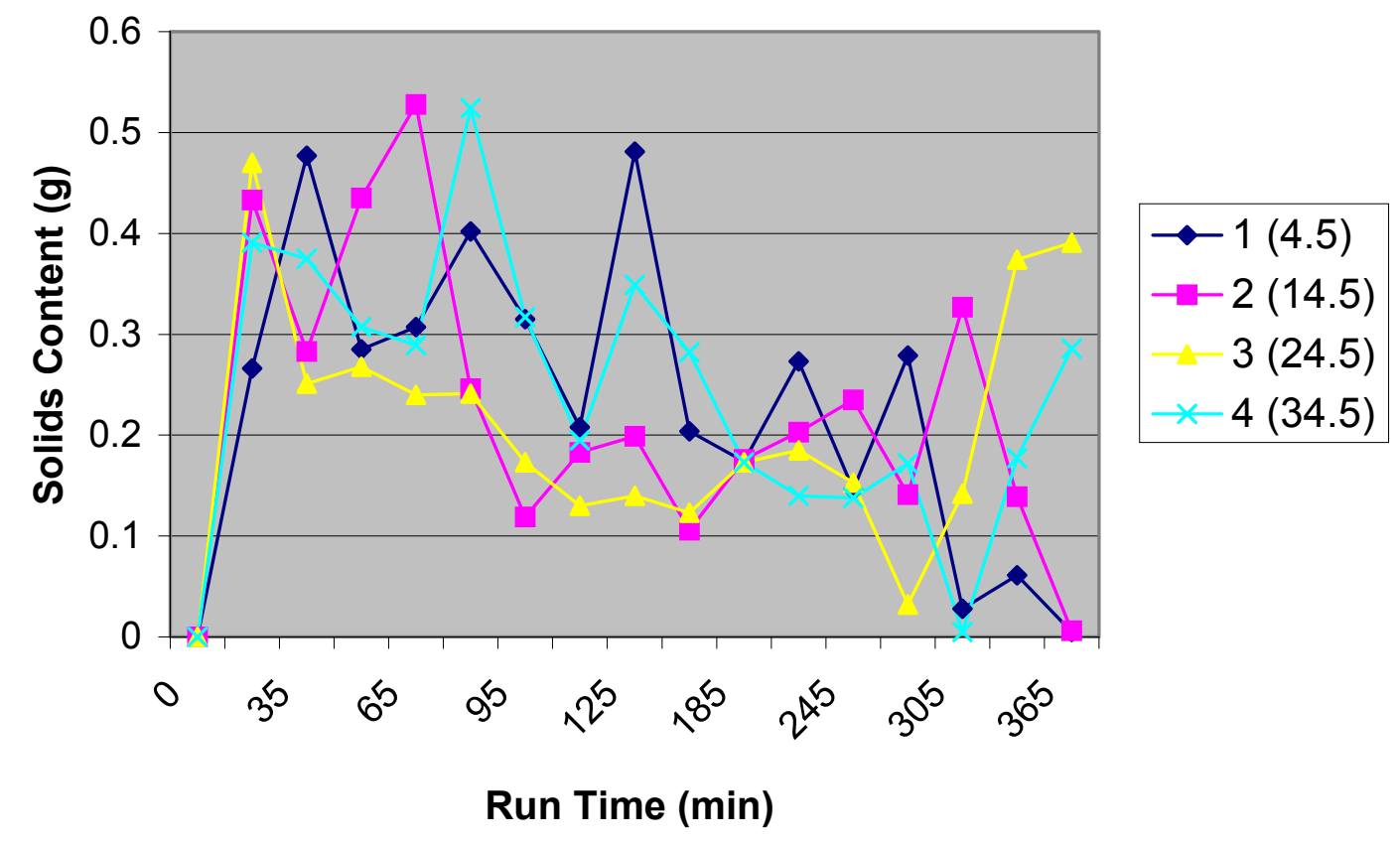

Fig. 31. Raw sample data from mixing test on August 15, 2000 where curve 1 is for the sample position nearest the floor of the mock tank, and curve 4 is for the sample position farthest from the floor (numbers in parentheses indicate height from floor of mock tank).

Based on the water level in the mock tank, the initial volume of material present for this test was $\sim 6,170$ gal. The total solids content in the waste surrogate slurry was estimated at 3,072 lb, which was determined by initially confining the concentrated waste surrogate to an $\sim 8 \times 10 \mathrm{ft}$ area, mixing the slurry, sampling and analyzing for solids content. The surrogate was uniformly distributed across the floor of the 
test tank and the PMP was positioned with the discharge nozzles $\sim 1$ in. off the floor of the tank. The operating conditions for this test were as follows:

$\begin{array}{ll}\text { Water depth } & \sim 31.5 \text { in. } \\ \text { Discharge header pressure } & \sim 90 \text { psig feed to AD } \\ \text { Eductor header pressure } & \sim 37 \text { psig } \\ \text { Cycle frequency } & \sim 2.1 \text { to } 1.5 / \mathrm{min} \\ \quad \text { Refill cycle time } & \sim 22.7 \text { to } 34.5 \mathrm{~s} \\ \quad \text { Discharge cycle time } & \sim 6.4 \mathrm{~s} \\ \text { Rotation angle } & 90 \text { degree } \\ \text { Mode of operation } & \text { Automatic } \\ \text { Control system } & \text { New }\end{array}$

A baseline set of samples was taken just before the start of the pump down test using the sampling tool shown in Fig. 30. The pump down rate was such that the test was completed after $\sim 3 \mathrm{~h}$ of operation when all the pumpable material was removed from the mock tank. The test was interrupted twice. The first interruption that occurred $\sim 1 \mathrm{~h}$ after the start of the test was caused by the failure of the integral position sensor on the Bimba pneumatic cylinder, which is used to control the rotational movement of the PMP. The test was restarted four days later after installation of a new pneumatic cylinder with an improved position sensor. A second interruption occurred $\sim 30$ min after restarting the test when a screw on the Trombetta solenoid mechanism become loose and caused erratic behavior of the unit. This problem was quickly diagnosed and corrected, and the test was completed without any further interruptions.

These interruptions undoubtedly had some impact on the test results because while the system was shut down for repairs, the more dense solid material would have had time to settle near the mock tank's inner wall. No determination could be made concerning remixing of any previously settled material at or near the mock tank wall. Based on the observations from previous tests using sand, it is unlikely that any of the sand material that may have settled at this region would be resuspended under the operating conditions specified for this test. However, the clay material was more likely to be easily mobilized and was observed to be the primary constituent of the solids concentrations represented in Fig. 32.

Furthermore, at the end of the test, only a small volume of sludge simulant remained in the mock tank. Fig. 32 shows the volume percent of solids in suspension during pump down of the contents of the mock tank for four sample elevations from the bottom of the mock tank. As the slurry level in the mock tank decreases, the upper sample points become exposed and result in zero sample collections. Although the upper sample point was positioned above the nominal fluid level in the mock tank, the turbulence and resulting waves produced by the PMP were sufficient to allow the collection of samples during the initial 30 min of the pump down test. 


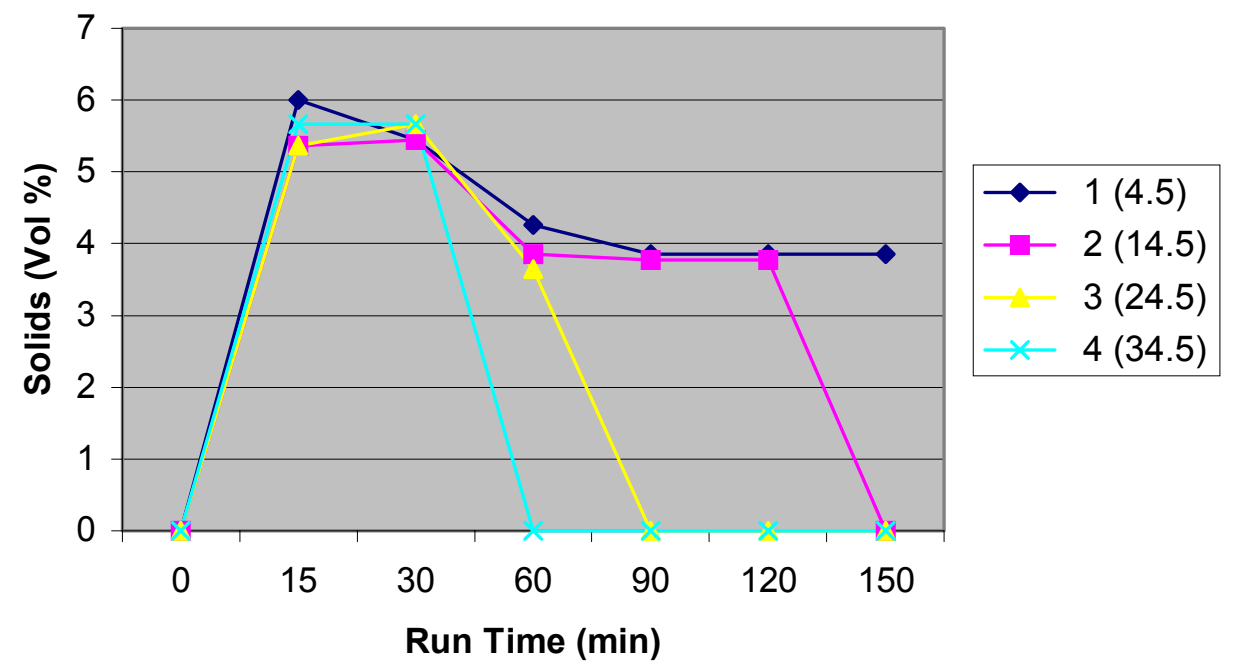

Fig. 32. Solids mixing profile during simulant retrieval where curve 1 is for the sample position nearest the floor of the mock tank, and curve 4 is for the sample position farthest from the floor (numbers in parentheses indicate height from floor of mock tank)

As expected, the fill time increased as the mock tank was depleted of material, which resulted in a decrease in head pressure from the fluid surrounding the PMP. The fill time was observed to vary from $\sim 22.7$ to $34.5 \mathrm{~s}$ and is shown in Fig. 33. The discharge time remained reasonably constant throughout the test at $6.43 \pm 0.31 \mathrm{~s}$. The variation in fill time resulted in a decrease in the discharge/refill frequency from $\sim 2.1$ to $\sim 1.5$ cycles per minute from the beginning to the end of the test, respectively.

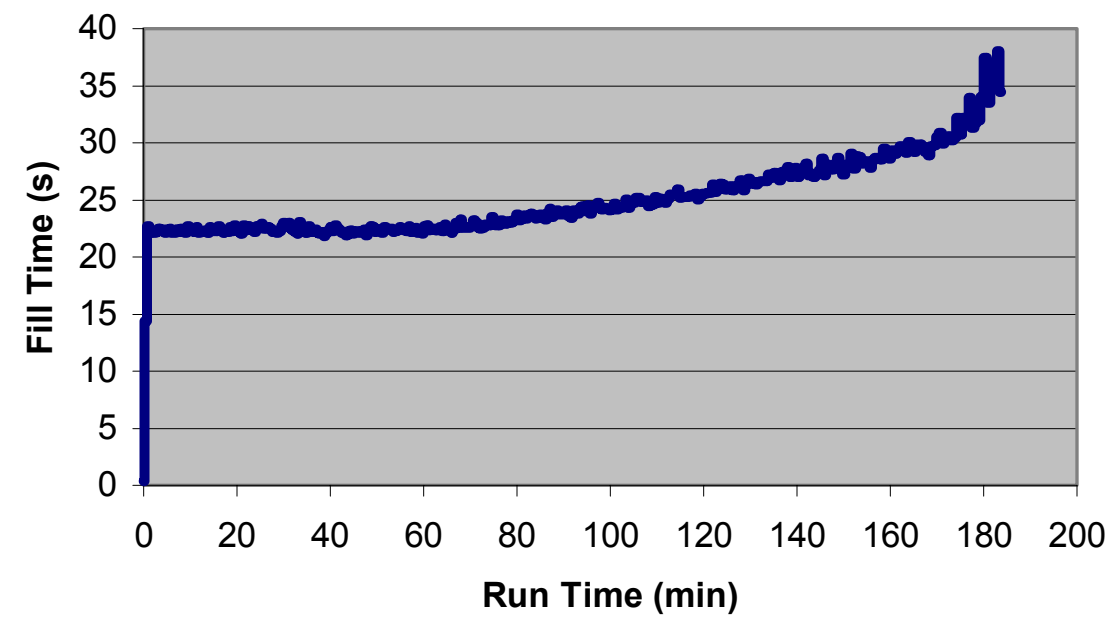

Fig. 33. Variation of fill time with run time for the PMP pump down test. 
Based on the relatively steady solids concentration values for the latter half of the test, it appears that the mixing performance remained adequate throughout the pump-down test. This observation implies that waste tanks can be pumped down to very low levels with little degradation in mixing performance using the PMP. For the cold test it was possible to pump down the mock tank inventory to within $\sim 6$ in. of the tank floor.

The flow rate from the dual air diaphragm pumps ranged from $\sim 39$ to $59 \mathrm{gal} / \mathrm{min}$. The flow rate variation is thought to be a result of the limited ability of the plant air supply system to deliver a constant pressure and volume of air to the two air diaphragm pumps and the PMP system. At the end of the pump-down, the remaining quantity of solids in the mock tank ranged from 0.375 to $0.50 \mathrm{in}$. in depth in the area of the tank away from the walls and was essentially composed entirely of kaolin clay. A small volume of sand and kaolin clay was observed close to the wall of the mock tank. 


\section{CONCLUSIONS AND RECOMMENDATIONS}

Cold testing of the Russian PMP system showed that the system was capable of performing as required. As a result of the cold testing, a variety of modifications were made to improve performance and simplify operations.

\subsection{CONCLUSIONS}

Based on the results of the cold testing, the following conclusions were made:

1. The observations from cold testing the Russian PMP system indicate that the PMP should be successful in mixing materials with characteristics similar to sand, kaolin clay, and gravel at moderate operating pressures in a 20 -ft-diam tank similar to the GAAT TH-4. The PMP was successfully operated for several hours in the presence of both floating and submerged debris and various waste surrogates.

2. The joint collaboration between the U.S. DOE and the Russian Mining and Chemical Combine of Zheleznogorsk is a excellent example of a successful international collaboration. This collaboration resulted in the development of a solution to an ORNL tank waste retrieval problem using an integrated team of U.S. and Russian scientists and engineers.

3. The Russian fabricated PMP exhibited good mixing and mobilization characteristics for the surrogate waste materials tested at the ORNL TTCTF. The minimum cleaning radius for the PMP varied from $\sim 5.5 \mathrm{ft}$ to $\sim 8 \mathrm{ft}$, depending on the operating conditions.

4. Three PMP units were designed and fabricated to Russian standards and were then evaluated against U.S. standards upon arrival at ORNL. The decision to proceed in this manner was made after the initial efforts to cross-map and compare U.S. and Russian fabrication standards proved to be beyond the scope and resources of the project.

5. Each PMP was inspected to U.S. standards and, in most cases, met those standards. However, in some cases, discrepancies existed, which necessitated modification of the PMP. Specifically, weld repairs were required on the PVs of units 2 and 3 to meet ASME B\&PV standards. The Russian and the U.S. fabrication standards for welding are similar. However, because the design specifications required only $25 \%$ radiographic inspection and because of the differences in radiographic film density requirements, the flaws on units 2 and 3 were not detected.

6. The functionality of the PMP was considered good. The design takes into consideration the simplicity and ease of maintenance for application in radioactive and chemically harsh environments. With the majority of the moving parts and seals above ground level, the PMP should be able to work efficiently over a long periods of time.

7. The jointly designed CS required MCC to develop the automation software and to assemble the automation hardware provided by the United States. The MCC does not provide a highly automated CS for its own PMP applications. As a result, the development and construction of the CS may have been more successful if the fabrication effort had required on-site support from the U.S. team. Unfortunately, because of vendor shipment delays, MCC had only $\sim 4$ weeks to develop, test, and debug the CS. This was insufficient time to completely debug the system before shipment to the United States.

8. The as-received CS design ultimately did not meet the U.S. design requirements. The ORNL team identified the critical weaknesses in the CS design and made the appropriate modifications and additions to allow stable operation of the system.

9. The TRI functionality and performance met the design requirements after modifications to correct minor deficiencies. During shipment to ORNL, the unit was damaged (broken 
Plexiglas panels) and experienced structural problems (loose bolts). Upon receipt, modifications were made to replace Plexiglas panels with metal sheeting; bolts were retightened, the electrical wiring of the unit was completed, and all incompatible components were replaced. The TRI enclosure incorporated simple design and construction techniques and was intended to perform multiple tasks, one of which included service as a lift fixture for the combined PMP and TRI. Prior to performing the lift tests, modifications were made to improve the lifting stability of the system. After repairs and modifications were completed, the unit performed well during all phases of testing.

10. The DSR met all design requirements and performed as specified. However, one concern is that the design incorporates two different operating pressure ranges (low pressure: $<500 \mathrm{psi}$ and high pressure: $2,000 \mathrm{psi}$ ) using different nozzle ratings. It is important that (1) lower pressure rated nozzles and equipment are readily identifiable, (2) staff are adequately trained to recognize the different components, and (3) administrative controls are in place to ensure that over pressurization of the lower pressure rated components does not occur.

11. The TC was designed to support the deployment/retrieval of the PMP system and allow the installation and removal of the system using only one overhead crane. The TC was also designed to serve as a maintenance and storage device. As a result of potential stability issues during cold testing, the decision was made to not use the TC in future operations.

12. The inspections and functionality tests conducted on the system helped to identify design strengths and weaknesses of the various components of the system. A variety of modifications and changes were made to the individual systems to ensure proper operation.

13. The performance tests provided a good understanding of the PMP system capabilities; however, due to time constraints and support system limitations, some tests could not be performed (i.e., PMP pressures $>100$ psi). For example PMP units 2 and 3 have undergone only hydrostatic pressure testing. Further testing of these units is needed to evaluate design improvements made on the later units.

\subsection{RECOMMENDATIONS}

Based on the conclusions and observations from this work the following recommendations are made:

1. Additional multinational participation during design and testing efforts should be included in future collaborations. Collateral support from each participating country should be provided to improve the overall quality and acceptance of the design.

2. PMP units 2 and/or 3 should be tested to the maximum allowable working pressure of $230 \mathrm{psi}$ to assess any performance improvements at these pressures and to evaluate the applicability of this technology in larger diameter tank applications.

3. Additional testing and evaluation of the ORNL-designed CS is needed to further simplify and refine the CS design.

4. Additional simulant mixing and retrieval tests should be performed to determine the mixing efficiency and retrieval rates using different simulants and operating conditions.

5. If a TC is used in future applications, more attention is needed in the design of guide systems and methods for locking and unlocking of the PMP in the TC. 


\section{REFERENCES}

${ }^{I}$ B. Hatchell, B. Lewis, J. Randolph, and M. Johnson, Russian Pulsating Mixer Pump Deployment in the Gunite and Associated Tanks at ORNL, Battelle Memorial Institute, Pacific Northwest National Laboratory, PNNL-SA-34056, March 2001, Richland, WA.

${ }^{2}$ Oak Ridge National Laboratory, Functions and Requirements for Russian Pulsating Mixer Pump Deployment in the Gunite and Associated Tanks at Oak Ridge National Laboratory, ORNL/X-OE-820, October 1999, Lockheed Martin Energy Research Corp., Oak Ridge National Laboratory, Oak Ridge, TN. 


\section{APPENDIX A. NONCONFORMANCE REPORTS}

As a result of various inspections and observations a series of Nonconformance Reports (NCRs) were issued in accordance with the Robotics and Process Systems Division (RPSD) Quality Assurance Program. The following provides a listing and brief summary of each of those NCRs and their resolution.

NCR-X00-RPS-PMP-001

NCR-X00-RPS-PMP-002

NCR-X00-RPS-PMP-003

NCR-X00-RPS-PMP-005

NCR-X00-RPS-PMP-006
Lack of fusion weld on the longitudinal weld segment of the PMP unit $2 \mathrm{PV}$. This NCR was produced for the purpose of rejection of the noted item and to direct it to the vendor for repair and post weld inspection. Since issuance of the NCR, the vendor has repaired and inspected the defective area, and the item has been received and accepted at ORNL.

Lack of fusion weld on the bottom girth weld segment of the PMP unit $3 \mathrm{PV}$. This NCR was produced for the purpose of rejection of the noted item and to direct it to the vendor for repair and post weld inspection. Since issuance of the NCR, the vendor has repaired and inspected the defective area, and the item has been received and accepted at ORNL.

Rejection of the ARES-supplied radiographic film of the PMP units PVs. Most of the film did not meet ASME standards requirement for film density. The U.S. standard for film density is 1.8 to 4.0. The majority of the film density measured on an ASME-qualified film reader either was below the 1.8 or above the 4.0. No action was required on the part of ARES, the PMP fabrication subcontractor.

Failure of TRI drive table 0.5 in by 13 Unified National Coarse (UNC) by 2 in. length studs. Three of the 16 studs broke. The studs were under minimal stress (projected to be $<10 \mathrm{ft}-\mathrm{lb}$ ) at the time of failure. The suggested cause of failure was that the studs failed at their weakest point (i.e., the recessed area where the bolt thickness is $\sim 0.0625$ in.) because of temperature variations. PMP unit 1 was installed at the TTCTF on a cold day in winter when the temperature was $\sim 15-20^{\circ} \mathrm{F}$. The PMP was placed on the TRI support table, and the nuts were basically hand tightened on the studs.

RPSD replaced all sixteen studs with Type FS F593-C, 316 stainless steel, 13 UNC by 0.5 in. by 2 -in. hex head bolts. Since replacement, no failures have been noted or reported.

Failure of the TRI Plexiglas ${ }^{\mathrm{TM}}$ panels. The original Plexiglas panels on the TRI were buckled, warped, and cracked, allowing the entrance of water and dust into the TRI. The panels were subsequently removed and replace with aluminum sheet metal. This change out occurred at ORNL with concurrence from Battelle. The system now provides the necessary protection from dust and water. 
NCR-X00-RPS-PMP-007

NCR-X00-RPS-PMP-008

NCR-X00-RPS-PMP-010 or 011

NCR-X00-RPS-PMP-013
Rejection of the TRI lift points by the ORNL hoisting and rigging (H\&R) committee. The ORNL H\&R committee determined that the TRI posed a risk for lifting the unit from the designated lift points. The remedial action was to relocate the lift points to the TRI support table. With concurrence from Battelle, ORNL removed the existing lift eyes and relocated the lift points to the TRI support table. A total of four lift eyes were installed on the table versus the two from the original design. The concern was based on the total weight of the assembly during a lift and the concentration of that load on four small bolts ( 1/8 in. diam), which were designed to hold the frame together. The change was recommended and approved by the ORNL H\&R committee and an ORNL structural engineer.

The vendor supplied wiring diagram for the TRI Drive/support system was rejected because it was simply an off-the-shelf diagram of the supplied motor control device, wiring of the drive components was incomplete, and incompatible hardware were provided with the assembly. ORNL replaced all incompatible components, completed the necessary wiring of the TRI Drive/support system, and, produced a new and accurate wiring diagram.

PMP CS wiring diagram deficiencies and incompatible CS hardwire. ORNL staff corrected the wiring diagrams after review of the provided diagrams and evaluation of the wiring scheme at the hardware end.

The design of the CS had a basic flaw because of a load mismatch between the FP modules and the electrically actuated valves. The load requirement to actuate a valve was almost double the load capacity of the FP module. Two of the FP modules failed during the start-up checkout evaluation. The failures were specific channels because of the mismatch in amperage load capabilities of the valve and the modules. A set of relays was installed between the FP modules and the valves to correct the problem.

PMP unit 1 experienced failure of a few of the lock washers used to connect the piping components of the PMP to the air distributor and the pressure vessel. The lock washers were evaluated by the ORNL QE\&I department and determined to be nearest 440C stainless steel with a high zinc content. Upon visual examination of the failed washers, the metal had the appearance of pot metal. No effort was made to conduct a more thorough determination due to time and funding constraints.

Remedial action resulted in replacement of all of the original bolts and lock washers with ASME-certified bolts and lock washers made of 316 stainless steel that were supplied by ARES. These items are qualified for use with pressure systems that are equivalent or greater than the PMP maximum allowable working pressure. 
The TRI was not qualified as a lift fixture as supplied by the vendor. A concern that the TRI was not qualified in the design and fabrication stages resulted in evaluation of the fixture for that purpose by the ORNL H\&R committee. The committee expressed concern for the structural integrity of the equipment for its intended purpose, especially because of the ease of which the bolts on the TRI became loose during shipment. See also, the concern noted about the selected lift points.

The remedial action required evaluation by Battelle engineers, the ORNL structural engineer, and the ORNL H\&R committee. The results of the effort led to the following action:
a. relocate the lift points and
b. retighten every bolt on the TRI frame.

NCR-X00-RPS-PMP-017

This NCR was issued because the transport cradle provided by Battelle did not provide lubrication to the hinge pins, and corrosion developed at this area. The TC hinges did not have means by which lubrication could be applied. The remedial action was to equip the hinges with grease fittings, clean all of the corroded areas, and apply grease to the pins and the hinges. 


\section{APPENDIX B. SUMMARY OF PROPOSED TECHNICAL APPROACH FOR ACCEPTANCE OF RUSSIAN MANUFACTURED PULSATING MIXER PUMP}

\section{INTRODUCTION}

The U.S. Department of Energy (DOE), through the Federal Energy Technology Center (FETC) and EM50 Tanks Focus Area, has selected the pulsating mixer pump (PMP) as a promising Russian technology with potential application at sites within the DOE complex. A contract has been awarded by FETC for fabrication of three PMP units, and DOE has selected the ORNL Gunite and Associated Tanks (GAAT) as the preferred location for a hot demonstration and initial deployment for testing and evaluation under field conditions.

During the design review process, identification of and compliance with appropriate standards for the fabricated components of the PMP system has become an issue. The ORNL WSS for engineering design applicable to industrial, radiological, and nonreactor nuclear facilities is the governing document identifying required codes and standards for the GAAT project. Because detail design and fabrication of the PMPs is occurring in a Russian facility that does not work to U.S. standards, strict compliance with the letter of the existing WSS is not feasible. As an alternative, it is proposed the equipment be fabricated to the appropriate existing Russian standards, with steps taken to ensure that the technical intent of U.S. standards is met. The standards of concern from the existing ORNL WSS set are ASME B31.3, Process Piping, and the ASME Boiler and Pressure Vessel Code (B\&PV). The B\&PV code and other U.S. standards are invoked by reference in ASME B31.3. Specifically, the issue is limited to the pressure boundary of the Russian-supplied equipment, which includes a pressure vessel and piping. For discussion, the items of concern can be grouped into process piping, welding, and pressure vessel. The process piping will not fully comply with B31.3 materials specifications, dimensional requirements, and requirements for examination, inspection, and testing. Welding of the piping and vessel will not fully comply with B31.3 or the B\&PV code requirements for welding procedure qualification, welder and weld examination personnel qualifications, welding materials, and documentation. Preparation, weld repair, and nondestructive testing may vary from the prescribed U.S. methods. The PV will not fully comply with B\&PV code requirements for materials, fabrication, inspection and tests, and markings and reports.

The PMP uses compressed air as the motive force to draw tank supernatant into a charge vessel and then evacuate the vessel through nozzles located near the tank floor. The PMP includes the charge vessel, eductor, and associated piping and equipment that will be located inside the gunite tank and is shown in Fig. B.1. A relatively short section of the PMP piping will extend through the tank riser to interface with the ORNL site equipment. The piping external to the tank will contain only compressed air and clean water for equipment flushing.

The PMP is being supplied by ARES Corporation under contract to FETC. A tank riser interface (TRI) component is being designed and manufactured in the United States by Battelle, Inc. under subcontract. The TRI provides the structural support interface for the PMP to ORNL's platform, includes a decontamination spray component for equipment removal, and will serve as a weather cover and personnel barrier during operation. The Russian-supplied equipment also includes valves for operating the system, instrumentation, and control hardware and software. The PMP will be shipped with installation, operating, and maintenance instructions translated into English. The valves, control software, control computer, and majority of the instrumentation are being purchased from commercial vendors manufacturing to U.S. standards. The EM-50 contractor will provide a recommended spare parts list and the appropriate spare parts with the PMP. 


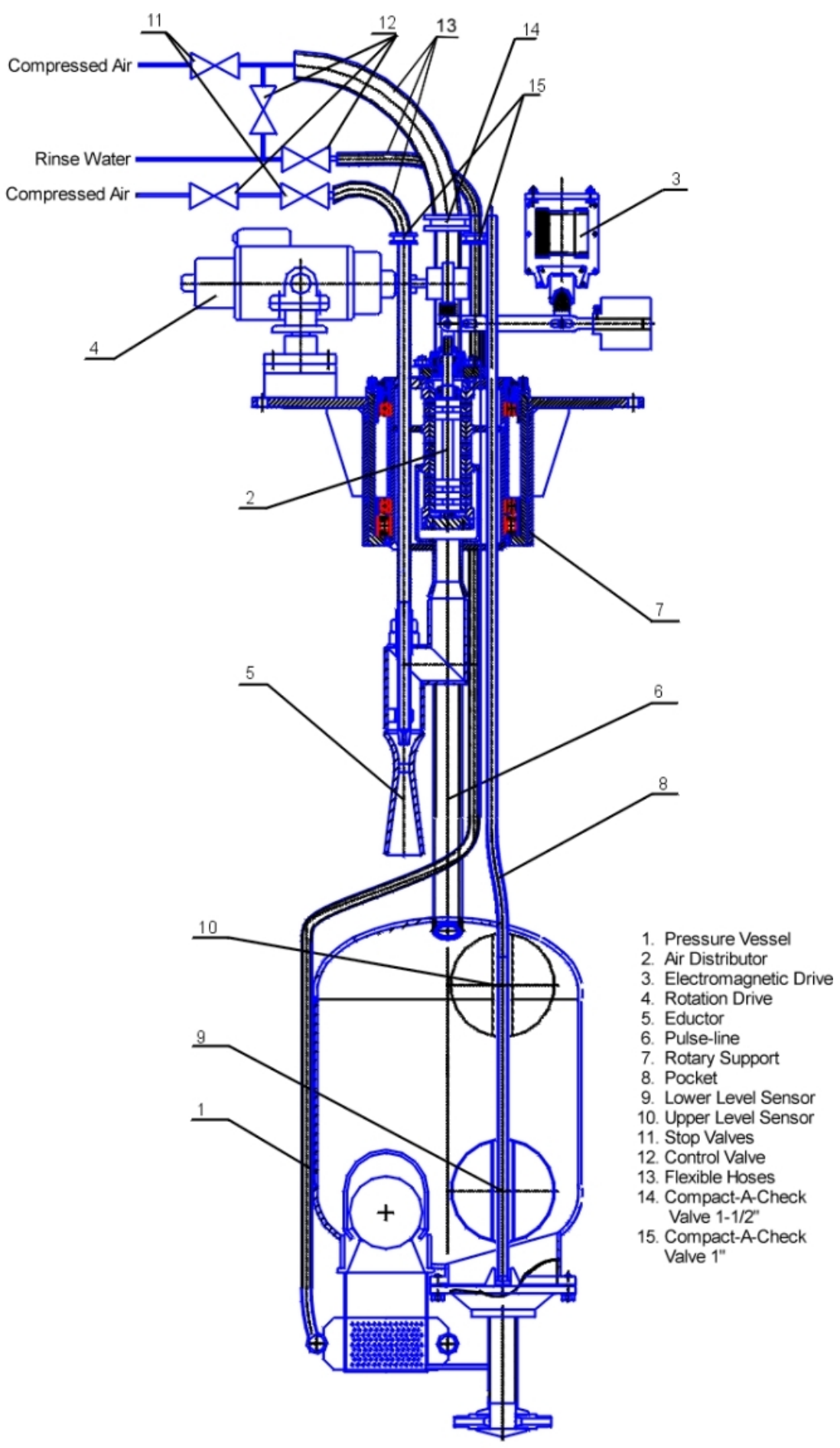

Fig. B.1. Russian PMP.

The PMP equipment is an adaptation of an existing Russian design in use for a similar radiochemical waste application in Russia. The PMP is being designed and fabricated by the Russian Federation Ministry for Atomic Energy Mining and Chemical Combine in Zheleznogorsk, which has extensive experience providing equipment for radiochemical service while working to the applicable Russian codes and standards. The Russian codes and standards being used in the fabrication process are generally based 
on ISO 9000 standards. A table developed by Bechtel Jacobs Co. for another activity lists the requirements of 10CFR830 and the corresponding ISO 9000 section for each requirement. This table was provided to the equipment vendor, who has identified the Russian standard(s) that implement each of the applicable ISO 9000 requirements. Although a detailed "crosswalk" of the adequacy of the Russian standards to each of the 10CFR830.120 requirements is outside of the scope of the current effort, it is apparent that Russian standards are in place, which address the 10CFR830 components. The table relating 10CFR830 requirements to ISO 9000 to the implementing Russian standards will be available as part of the manufacturer's data package for the PMP.

Additional equipment required for operation of the PMP, including tank-level instrumentation, waste removal and transfer pump and piping, tank off gas, and air compressor, will be designed and specified to applicable U.S. standards and is not addressed here. Appropriate safety documentation as required by DOE orders will address the complete system.

\section{PROCESS PIPING}

According to the ORNL WSS, fabrication of the piping in the PMP falls under chapters I through VI of ASME B31.3 as metallic piping for normal fluid service. For the Russian-fabricated piping, B31.3 listed specifications will not be fully satisfied for materials, dimensional requirements, and requirements for examination, inspection, and testing. The piping is designed for a pressure of $230 \mathrm{psi}(1.6 \mathrm{MPa})$, and will operate at ambient temperature. As noted earlier, the majority of the piping for the PMP is designed for nonradioactively contaminated compressed air; the next most common piping is for noncontaminated process water (for equipment flushing), and includes a short length of pipe and nozzles for low-level liquid waste service.

The piping used to manufacture the PMP will be seamless alloy steel, conforming to materials specifications defined in Russian standard GOST 9941, and flanges of rolled sheet steel, conforming to GOST 7350-77. Based on analytical data provided by the manufacturer, the alloy is comparable to, but not an exact match with, U.S. ASTM and ASME specifications for type 304 stainless steel. The chemical and mechanical properties of the materials to be used in fabrication are within the range of acceptable materials identified in B31.3. The Russian equivalent of a Certified Materials Test Report will be provided for all pipe and fittings used in fabricating the equipment.

All piping will be subject to pneumatic and/or hydrostatic testing by the fabricator prior to shipping. Additional hydrostatic testing of the system will be performed at ORNL prior to the initial operation or cold testing. In accordance with the requirements of ASME B31.3, all hydrostatic testing will be conducted at a pressure not less than $150 \%$ of the design pressure, and pneumatic testing will be performed at a pressure not less than $110 \%$ of the design pressure. Testing and inspections performed by the fabricator will not be by inspectors qualified per ASME. The ORNL tests will meet applicable ASME requirements.

With the exception of clean process water and compressed air connections extending approximately $5 \mathrm{ft}$ through the Gunite tank riser, all of the Russian-fabricated piping will be located inside the existing Gunite tank or tank riser during normal operation. The connections above the tank will be located within a TRI enclosure that provides a barrier for personnel during normal operation. Prior to deployment in the Gunite tanks, equipment integration and checkout, cold testing, and operator training will be performed at the ORNL Tanks Technology Cold Test Facility (TTCTF) located adjacent to Building 7601. During the cold tests, appropriate barriers and/or administrative controls will be used to restrict personnel from entering the test pit while the PMP is in operation. 


\section{WELDING}

B31.3 and Section IX of the B\&PV code currently govern piping and PV welding. For the Russianfabricated components, welding will not fully comply with B31.3 or the B\&PV code requirements for welding procedure qualification, welder and weld examination personnel qualifications, welding materials, and documentation. Preparation, weld repair, and nondestructive testing performed to the Russian standards and procedures may vary from the prescribed U.S. methods. In lieu of ASME certification, all aspects of pipe and vessel welding on the PMP are addressed by applicable Russian standards. The Russian welding program appears to be substantially equivalent to the U.S. program, but the procedures and personnel would have to be qualified to U.S. standards for full compliance. Elements of the two programs include those listed in Table B.1.

According to the Russian standards, immediately prior to performing the actual weld, the same welder will perform control (test) welds under identical conditions to the actual weld. Test welds will be subject to destructive testing as specified in the applicable Russian standards. As a part of fabrication, $100 \%$ visual and hydrostatic testing of welded joints will be performed and documented. Additionally, a minimum of $25 \%$ of welds will be subject to radiographic examination (RT), with random welds selected in accordance with the Russian standards. The film shot during RT will be submitted to ORNL. Weld inspectors at ORNL will review the films to evaluate the quality of the welds. While this will not constitute compliance with the U.S. standards, it will provide additional assurance of the Russian process. Furthermore, the minimum number of welds subjected to RT inspection exceeds the $10 \%$ required by ASME B31.3. Welds that cannot be radiographed may be inspected by liquid dye penetration (PT) methods. PT examination will follow the applicable Russian standards for inspection of the root, each fill, and the cap pass. All destructive and nondestructive inspection results and acceptance criteria will be included as part of the manufacturer's data submittals.

Upon receipt of the equipment and prior to operation, a visual inspection of accessible external welds by qualified ORNL personnel will be performed. This inspection, combined with ORNL's review of the examination data submitted by the manufacturer, is intended to provide a qualitative check of the weld examination and quality assurance processes employed during fabrication and testing in Russia.

\section{PRESSURE VESSEL}

Sections II, V, VIII, and IX of the ASME Boiler and Pressure Vessel Code govern fabrication of the accumulator vessel and are applicable under the existing ORNL WSS set. Because the Russian fabricator does not have a certificate of authorization ("code stamp") from ASME, strict compliance with the B\&PV code cannot be achieved. However, precedent exists for use of noncode stamped vessels on site if they are isolated from personnel during operation. For this application, the vessel will be located inside the existing Gunite tank, which provides a natural barrier, during normal use. Personnel access to the equipment while potentially pressurized during cold testing and prior to installation into the tank will be controlled by use of barriers and administrative controls.

Russian standards GOST 7350-77 for rolled sheet steel and GOST 5632 for corrosion resistant steels govern materials of construction. Based on the manufacturer's composition analysis and independent analysis at ORNL of a test coupon provided by the fabricator, the steel is within the range for comparable U.S. material and acceptable for the intended application when compared against the U.S. standards. While not an exact match with ASTM and ASME standards, the material is an austenitic grade stainless steel approximate to U.S. type 304L. 
Table B.1. Alignment of ASME and Russian welding requirements

\begin{tabular}{|c|c|}
\hline ASME requirement & Russian equivalent \\
\hline $\begin{array}{l}\text { B\&PV Section IX, Part QW, Article I } \\
\text { (Welding General Requirements) }\end{array}$ & $\begin{array}{l}\text { OST } 95.10441 \text { (general requirements for } \\
\text { welding) }\end{array}$ \\
\hline $\begin{array}{l}\text { B31.3 Section } 328.3 \text { (Welding Materials) } \\
\text { B\&PV Section IX, Part QW, Article } \\
\text { IV(Welding Data) }\end{array}$ & $\begin{array}{l}\text { OST } 95.10439, \text { GOST 23949, GOST } 2246 \\
\text { (quality and properties of base metal and } \\
\text { electrodes) }\end{array}$ \\
\hline $\begin{array}{l}\text { B31.3 Section } 328.5 \text { (Welding Requirements) } \\
\text { B\&PV Section VIII, Subsection B (design, } \\
\text { fabrication of welded vessels) }\end{array}$ & OST 95.10440 (type, design, and size of welds) \\
\hline $\begin{array}{l}\text { B\&PV Section IX, Part QW, Article } \\
\text { IV(Welding Data) }\end{array}$ & GOST 10157 (protective gas) \\
\hline $\begin{array}{l}\text { B31.3 Section } 328.2 \text { (Welder Qualifications) } \\
\text { B\&PV Section IX, Part QW, Article III } \\
\text { (Welding Performance Qualification) }\end{array}$ & PNAEG-7-003 (welder certification) \\
\hline $\begin{array}{l}\text { B\&PV Section VIII; Section IX, Part QW, } \\
\text { Article I(Welding General Requirements); } \\
\text { Article II (Welding Procedure Qualification) }\end{array}$ & $\begin{array}{l}\text { OST } 95.39 \text { (testing of control welds performed } \\
\text { by welder(s)) }\end{array}$ \\
\hline $\begin{array}{l}\text { B31.3 Section } 328.4 \text { (Preparation for Welding) } \\
\text { B\&PV Section VIII, Subsection B }\end{array}$ & OST 95.1041 (preparation and assembly) \\
\hline $\begin{array}{l}\text { B31.3 Section 328.6 (Weld Repair) } \\
\text { B\&PV Section IX, Part QW }\end{array}$ & OST 95.39 (weld defect repair) \\
\hline $\begin{array}{l}\text { B31.3 Section } 341 \text { and } 343 \\
\text { B\&PV Section V, Subsection A; Section VIII, } \\
\text { Subsection B; Section IX, Part QW }\end{array}$ & $\begin{array}{l}\text { OST } 95.39 \text { (weld quality control and } \\
\text { inspection) }\end{array}$ \\
\hline $\begin{array}{l}\text { B31.3 Section } 342 \text { (Examination Personnel) } \\
\text { B\&PV Section V, Subsection A; Section IX, } \\
\text { Part QW }\end{array}$ & $\begin{array}{l}\text { OST 95.852, OST } 95.39 \text { (weld examiner } \\
\text { qualification) }\end{array}$ \\
\hline $\begin{array}{l}\text { B31.3 Section } 341 \text { and } 343 \\
\text { B\&PV Section V, Subsection A; Section VIII, }\end{array}$ & OST 95.852, GOST 18442 (weld examination) \\
\hline $\begin{array}{l}\text { Subsection B; Section IX, Part QW } \\
\text { B31.3 Section } 343 \\
\text { B\&PV Section VIII, Subsection B; Section IX, } \\
\text { Part QW, Article I }\end{array}$ & $\begin{array}{l}\text { OST } 95.10441 \text { (documentation and record } \\
\text { keeping requirements) }\end{array}$ \\
\hline
\end{tabular}

The vessel will be fabricated according to the vendor's design drawings and calculations, which were reviewed by Lockheed Martin Energy Systems (LMES) engineering personnel for comparison to the technical requirements of the B\&PV code. During the initial review, it was determined the vessel met U.S. requirements with the exception of weld reinforcement at one nozzle. The fabricator subsequently provided a revised drawing, which includes additional reinforcing at the nozzle connection. Based on this information, the vessel meets the technical requirements for PV design contained in Subsections A and B of B\&PV Section VIII. In addition to the materials and design items addressed here, fabrication, inspection and tests, and markings and reports addressed in applicable sections of the B\&PV will be in compliance with the applicable Russian standards.

Welding will be performed according to the applicable Russian standards in lieu of Section IX as described above. The vessel will be hydrostatic tested by the fabricator prior to shipping, and it will be 
tested again as a system with the piping after it is received by ORNL. Hydrostatic testing will be performed at a minimum of 1.5 times the design pressure for the system. The test documentation will be submitted to ORNL when the equipment is delivered.

The vessel has a design pressure of $230 \mathrm{psi}(1.6 \mathrm{MPa})$ and is open to the Gunite tank contents during normal operation. The source of pressure will be compressed air supplied from an external source. As part of the equipment installation, a pressure relief device will be installed in the system to protect from inadvertent over pressurization. This device will be procured and installed by ORNL after the system is on site and will be in accordance with B\&PV Section VIII requirements for pressure relief devices.

\section{SUMMARY}

The PMP equipment in question will be designed and fabricated to applicable Russian standards, and is an adaptation of an existing design in service for a radiochemical waste application in Russia. The manufacturer will be responsible for adherence of all fabrication activities to the appropriate Russian standards. While it is not feasible to achieve strict compliance with the U.S. codes discussed above and identified in the existing ORNL WSS, independent checks will be made to ensure that the intent and applicable technical requirements are incorporated during design, fabrication, and testing of the equipment.

It is recognized that the equipment will not comply with U.S. standards. Material composition, component dimensions, personnel certifications, and QA documentation will not match the U.S. requirements. An evaluation of selected critical elements (such as materials composition and properties, piping wall thickness, PV design) indicates the minimum technical requirements of the U.S. codes will be met or exceeded. Tests required by the U.S. standards will be performed as if the equipment were fabricated to U.S. code. An appropriate pressure relief device will be installed by ORNL in full compliance with U.S. requirements. Examination of materials analysis and weld radiographs provided by the fabricator and on-site hydrostatic testing to U.S. requirements will provide additional assurance that the equipment is of high quality and suitable for the proposed use.

A deviation request is being prepared to address the known noncompliance items. Approval of the deviation request will be required prior to cold test operation. The deviation request addresses the proposed use of the equipment in cold testing and at GAAT tanks W-7, W-8, W-9, W-10, and TH-4. Manufacturer's data, including materials analysis, design documents and certifications of compliance, and test and inspection results will be delivered with the equipment. This information, along with documentation of independent review and pressure testing by ORNL inspectors, will be available prior to hot deployment at the GAAT. 


\section{INTERNAL DISTRIBUTION}

1. R. D. Bradley

2. D. C. Dunning

3. C. L. Fitzgerald

4. D. E. Hobson

5. S. M. Killough

6. B. E Lewis
7. J. D. Randolph

8. H. Toy

9. S. D. Van Hoesen

10. Central Research Library

11. ORNL Laboratory Records-RC

12. ORNL Laboratory Records-OSTI

\section{EXTERNAL DISTRIBUTION (ELECTRONIC)}

13. Tom Albert, American Russian Environmental Services

14. J. W. Cammann, CH2M Hill Hanford Group, Inc.

15. J. B. Gardner, Y-12 National Security Complex

16. P. W. Gibbons, Numatech Hanford Co.

17. C. R. Hammond, Y-12 National Security Complex

18. W. Haselbacher, National Environmental Technology Laboratory

19. B. A. Hatchell, Pacific Northwest National Laboratory

20. M. A. Johnson, Tetra Tech Inc.

21. T. M. Koepp, Bechtel-Jacobs Company, LLC

22. J. R. Noble-Dial, U.S. DOE Oak Ridge Operations

23. V. Panesco, Waste Policy Institute, 3250 Port of Benton Boulevard, Richland, WA 99352

24. M. Stover, Waste Policy Institute, 3250 Port of Benton Boulevard, Richland, WA 99352

\section{EXTERNAL DISTRIBUTION (PAPER)}

25. Boris Barakov, Mining and Chemical Combine, Zheleznogorsk, Russia

26. K. D. Gerdes, DOE Office of Science and Technology, 19901 Germantown Rd., 1154 Cloverleaf Bldg., Germantown, MD, 20874-1290

27. Konstanin Kudinov, Mining and Chemical Combine, Zheleznogorsk, Russia

28. T. P. Pietrock, U.S. Department of Energy, Richland Operations Office, PO Box 550, MS: K8-50, Richland, WA 99352

29. B. J. Williams, Pacific Northwest National Laboratory, PO Box 999, MSIN K9-69, Richland, WA 99352

30. Vasily Zhidkov, Mining and Chemical Combine, Zheleznogorsk, Russia 